UNIVERSIDADE DE SÃO PAULO

ESCOLA DE ENFERMAGEM

CAMILA DA SILVA CRUZ

CINESIOTERAPIA SUPERVISIONADA DO ASSOALHO PÉLVICO EM GESTANTES COM INCONTINÊNCIA URINÁRIA: ENSAIO CLÍNICO ALEATORIZADO CONTROLADO

SÃO PAULO

2015 


\title{
CINESIOTERAPIA SUPERVISIONADA DO ASSOALHO PÉLVICO EM GESTANTES COM INCONTINÊNCIA URINÁRIA: ENSAIO CLÍNICO ALEATORIZADO CONTROLADO
}

\author{
Versão corrigida da Dissertação \\ apresentada ao Programa de Pós- \\ Graduação da Escola de Enfermagem da \\ Universidade de São Paulo para obtenção \\ do título de Mestre em Ciências
}

Área de Concentração: Cuidado em Saúde

Orientadora:

Prof ${ }^{a}$. Dr ${ }^{a}$. Maria Luiza Gonzalez Riesco

\begin{abstract}
VERSÃO CORRIGIDA
A versão original encontra-se disponível na Biblioteca da Escola de Comunicação e Artes da Universidade de São Paulo e na Biblioteca Digital de Teses e Dissertações da Universidade de São Paulo
\end{abstract}

São Paulo

2015 
AUTORIZO A REPRODUÇÃO E DIVULGAÇÃO TOTAL OU PARCIAL DESTE TRABALHO, POR QUALQUER MEIO CONVENCIONAL OU ELETRÔNICO, PARA FINS DE ESTUDO E PESQUISA, DESDE QUE CITADA A FONTE.

Assinatura:

Data:

\section{Catalogação na Publicação (CIP)}

Biblioteca "Wanda de Aguiar Horta"

Escola de Enfermagem da Universidade de São Paulo

Cruz, Camila da Silva

Cinesioterapia supervisionada do assoalho pélvico em gestantes com incontinência urinária: ensaio clínico aleatorizado controlado / Camila da Silva Cruz. São Paulo, 2015.

$78 \mathrm{p}$

Dissertação (Mestrado) - Escola de Enfermagem da Universidade de São Paulo.

Orientadora: Prof. ${ }^{\text {a }}$ Dr. ${ }^{\text {a }}$ Maria Luiza Gonzalez Riesco

Área de concentração: Cuidado em Saúde

1. Gravidez. 2. Força muscular. 3. Incontinência urinária. 4. Períneo. 5. Terapia por exercício. 6. Ensaio clínico. I. Título. 


\section{Nome: Camila da Silva Cruz}

Título: Cinesioterapia supervisionada do assoalho pélvico em gestantes com incontinência urinária: ensaio clínico aleatorizado controlado

Dissertação apresentada ao Programa de Pós-Graduação em Enfermagem da Escola de Enfermagem da Universidade de São Paulo para obtenção do título de Mestre em Ciências.

Aprovada em:

Banca Examinadora

Prof. Dr. Instituição:

Julgamento: Assinatura:

Prof. Dr. Instituição:

Julgamento: Assinatura:

Prof. Dr. Instituição:

Julgamento: Assinatura: 


\section{DEDICATÓRIA}

A Deus pela vida, pelas oportunidades e principalmente, por ter colocado pessoas especiais em meu caminho...

A meus avós, Jayme e Joana, meus anjos, por toda luz, força e proteção, presentes em todos os momentos, as estrelas mais lindas a me guiar...

A meus pais, Daniel e Nilce por todo amor, dedicação, incentivo e por estarem sempre a meu lado, meus exemplos, meus melhores amigos, minha base... Amo infinitamente vocês...

Aos meus irmãos Rafael e Joyce, por deixarem minha vida mais colorida e fazerem-me aprender mais uma forma de amor, como a que existe entre nós...

E toda minha família, avós que são como pais, tias como mães, e primos como irmãos, por todo apoio, amizade e carinho, sem vocês nada teria sentido, vocês fazem parte dos meus sonhos, planos e da minha felicidade...

Obrigada por existirem, vocês são meus melhores motivos para sorrir! 


\section{AGRADECIMENTOS}

Em primeiro lugar, a Deus por iluminar meu caminho e por tornar possível um dos meus sonhos...

A minha orientadora Prof ${ }^{a}$. Dr ${ }^{a}$. Maria Luiza Gonzalez Riesco, pela dedicação, paciência, disponibilidade, atenção e cuidado com o trabalho e por todo aprendizado científico e pessoal...

A professora Miriam Raquel Diniz Zanetti por todo apoio, amizade, incentivo e exemplo profissional...

A Dr ${ }^{\mathrm{a}}$ Sonia Maria Junqueira Vasconcellos de Oliveira e a $\operatorname{Dr}^{\mathrm{a}}$ Adriana de Souza Caroci membros da banca de qualificação pelas sugestões ao enriquecimento do trabalho...

As minhas colegas de trabalho Karina Fernandes Trevisan e Nathalie Leister, pela colaboração na coleta e banco de dados e a todas auxiliares de pesquisa...

A toda equipe da SEISA, por ter aceitado e colaborado com o trabalho, em especial, a enfermeira Aldrin Veiga Zilet por ter ajudado diretamente na pesquisa, pela amizade e o carinho de Priscila Letícia, Marielle Tamburi e Luciana Helena...

As pacientes que contribuíram para a realização deste trabalho...

Ao Bernardo dos Santos, pela assessoria estatística e a Prof ${ }^{\mathrm{a}}$. Ivone Borelli, pela revisão de língua portuguesa.

À FAPESP, pelo auxílio financeiro ao projeto e pela bolsa de treinamento técnico. Ao CNPq, pelo auxílio financeiro ao projeto.

À Capes, pela bolsa de mestrado.

E a minha família que me ensina a cada dia que a maior lição está nos gestos de fé, amor, respeito, simplicidade e gratidão... As conquistas valem mais a pena, pelos abraços e sorrisos de vocês... 
As nuvens mudam sempre de posição, mas são sempre nuvens no céu. Assim devemos ser todo dia, mutantes, porém, leais com o que pensamos e sonhamos; lembre-se, tudo se desmancha no ar, menos os pensamentos.

(Paulo Baleki) 
Cruz CS. Cinesioterapia supervisionada do assoalho pélvico em gestantes com incontinência urinária: ensaio clínico aleatorizado controlado [dissertação]. São Paulo: Escola de Enfermagem, Universidade de São Paulo; 2015.

\section{RESUMO}

Introdução: Durante o período gestacional, os músculos do assoalho pélvico (AP) sofrem alterações que predispõem a mulher a desenvolver incontinência urinária (IU). Objetivos: 1. Avaliar o efeito da cinesioterapia (CT) supervisionada do AP na incontinência urinária e a interferência da IU na vida da gestante; 2. Avaliar o efeito da CT supervisionada do AP na força dos músculos do AP (FMAP) em gestantes incontinentes. Método: Ensaio clínico paralelo, controlado e aleatorizado, aninhado a uma coorte de gestantes, realizado em um serviço do setor suplementar de saúde, em Guarulhos, SP. A população constituiu-se de gestantes incluídas na referida coorte, que apresentaram IU entre 20 e 27 semanas de gestação. $\mathrm{O}$ tamanho amostral foi estimado em 74 gestantes, distribuídas nos grupos experimental $(\mathrm{GE}=37)$ e controle $(\mathrm{GC}=37)$, com nível de significância de $5 \%$ e o poder do teste de $80 \%$. Mas, com a amostra final obtida de 53 gestantes $(\mathrm{GE}=31$ e $\mathrm{GC}=22)$, o poder do teste foi de $41 \%$. A intervenção no GE consistiu de seis sessões quinzenais de CT do AP, supervisionadas por fisioterapeuta. As gestantes de ambos os grupos foram orientadas, verbalmente e por escrito, a realizarem os mesmos exercícios perineais em casa. Os dados foram coletados antes e após a intervenção, utilizando o International Consultation on Incontinence Questionnaire-Short Form (ICIQ-SF) e a perineometria (Peritron ${ }^{\mathrm{TM}}$ ), no segundo e terceiro trimestre da gestação. Foi realizada análise descritiva, inferencial e multivariada. Resultados: 96 gestantes foram consideradas elegíveis, 17 recusaram-se a participar e 79 foram alocadas aleatoriamente no GE $(n=43)$ e $\mathrm{GC}(\mathrm{n}=36)$. Ao final do estudo, foram avaliadas 31 gestantes no GE e 22 no GC. No GE, $18(58,1 \%)$ gestantes deixaram de apresentar IU e no GC foram 10 (45,5\%), sem diferença estatisticamente significante. No entanto, a redução da IU foi significante $(p=0,028)$ entre as gestantes do GE que frequentaram, pelo menos, quatro sessões de CT do AP, indicando que cada sessão reduziu 24\% a chances de IU (OR=0,76; 95\% IC 0,62-0,95; $\mathrm{p}=0,014)$. As gestantes de ambos os grupos que realizaram exercícios perineais em casa, regularmente (pelo menos, duas vezes por semana), apresentaram menos queixa de IU no terceiro trimestre $(=0,014)$. No início do estudo, o escore do ICIQ-SF foi 8,7 (d.p.=3,1) e 7,6 (d.p.=4,9) nos grupos experimental e controle, respectivamente. No terceiro trimestre da gestação, este escore foi 7,7 (d.p.=3,9) no GE e 9,3 (d.p.=4,6) no GC, sem diferenças estatisticamente significantes para o efeito de grupo ou trimestre gestacional. Em relação à FMAP, no segundo trimestre da gestação, a média no GE foi 26,3 (d.p.=16,8) $\mathrm{cmH}_{2} \mathrm{O}$ e no GC foi 25,7 (d.p.=14,8) $\mathrm{cmH}_{2} \mathrm{O}$. Considerando apenas as gestantes do GE que frequentaram pelo menos, quatro sessões de CT do AP, no terceiro trimestre da gestação, a média da FMAP foi 29,1 (d.p.=17,6) e 23,7 (d.p.12,8) $\mathrm{cmH}_{2} \mathrm{O}$, nos grupos experimental e controle, respectivamente, com diferença estatisticamente significante $(\mathrm{p}=0,013)$. As gestantes com sobrepeso e obesidade apresentaram FMAP menor $(\mathrm{p}=0,013)$, independente do grupo e do trimestre gestacional. Não houve associação estatisticamente significante entre FMAP e IU, no terceiro trimestre da gestação. Conclusão: $\mathrm{O}$ efeito da CT supervisionada do AP na redução da IU na gestação depende do número de sessões. Exercícios perineais realizados em casa, regularmente, têm efeito na redução da IU e no aumento da FMAP. O sobrepeso e a obesidade na gestação têm efeitos na redução da FMAP.

PALAVRAS-CHAVE: Gravidez. Força Muscular. Incontinência Urinária. Períneo. Terapia por Exercício. Ensaio Clínico. 
Cruz CS. Supervised pelvic floor muscle training among pregnant women with urinary incontinence: a randomized controlled trial [dissertation]. São Paulo: Escola de Enfermagem, Universidade de São Paulo; 2015.

\begin{abstract}
Introduction: During pregnancy, the functions of the pelvic floor muscles are modified, which predispose women to develop urinary incontinence (UI). Aims: 1. To evaluate the effect of a supervised pelvic floor muscle exercise (PFME) program on UI and the interference of the UI in the quality of life of pregnant women; 2. To evaluate the effect of a supervised PFME program in the pelvic floor muscle strength (PFMS) among incontinent pregnant women. Methods: Parallel randomized controlled trial, nested into a cohort of women during pregnancy, conducted on an insurance health care facility, in Guarulhos, SP. The population was women with UI, from 20 to 27 gestational weeks. The sample size was estimated at 74 pregnant women allocated into the experimental group $(E G=37)$ and control group $(\mathrm{CG}=37)$, with a significance level of $5 \%$ and power of $80 \%$. However, as the final sample obtained was 53 pregnant women $(\mathrm{EG}=31$ and $\mathrm{GC}=22)$, the power of the test was recalculated to $41 \%$. The EG intervention consisted of six biweekly sessions of PFME supervised by a physical therapist. Women in both groups were instructed verbally and in writing to perform the same perineal exercises at home. Data were collected before and after the intervention, in the second and third trimesters of pregnancy respectively, by the International Consultation on Incontinence Questionnaire-Short Form (ICIQ-SF) and perineometry (Peritron ${ }^{\mathrm{TM}}$ ). Descriptive, inferential and multivariate analysis was performed. Results: 96 women were considered eligible, 17 refused to participate and 79 were randomly allocated in EG $(n=43)$ and CG $(n=36)$. At the end of the study, 31 women of the EG and 22 of the CG were assessed. In the EG, 18 (58.1\%) and in the CG $10(45.5 \%)$ women were continent, without statistically significant difference. Nevertheless, the IU reduction was significant $(\mathrm{p}=0.028)$ among the women of $\mathrm{EG}$ who attended at least four PFME sessions, and indicates that each session reduced $24 \%$ the chance of UI (OR $=0.76$; $95 \%$ CI $0.62-0.95 ; p=0.014)$. Women of both groups who underwent regularly perineal exercises at home (at least twice a week) had less UI in the third trimester of pregnancy $(\mathrm{p}=0.014)$. At the beginning of the trial, the ICQ-SF score was $8.7(\mathrm{SD}=3.1)$ in the EG and $7.6(\mathrm{SD}=4.9)$ in the $\mathrm{CG}$. However, in the third trimester of pregnancy, this score was 7.7 $(\mathrm{SD}=3.9)$ in $\mathrm{EG}$ and $9.3(\mathrm{SD}=4.6)$ in the $\mathrm{GC}$, with no statistically significant differences for the group effect or trimester of pregnancy. Regarding PFMS in the second trimester of pregnancy, the average in the GE was $26.3(\mathrm{SD}=16.8) \mathrm{cmH}_{2} \mathrm{O}$ and in the $\mathrm{GC}$ was 25.7 $(\mathrm{SD}=14.8) \mathrm{cmH}_{2} \mathrm{O}$. Considering only the pregnant women of $\mathrm{GE}$ who attended at least four PFME sessions, in the third trimester of pregnancy the PFMS average was 29.1 ( $\mathrm{SD}=17.6)$ and $23.7(\mathrm{SD}=12.8) \mathrm{cmH}_{2} \mathrm{O}$ in the experimental and control groups, respectively, with a statistically significant difference $(\mathrm{p}=0.013)$. Pregnant women with overweight and obesity showed lower PFMS ( $\mathrm{p}=0.013$ ), independently of the group and trimester of pregnancy. There was no statistically significant association between PFMS and IU in the third trimester of pregnancy. Conclusion: The effect of the supervised PFME program in reducing UI during pregnancy depends on the number of sessions. Perineal exercises regularly performed at home are effective to reduce UI and to increase PFMS. Overweight and obesity during pregnancy have effect on reducing the PFMS.
\end{abstract}

KEYWORDS: Pregnancy. Muscle Strength. Urinary Incontinence. Perineum. Exercise Therapy. Clinical Trial. 


\section{LISTA DE FIGURAS}

Figura 1 - Peritron ${ }^{\mathrm{TM}}$ com sensor vaginal.

Figura 2 - Fluxograma das participantes, Guarulhos, SP, 2013-2014.

Figura 3 - Média do escore do ICIQ-SF das gestantes dos grupos experimental e controle antes e depois da CT supervisionada do AP, Guarulhos, SP, 2013-2014..

Figura 4 - Média do escore do ICIQ-SF das gestantes do grupo experimental que realizaram pelo menos quatro sessões de CT e das gestantes do grupo controle antes e depois da CT supervisionada do AP, Guarulhos, SP, 2013-2014..

Figura 5 - Média da FMAP das gestantes dos grupos experimental e controle antes e depois da CT supervisionada do AP, Guarulhos, SP, 2013-2014.

Figura 6 - Média da FMAP das gestantes dos grupos experimental e controle antes e depois da CT supervisionada do AP, Guarulhos, SP, 2013-2014

\section{LISTA DE TABELAS}

Tabela 1 - Caracterização das gestantes alocadas nos grupos experimental e controle e valor-p, Guarulhos, SP, 2013-2014

Tabela 2 - Distribuição das gestantes dos grupos experimental e controle segundo a IU e valor-p, Guarulhos, SP, 2013-2014.

Tabela 3 - Distribuição das gestantes dos grupos experimental segundo a IU e o número de sessões de CT do AP e valor-p, Guarulhos, SP, 2013-2014.

Tabela 4 - Distribuição das gestantes do grupo experimental que realizaram pelo menos quatro sessões de CT do AP e das gestantes do grupo controle segundo a IU e valor-p, Guarulhos, SP, 2013-2014

Tabela 5 - Distribuição das gestantes dos grupos experimental e controle segundo o estado nutricional antes da intervenção, Guarulhos, SP, 2013-2014......

Tabela 6 - Distribuição das gestantes dos grupos experimental e controle segundo a CT não supervisionada do AP antes da intervenção, Guarulhos, SP, 2013-2014.

Tabela 7 - Distribuição das gestantes dos grupos experimental e controle segundo a IU e o estado nutricional após a intervenção e valor-p, Guarulhos, SP, 2013-2014.

Tabela 8 - Distribuição das gestantes dos grupos experimental e controle segundo a IU e a CT não supervisionada do AP após a intervenção e valor-p, Guarulhos, SP, 2013-2014.

Tabela 9 - Média e desvio-padrão do escore do ICIQ-SF das gestantes dos grupos experimental e controle antes e depois da CT supervisionada do AP e valor-p, Guarulhos, SP, 2013-2014. 
Tabela 10 - Média e desvio-padrão (d.p.) do escore do ICIQ-SF das gestantes dos grupos experimental e controle antes e depois da CT supervisionada do AP segundo o número de sessões e valor-p, Guarulhos, SP, 2013-2014.

Tabela 11 - Média e desvio-padrão do escore do ICIQ-SF das gestantes do grupo experimental que realizaram pelo menos quatro sessões de CT e das gestantes do grupo controle antes e depois da CT supervisionada do AP e valorp, Guarulhos, SP, 2013-2014

Tabela 12 - Distribuição das situações em que ocorre IU nas etapas 2 e 3 segundo respostas das gestantes à questão 6 do ICIQ-SF (Quando você perde urina?), Guarulhos, 2013-2014.

Tabela 13 - Média e desvio-padrão da FMAP das gestantes dos grupos experimental e controle antes e depois da CT supervisionada do AP e valor-p, Guarulhos, 2013-2014.

Tabela 14 - Média e desvio-padrão da FMAP das gestantes do grupo experimental antes e depois da CT supervisionada do AP segundo o número de sessões e valor-p, Guarulhos, SP, 2013-2014

Tabela 15 - Média e desvio-padrão da FMAP das gestantes do grupo experimental que realizaram pelo menos quatro sessões de CT e das gestantes do grupo controle antes e depois da CT supervisionada do AP e valor-p, Guarulhos, SP, 2013-2014.

Tabela 16 - Distribuição das gestantes dos grupos experimental e controle segundo a FMAP e o estado nutricional antes e depois da intervenção e valor-p, Guarulhos, SP, 2013-2014.

Tabela 17 - Distribuição das gestantes dos grupos experimental e controle segundo a FMAP e a CT não supervisionada do AP antes e depois da intervenção e valor-p, Guarulhos, SP, 2013-2014.

Tabela 18 - Média, desvio-padrão e intervalo de confiança de 95\% da FMAP das gestantes dos grupos experimental e controle segundo a IU depois da CT supervisionada do AP e valor-p, Guarulhos, SP, 2013-2014.

\section{LISTA DE QUADROS}

Quadro 1 - Estudos sobre CT do AP, IU e FMAP no ciclo gravídico.

Quadro 2 - Desempenho e queixas das gestantes durante as sessões de CT do AP, Guarulhos, SP, 2013-2014. 


\section{LISTA DE ABREVIATURAS E SIGLAS}

$95 \% \mathrm{IC}$

AFA

AP

CCOPN

$\mathrm{cm}$

$\mathrm{cmH}_{2} \mathrm{O}$

CT

FMAP

g

GEE

IA

ICIQ-SF

IMC

IIQ-7

IU

IUE

KHQ

LMM

OR

RN

TCLE

UDI-6

WHOOL-Bref
Intervalo de confiança de $95 \%$

Avaliação funcional do assoalho pélvico

Assoalho pélvico

Centro Clínico de Obstetrícia e Pré-Natal

Centímetro

Centímetros de água

Cinesioterapia

Força muscular do assoalho pélvico

Gramas

Equações de Estimação Generalizadas

Incontinência anal

International Consultation on Incontinence Questionnaire-Sort Form

Índice de massa corpórea

Incontinence Impact Questionnaire-7

Incontinência urinária

Incontinência urinária de esforço

King's Health Questionnaire

Modelo Linear de Efeitos Mistos

Odds ratio

Recém-nascido

Termo de Consentimento Livre e Esclarecido

Urogenital Distress Inventory-6

World Health Organization Quality of Life-Bref 
1. INTRODUÇÃO

\section{SUMÁRIO}

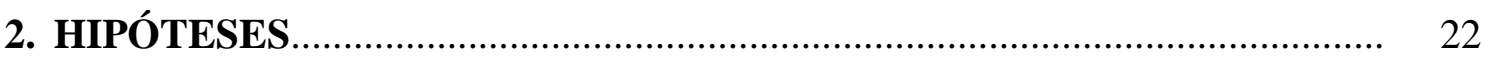

3. OBJETIVOS

4. MÉTODO

4.1 Tipo de estudo........................................................................... 24

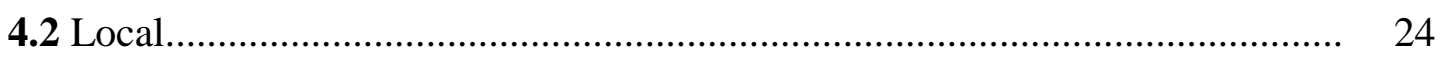

4.3 População e amostra................................................................................... 25

4.4 Critérios de inclusão e amostra....................................................................... 25

4.4.1 Cálculo do tamanho da amostra........................................................... $\quad 25$

4.4.2 Recrutamento e alocação.................................................................... 26

4.4.3 Aleatorização e cegamento...................................................................... 27

4.5 Exposição e desfechos................................................................................ 27

4.6 Medidas e instrumentos de avaliação dos desfechos....................................... 28

4.6.1 Perineometria........................................................................... 28

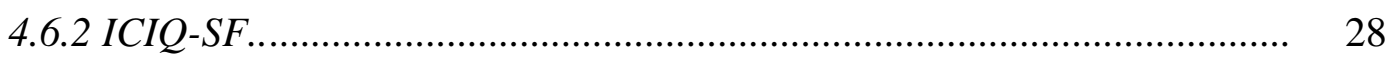

4.7 Coleta de dados e seguimento.................................................................... 29

4.7.1 Técnica de mensuração da FMAP......................................................... 29

4.7.2 Aplicação do ICIQ-SF..................................................................... 31

4.8 Intervenção....................................................................................... 31

4.9 Avaliação dos desfechos..................................................................... 32

4.10 Variáveis do estudo................................................................................ 32

4.10.1 Independentes.............................................................................. 32

4.10.2 Dependentes .............................................................................. 32

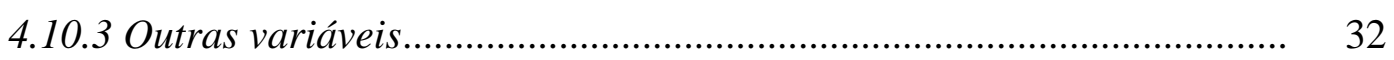

4.10.3.1 Dados sóciodemográficos............................................................. $\quad 32$

4.10.3.2 Dados obstétricos e clínicos e sintomas do trato urinário................... 33

4.11 Análise de dados ................................................................................ 33

4.11.1 Análise descritiva ........................................................................ 34

4.11.2 Análise inferencial..................................................................... 34

4.12 Aspectos éticos ........................................................................... 35

4.13 Registro do protocolo........................................................................ 


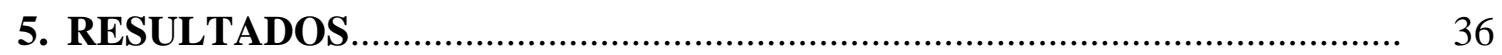

5.1 Caracterização da amostra....................................................................... 38

5.2 Análise da IU, ICIQ-SF e FMAP........................................................... 40

5.3 Considerações sobre a participação das gestantes nas sessões de CT supervisionada do AP................................................................................ 53

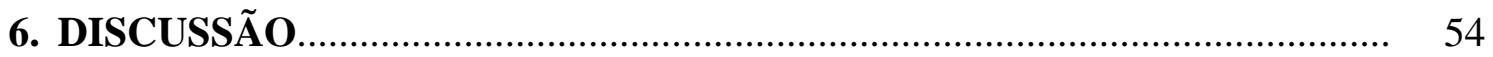

6.1 Efeito da CT do AP na IU ............................................................................ 54

6.2 Efeito da CT do AP na FMAP em gestantes incontinentes........................... 59

6.3 Limitações da pesquisa.......................................................................... 60

6.4 Implicações para a pesquisa e a prática....................................................... 61

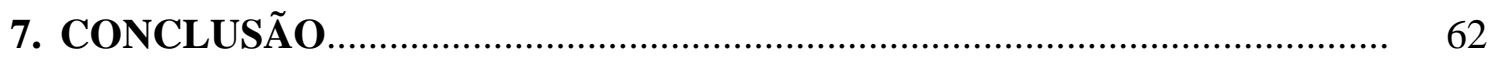

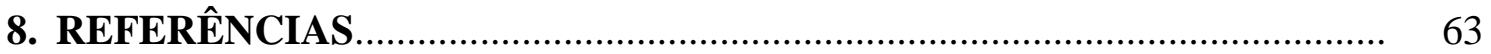

APÊNDICE A - Termo de Consentimento Livre e Esclarecido.............................. 67

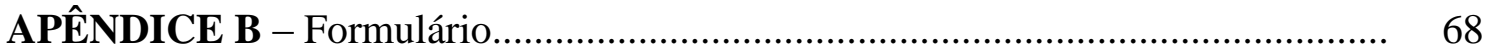

APÊNDICE C - Guia de Exercícios Perineais Durante a Gestação e Depois do Parto.

APÊNDICE D - Programa de Cinesioterapia Supervisionada do Assoalho Pélvico.

APÊNDICE E - Termo de Autorização para a Realização de Pesquisa

Científica

ANEXO 1 - International Consultation on Incontinence Questionnaire-Short Form (ICIQ-SF)

ANEXO 2 - Parecer do Comitê de Ética em Pesquisa 


\section{INTRODUÇÃO}

O assoalho pélvico (AP) é o conjunto de músculos, fáscias e ligamentos que reveste a parte inferior da pelve e circunda a região da uretra, vagina e ânus, sendo sua função manter a continência urinária e fecal, contribuir com suporte apropriado dos órgãos pélvicos e abdominais e participar da função sexual (Grosse, Sengler, 2002).

O tecido muscular desta região é constituído por dois tipos de fibras, as do tipo I que realizam contração lenta ou sustentada e as do tipo II, de contração rápida (Grosse, Sengler, 2002).

Durante o período gestacional, os músculos do AP sofrem sobrecarga de peso devido ao crescimento do útero gravídico associado ao peso do feto. Nesse período ocorrem alterações hormonais que diminuem a força dessa musculatura (Wijma et al., 2001). Esses fatores predispõem a gestante a desenvolver disfunções tais como a incontinência urinária (IU) e fecal, prolapso dos órgãos pélvicos e a disfunção sexual (Bump, Norton, 1998; Devreese et al., 2004).

A International Continence Society estabelece que a IU é "a perda involuntária de urina, que determina desconforto social e higiênico à mulher" (Abrams et al., 2003).

$\mathrm{Na}$ gestação, a prevalência de IU é elevada. Em estudo realizado por B $\emptyset$, Haakstad e Voldner (2007), 24\% das mulheres gestantes apresentaram problemas com IU. Em estudo de coorte, Solans-Domènech, Sánchez e Espuña-Pons (2010) verificaram que $39,1 \%$ das mulheres apresentaram IU. No estudo de Valeton e Amaral (2011), a IU aparece em 30,61\% das gestantes e no estudo de Mørkved e Bø (1999), em 42\% delas.

Essa condição ocasiona limitações físicas, alterações nas atividades sociais, ocupacionais e domésticas influenciando de forma negativa no estado emocional e na vida sexual. Além disso, podem provocar desconforto social e higiênico, pelo medo da perda urinária, o odor, a necessidade de utilizar protetores e de trocas mais frequentes de roupas, o que afeta adversamente a qualidade de vida das mulheres acometidas (Kelleher, 2000; Saleh et al., 2005).

O desenvolvimento e a validação de um questionário abreviado - International Consultation on Incontinence Questionnaire-Sort Form (ICIQ-SF) - tem auxiliado a avaliar a qualidade de vida relacionada com a IU. Trata-se de um questionário simples e 
breve, que foi originalmente desenvolvido e validado em inglês e, depois, adaptado e validado para o português por (Tamanini et al., (2004). No ICIQ-SF, todas as mulheres que relatam não ter qualquer perda de urina são definidas como continentes e as que relatam sintomas são definidas como incontinentes.

Oliveira et al. (2013) realizaram um estudo multicêntrico com 495 mulheres. Com objetivo de verificar a ocorrência de IU em mulheres grávidas, e a relação com variáveis sociodemográficas e a qualidade de vida. Os dados foram coletados imediatamente após o parto, por meio de um questionário contendo características sociodemográficas, raça, escolaridade, realização de exercícios físicos regulares, fortalecimento do AP durante a gestação e preenchimento do questionário ICIQ-SF. Dentre as mulheres, $71,1 \%$ apresentaram a IU durante as últimas quatro semanas de gestação, o ICIQ-SF mostrou uma pontuação mediana de 11 pontos, considerada um severo impacto na qualidade de vida, e 98\% relataram não realizar exercícios do AP na gestação.

Em um estudo para comparar a qualidade de vida de gestantes com e sem perda urinária, identificando os principais fatores que interferem negativamente na qualidade de vida durante esse período, foram avaliadas 40 gestantes, em dois momentos, entre 24 e 26 semanas e entre 34 e 36 semanas de gestação, por meio de dois questionários de qualidade de vida (King's Health Questionnaire-KHQ e World Health Organization Quality of Life-WHOQOL-Bref). As gestantes sem sintomas miccionais apresentaram melhor qualidade de vida, em relação àquelas com sintomas miccionais, nos domínios físico, social e ambiental (Moccellin, Rett, Driusso, 2014).

Com objetivo de descrever a prevalência de IU no terceiro trimestre gestacional e verificar quais variáveis estão associadas à IU nesse período, Sacomori et al. (2013) incluíram em um estudo transversal 242 mulheres que se encontravam no puerpério imediato. Foram avaliados fatores sociodemográficos, história clínica, antecedentes ginecológicos e obstétricos. A avaliação das perdas urinárias foi realizada por meio do ICIQ-SF, sendo verificada uma prevalência de IU de 59,5\% no terceiro trimestre gestacional. Desta forma, os autores concluíram que sua prevalência durante a gestação ainda é elevada, configurando pouca importância atribuída ao fator preventivo.

Estudo que teve como objetivo investigar prevalência de IU em uma população multiétnica de mulheres grávidas e analisar possíveis associações dos fatores de risco incluiu 722 mulheres. No estudo transversal de base populacional, os sintomas urinários 
foram medidos pelo ICIQ-SF com 28 semanas de gestação e o maior escore foi entre mulheres do Leste Asiático, com média de 8,6 (d.p.=4,2). A prevalência de IU foi de $41,7 \%$, com variação de $26 \%$ a $45 \%$, nas diferentes etnias (Bø et al., 2012).

É conhecido que a prática de exercícios para o fortalecimento do AP na gestação pode tratar disfunções, em especial, a IU (Mørkved, 2003). Segundo Burgio et al. (2003), mulheres incontinentes, com capacidade de contrair adequadamente os músculos do AP, podem diminuir a perda urinária aos esforços antes de completar o treinamento de ganho de força muscular, como uma das modalidades de cinesioterapia (CT) do AP, apenas acionando adequadamente essa musculatura nos momentos de aumento da pressão intra-abdominal.

Conforme a revisão sistemática de literatura, realizada por Hay-Smith et al. (2011), o treinamento dos músculos do AP em gestantes primigestas reduz a prevalência de IU nesse período. Desta forma, os autores concluíram que se deve recomendar o treinamento dessa musculatura durante o pré-natal.

Mørkved e B $\varnothing$ (2014) também demonstraram que o treinamento da musculatura do AP, durante a gestação e após o parto, pode prevenir e tratar a IU. Os autores recomendam um protocolo de treinamento supervisionado, enfatizando contrações máximas e com duração mínima de 8 semanas.

Com base na prevalência de IU, o treinamento da musculatura do AP deve ser inserido como parte da rotina de programas de exercício das mulheres em geral.

Um estudo de coorte realizado em Botucatu (SP), com 120 primíparas, pesquisou a associação de exercícios perineais realizados na gestação e a IU no pósparto. As mulheres foram divididas em quatro grupos: G1 - realizaram exercícios perineais durante a gestação, exercícios domiciliares diários e supervisionados mensalmente por um fisioterapeuta; G2 - realizaram exercícios domiciliares diariamente sem supervisão; G3 - não realizaram exercícios, mas utilizavam o mesmo serviço de saúde do G1 e G2; G4 - não tiveram nenhum contato com exercícios perineais. Os principais resultados mostraram que os exercícios reduziram significativamente a incidência de IU em todos os períodos no pós-parto (Assis, 2013).

Objetivando avaliar se as mulheres grávidas que receberam treinamento dos músculos do AP eram menos propensas a relatar IU e fecal, Stafne et al. (2012) realizaram um ensaio clínico controlado randomizado que incluiu 762 mulheres, 
divididas em grupo de intervenção e grupo controle. No grupo de intervenção, as gestantes realizaram um programa de treinamento dos músculos do AP em grupo, instruído por pelo fisioterapeuta. Ambos os grupos receberam informações e recomendações detalhadas para realização do treinamento do AP em casa. Menos mulheres do grupo de intervenção relataram IU semanal (11\% contra 19\%; $\mathrm{p}=0,004)$, $67 \%$ do grupo do grupo de intervenção e $40 \%$ do grupo controle tiveram adesão ao protocolo de exercícios, realizando o treinamento três ou mais vezes na semana.

Sangsawang e Serisathien (2011) examinaram os efeitos do treinamento dos músculos do AP sobre a gravidade da IU de esforço (IUE) em mulheres grávidas. Foram incluídas 66 mulheres que frequentavam o pré-natal com IUE e idade gestacional de 20 a 30 semanas. Ambos os grupos responderam a um questionário sobre informações pessoais e avaliação subjetiva da IU, severidade percebida, registro de frequência e quantidade da perda. As gestantes do grupo experimental $(n=31)$ seguiram um programa de treinamento dos músculos do AP, realizado pelo pesquisador em pequenos grupos, e receberam um manual com as instruções detalhadas do treinamento. Após o programa de exercício, as mulheres do grupo experimental tiveram a frequência e a quantidade de perda de urina significativamente inferiores ao grupo de controle. $\mathrm{O}$ estudo concluiu que o programa de exercícios da musculatura do AP de 6 semanas foi capaz de diminuir a gravidade dos sintomas em mulheres grávidas com IUE.

Com o objetivo de avaliar o número de mulheres que realizou o treinamento da musculatura do AP durante a gravidez, Bø, Haakstad e Voldner (2007) incluíram no estudo 467 mulheres no terceiro trimestre de gestação, que responderam a um questionário sobre a prática de atividades físicas regulares, incluindo o fortalecimento do AP. Dentre elas, apenas $17 \%$ relataram a realização dos exercícios de fortalecimento do AP durante a gravidez.

Mørkved et al. (2003) realizaram um estudo randomizado e controlado com 301 gestantes nulíparas, divididas aleatoriamente em dois grupos, de treinamento dos músculos do AP e controle. Todas participantes foram instruídas individualmente por fisioterapeuta quanto à forma correta de executar a contração dessa musculatura. $\mathrm{O}$ grupo de treinamento iniciou os exercícios entre a $20^{\mathrm{a}}$ e $36^{\mathrm{a}}$ semana de gestação, realizados durante 12 semanas, e as mulheres foram orientadas a fazerem os exercicíos em casa, duas vezes por dia. As mulheres do grupo controle receberam informações obstétricas e clínicas e não foram desencorajadas a realizar os exercícios por conta 
própria. A força muscular do assoalho pélvico (FMAP) foi significantemente maior no grupo de treinamento com 36 semanas de gestação, e as gestantes desse grupo desenvolveram menos IU (32\%) que as do grupo controle (48\%).

Objetivando avaliar os efeitos do treinamento dos músculos do AP em gestantes nulíparas, Oliveira et al. (2007) realizaram um estudo que incluiu 46 gestantes, divididas em dois grupos, sendo um controle e outro de treinamento, que realizou exercícios do AP supervisionados, durante 12 semanas. Os dois grupos tiveram informações sobre a localização, a função e a correta contração dessa musculatura. $\mathrm{O}$ grupo de treinamento realizou durante 20 semanas consecutivas quatro séries de 10 contrações, sustentadas por 6 segundos, seguidas de 12 segundos de relaxamento, nas posições dorsal, lateral, sentada e em pé e receberam instruções para realizarem em casa uma vez por dia.

Os resultados foram analisados por palpação vaginal digital, com escala de Ortiz para classificação e perineometria com e sem biofeedback, na $20^{\mathrm{a}}$ e $36^{\mathrm{a}}$ semanas de gestação. Os pesquisadores encontraram um aumento significativo na função muscular, por meio da palpação e da perineometria, tanto no grupo de treinamento, como no grupo controle, com maior significância no grupo que realizou o treinamento. Perceberam que o aumento de força muscular no grupo controle poderia estar relacionado com a percepção correta da região perineal durante a avaliação. $\mathrm{O}$ treinamento dos músculos do AP resultou em um aumento significativo na pressão e na força nessa região durante a gravidez.

Em um estudo para verificar a eficácia dos exercícios para os músculos do AP no tratamento da IU durante a gravidez, foram incluídas 80 gestantes incontinentes, divididas em dois grupos iguais, avaliadas quanto à FMAP por meio do perineômetro e queixas urinárias com diário miccional e Pad-teste, na $36^{\mathrm{a}}$ e $38^{\mathrm{a}}$ semanas de gestação. Desse modo, as mulheres de ambos os grupos foram orientadas quanto à realização da contração dos músculos do AP antes da avaliação. As mulheres do grupo de estudo foram treinadas para realizarem a contração corretamente e só depois foram incluídas no protocolo de treinamento com exercicios diários e graduais para serem feitos em casa. Uma semana depois, essas mulheres foram avaliadas novamente e as que fizeram de forma incorreta a contração foram submetidas novamente ao treinamento e reavaliadas 
após uma semana; os exercícios também eram verificados durante as consultas de prénatal.

Assim, o grupo controle não recebeu orientações para realização dos exercícios. As mulheres do grupo de estudo apresentaram diminuição significativa nos episódios de IU durante a gravidez e houve aumento da força. Os exercícios para os músculos do AP mostraram-se eficazes no aumento da FMAP, conseqüentemente, no tratamento da IU (Dinc, Beji,Yalcin, 2009).

Em estudo que teve como objetivo comparar a FMAP de mulheres nulíparas (não grávidas) e primíparas, com total de 100 mulheres, estas foram prospectivamente distribuídas em dois grupos: grupo $1(n=50)$ e grupo $2(n=50)$. A FMAP foi avaliada subjetivamente, usando palpação digital vaginal e objetivamente por meio do perineômetro portátil, na $20^{\mathrm{a}}$ e $36^{\mathrm{a}}$ semanas de gestação. No grupo 2 , a avaliação da palpação digital vaginal mostrou importante comprometimento da FMAP na $36^{\text {a }}$ semana de gestação $(\mathrm{p}=0,0006)$, em comparação ao grupo 1 . Todas as mulheres do grupo 2 relataram que eram continentes antes da gestação, $19 \%$ relataram IU na $20^{\mathrm{a}}$ semana de gestação e $27 \%$ na $36^{\mathrm{a}}$, o que pode indicar um aumento gradual dos episódios de IU durante a gestação. Houve também uma redução significativa na força muscular do grupo 2, na $36^{\mathrm{a}}$ semana. $\mathrm{O}$ estudo concluiu que a gravidez pode causar fraqueza dos músculos do AP (Gameiro et al., 2011).

Pelaez et al. (2014) realizaram um estudo randomizado controlado com 169 mulheres, com o objetivo de investigar o efeito do treinamento dos músculos do AP durante a gravidez na prevenção da IU em gestantes continentes nulíparas. As mulheres foram divididas em dois grupos: experimental, submetido a exercícios, incluindo 10 minutos de treinamento, durante 22 semanas, três vezes por semana, e o grupo controle, recebeu os cuidados habituais. As gestantes foram avaliadas entre 10 e 14 semanas de gestação e após a intervenção, com 36 a 39 semanas, pelo do ICIQ-SF. No final da intervenção, no grupo experimental, 95,2\% das mulheres não relataram IU, e no grupo controle, foram $60,7 \%$ sem IU.

$\mathrm{K} \varnothing$ et al. (2011) avaliaram o efeito do exercício muscular do AP no pré-natal, para prevenção e tratamento da IU durante a gravidez. Trezentas mulheres foram aleatoriamente divididas em um grupo de treinamento da musculatura do AP e um grupo controle. Os sintomas urinários foram medidos pelo Inventário Urogenital Distress-6 (UDI-6), questionário sobre o impacto da incontinência Questionário-7 (IIQ- 
7) e questão de autorrelato de IU. Assim, as mulheres do grupo de estudo foram orientadas individualmente por um fisioterapeuta quanto à anatomia e contração correta do AP e realizaram o treinamento que consistia de exercícios com três séries de oito repetições com 6 segundos de sustentação e com 2 minutos de repouso, uma vez por semana, durante 12 semanas, com acompanhamento fisioterápico e orientação para realização duas vezes por dia em casa. O grupo controle não recebeu orientações para realização dos exercícios. $\mathrm{Na} 36^{\mathrm{a}}$ semana de gestação, o grupo que participou do treinamento apresentou redução significativa na pontuação total dos questionários (UDI-6 e IIQ-7) e a taxa de autorrelato de IU também foi inferior ao grupo controle.

Elenskaia et al. (2011), em um estudo com 403 gestantes, analisaram prospectivamente o efeito da gravidez na FMAP. Utilizaram a escala de Oxford e a perineometria para realizar as avaliações, durante a $20^{\mathrm{a}}$ e $36^{\mathrm{a}}$ semanas de gestação. Perceberam que houve aumento na pressão avaliada por meio da perineometria com balão vaginal entre o segundo e o terceiro trimestre de gestação, e o estudo teve como hipótese que o aumento da força poderia ocorrer durante a gravidez em resposta ao aumento do útero gravídico.

Após explanação sobre a importância do AP na vida da mulher, pode-se observar que distúrbios nessa musculatura podem trazer complicações físicas e sociais, ocasionadas pela IU, condição que vem sendo relacionada com frequência com o período gestacional. Desta forma, torna-se fundamental avaliar a musculatura do AP durante o período gestacional e verificar se o tratamento modifica a condição dessa musculatura. Além disso, é importante que se analise se a efetividade do tratamento é melhor com o acompanhamento fisioterápico, já que a maioria das mulheres realiza a contração dos músculos do AP de modo insatisfatório.

A seguir, os dados do Quadro 1, sumarizam os principais estudos referidos. 
Quadro 1 - Estudos sobre CT do AP, IU e FMAP no ciclo gravídico*

\begin{tabular}{|c|c|c|c|}
\hline $\begin{array}{l}\text { Autor } \\
\text { Ano } \\
\text { País }\end{array}$ & Objetivos & $\begin{array}{c}\text { Método } \\
\text { Desenho/População/Amostra/Coleta de } \\
\text { dados/Intervenção/Análise dos dados }\end{array}$ & Principais resultados \\
\hline $\begin{array}{l}\text { Moccellin, Rett } \\
\text { e Driusso } \\
2014 \\
\text { Brasil }\end{array}$ & $\begin{array}{l}\text { Comparar a qualidade de vida de } \\
\text { gestantes com e sem perda urinária, } \\
\text { identificando os principais fatores } \\
\text { que interferem negativamente na } \\
\text { qualidade de vida durante essa fase } \\
\text { de vida da mulher. }\end{array}$ & $\begin{array}{l}\text { Desenho: estudo observacional } \\
\text { População: gestantes que frequentaram o serviço } \\
\text { de pré-natal em duas unidades de saúde em } \\
\text { Aracaju, SE } \\
\text { Amostra: } 40 \text { gestantes } \\
\text { Coleta de dados: as gestantes foram avaliadas em } \\
\text { dois momentos, entre } 24 \text { e } 26 \text { semanas e entre } 34 \\
\text { e } 36 \text { semanas de gestação; foram aplicados dois } \\
\text { questionários de qualidade de vida (KHQ e } \\
\text { WHOQOL-Bref) } \\
\text { Análise de dados: descritiva e inferencial } \\
\end{array}$ & $\begin{array}{l}\text { As gestantes sem sintomas } \\
\text { miccionais apresentaram melhor } \\
\text { qualidade de vida, em relação } \\
\text { àquelas com sintomas miccionais, } \\
\text { nos domínios físico, social e } \\
\text { ambiental. Para as gestantes com } \\
\text { sintomas miccionais, ocorreu piora } \\
\text { dos escores dos domínios percepção } \\
\text { geral de saúde e impacto da } \\
\text { incontinência, entre a primeira e a } \\
\text { segunda avaliação. } \\
\end{array}$ \\
\hline $\begin{array}{l}\text { Mørkved e B } \emptyset \\
2014\end{array}$ & $\begin{array}{l}\text { Avaliar o efeito dos exercícios } \\
\text { perineais durante a gestação e após } \\
\text { o parto como prevenção e } \\
\text { tratamento de IU. }\end{array}$ & $\begin{array}{l}\text { Desenho: revisão sistemática } \\
\text { População: estudos randomizados ou quasi- } \\
\text { experimentais publicados em língua inglesa, } \\
\text { realizados com gestantes ou puérperas, em que a } \\
\text { intervenção tenha sido exercício perineal com ou } \\
\text { sem biofeedback, cone vaginal ou } \\
\text { eletroestimulação } \\
\text { Amostra: } 22 \text { estudos } \\
\text { Análise de dados: descritiva }\end{array}$ & $\begin{array}{l}\text { Com base nos estudos com amostra } \\
\text { relevante, boa adesão ao protocolo de } \\
\text { treinamento do AP e bom } \\
\text { acompanhamento, foi identificado } \\
\text { que exercícios perineais durante e } \\
\text { após o parto podem prevenir e tratar } \\
\text { IU. Um protocolo de treinamento dos } \\
\text { músculos do AP, enfatizando } \\
\text { contração máxima e duradoura por } \\
\text { oito semanas, deve ser recomendado. }\end{array}$ \\
\hline
\end{tabular}

(continua)

*Extraído e adaptado de Riesco MLG. Cuidado perineal na gestação e após o parto: prevenção e morbidade relacionadas à força muscular perineal, função sexual e continência urinária [relatório de pesquisa]. São Paulo: Escola de Enfermagem, Universidade de São Paulo; 2015. 
Quadro 1

\begin{tabular}{|c|c|c|c|}
\hline $\begin{array}{l}\text { Autor } \\
\text { Ano } \\
\text { País }\end{array}$ & Objetivos & $\begin{array}{c}\text { Método } \\
\text { Desenho/População/Amostra/Coleta de } \\
\text { dados/Intervenção/Análise dos dados }\end{array}$ & Principais resultados \\
\hline $\begin{array}{l}\text { Pelaez et al. } \\
2014 \\
\text { Espanha }\end{array}$ & $\begin{array}{l}\text { Investigar o efeito do programa de } \\
\text { treinamento dos músculos do AP } \\
\text { durante a gravidez na prevenção da } \\
\text { IU. }\end{array}$ & $\begin{array}{l}\text { Desenho: ensaio clínico randomizado e } \\
\text { controlado } \\
\text { População: nulíparas continentes entre } 10 \text { e } 14 \\
\text { semanas de gestação } \\
\text { Amostra: } 169 \text { gestantes ( } 73 \text { no grupo } \\
\text { experimental-GE e } 96 \text { no grupo controle-GC) } \\
\text { Coleta de dados: ICIQ-SF, entre } 10-14 \text { semanas } \\
\text { de gestação e após a intervenção, com 36-39 } \\
\text { semanas } \\
\text { Intervenção: } 10 \text { minutos de treinamento dos } \\
\text { músculos do AP, três vezes por semana, durante } \\
22 \text { semanas } \\
\text { Análise de dados: descritiva, inferencial e } \\
\text { multivariada }\end{array}$ & $\begin{array}{l}\text { Após a intervenção, } 95,2 \% \text { das } \\
\text { gestantes do grupo experimental não } \\
\text { relataram IU, enquanto no grupo } \\
\text { controle, essa proporção foi de } \\
60,7 \%(p<0,001) \text {. Houve diferença } \\
\text { estatisticamente significativa no } \\
\text { ICIQ-SF entre os grupos após o } \\
\text { período de intervenção: GE=0,2 } \\
(\text { d.p.=1,2); GC=2,7 (d.p. }=4,1) ; \\
(p<0,001) .\end{array}$ \\
\hline
\end{tabular}

(continua) 
Quadro 1

\begin{tabular}{|c|c|c|c|}
\hline $\begin{array}{c}\text { Autor } \\
\text { Ano } \\
\text { País }\end{array}$ & Objetivos & $\begin{array}{c}\text { Método } \\
\text { Desenho/População/Amostra/Coleta de } \\
\text { dados/Intervenção/Análise dos dados }\end{array}$ & Principais resultados \\
\hline $\begin{array}{l}\text { Assis } \\
2013 \\
\text { Brasil }\end{array}$ & $\begin{array}{l}\text { Verificar a associação entre a } \\
\text { realização de exercícios durante a } \\
\text { gestação e IU dois anos após o } \\
\text { parto. }\end{array}$ & $\begin{array}{l}\text { Desenho: estudo de coorte } \\
\text { População: primíparas atendidas em unidades } \\
\text { básicas de saúde } \\
\text { Amostra: } 120 \text { mulheres } \\
\text { Intervenção: as mulheres foram divididas em } \\
\text { quatro grupos - G1 (n=29) realizaram exercícios } \\
\text { perineais durante a gestação, exercícios } \\
\text { domiciliares diariamente e supervisionados } \\
\text { mensalmente por um fisioterapeuta; G2 (n=29) } \\
\text { realizaram exercícios domiciliares diariamente } \\
\text { sem supervisão; G3 (n=29) não realizaram } \\
\text { exercícios, mas utilizavam o mesmo serviço de } \\
\text { saúde do G1 e G2; G4 (n=33) não tiveram } \\
\text { nenhum contato com exercícios perineais } \\
\text { Coleta de dados: palpação vaginal digital, } \\
\text { perineometria, diário miccional e questionário } \\
\text { com informações pessoais e condições pré- } \\
\text { gestacionais, do parto e pós-parto } \\
\text { Análise de dados: descritiva e inferencial }\end{array}$ & $\begin{array}{l}\text { Na } 38^{a} \text { semana de gestação, a } \\
\text { incidência de IU foi } 96,6 \% \text { no G3 e } \\
24,2 \% \text { no G4, enquanto G1 e G2 } \\
\text { apresentaram o menor número de } \\
\text { gestantes com IU ( } 6,9 \% \text { e } 7,1 \%, \\
\text { respectivamente) (p<0,001); com } 12 \\
\text { meses pós-parto, G1 e G2 } \\
\text { permaneceram com a menor } \\
\text { incidência, enquanto G3 apresentava } \\
37,9 \% \text { e G4 39,4\% (p=0,002); com } 24 \\
\text { meses, G1 e G2 deixaram de } \\
\text { apresentar IU e G3 e G4 mantiveram } \\
37,9 \% \text { e } 40 \% \text {, respectivamente } \\
\text { (p<0,001); com } 12 \text { meses pós-parto, } \\
82,75 \% \text { das participantes do G1 e } \\
57,15 \% \text { do G2 relataram realizar } \\
\text { treinamento dos músculos do AP; com } \\
24 \text { meses, } 100 \% \text { das participantes, em } \\
\text { ambos os grupos, realizavam } \\
\text { exercícios. Em relação ao G3 e G4, } \\
\text { nenhuma participante relatou que } \\
\text { realizava o treinamento do AP, nos } \\
\text { dois momentos avaliados. Os } \\
\text { exercícios reduziram } \\
\text { significativamente a incidência de IU } \\
\text { em todos os períodos no pós-parto. }\end{array}$ \\
\hline
\end{tabular}


Quadro 1

\begin{tabular}{|c|c|c|c|}
\hline $\begin{array}{c}\text { Autor } \\
\text { Ano } \\
\text { País }\end{array}$ & Objetivos & $\begin{array}{c}\text { Método } \\
\text { Desenho/População/Amostra/Coleta de } \\
\text { dados/Intervenção/Análise dos dados }\end{array}$ & Principais resultados \\
\hline $\begin{array}{l}\text { Oliveira et al. } \\
2013 \\
\text { Brasil }\end{array}$ & $\begin{array}{l}\text { Investigar a ocorrência de IU em } \\
\text { mulheres grávidas e a relação com } \\
\text { variáveis sociodemográficas e a } \\
\text { qualidade de vida. }\end{array}$ & $\begin{array}{l}\text { Desenho: estudo transversal multicêntrico } \\
\text { Amostra: } 495 \text { mulheres } \\
\text { Coleta de dados: coletados no dia do parto, nas } \\
\text { maternidades elegidas e aplicado o ICIQ-SF } \\
\text { Análise de dados: análise descritiva, inferencial e } \\
\text { multivariada, com comparação entre os grupos } 1 \\
\text { (incontinente) e } 2 \text { (continente) }\end{array}$ & $\begin{array}{l}71,1 \% \text { apresentaram IU nas últimas } \\
\text { quatro semanas de gestação. O grupo } \\
1 \text { apresentou escore do ICIQ- } \\
\mathrm{SF}=12,1 \text {, considerado como impacto } \\
\text { severo na qualidade de vida. Na } \\
\text { análise multivariada. foi encontrada } \\
\text { maior relação entre o relato de IU } \\
\text { com as seguintes variáveis: } \\
\text { escolaridade abaixo de oito anos } \\
(\mathrm{OR}=2,99 ; \mathrm{p}<0,001) \text {, raça negra } \\
(\mathrm{OR}=2,32 ; \mathrm{p}=0,005), \text { mais de três } \\
\text { filhos }(\mathrm{OR}=4,93 ; \mathrm{p}<0,001), \\
\text { obesidade }(\mathrm{OR}=4,22 ; \mathrm{p}<0,001) \text { e } \\
\text { parto normal }(\mathrm{OR}=2,59 ; \mathrm{p}<0,001) .\end{array}$ \\
\hline
\end{tabular}


Quadro 1

(cont.)

\begin{tabular}{|c|c|c|c|}
\hline $\begin{array}{l}\text { Autor } \\
\text { Ano } \\
\text { País }\end{array}$ & Objetivos & $\begin{array}{c}\text { Método } \\
\text { Desenho/População/Amostra/Coleta de } \\
\text { dados/Intervenção/Análise dos dados }\end{array}$ & Principais resultados \\
\hline $\begin{array}{l}\text { Bø et al. } \\
2012 \\
\text { Noruega }\end{array}$ & $\begin{array}{l}\text { Investigar prevalência de IU em } \\
\text { uma população multiétnica de } \\
\text { mulheres grávidas e analisar } \\
\text { possíveis associações dos fatores de } \\
\text { risco. }\end{array}$ & $\begin{array}{l}\text { Desenho: Estudo transversal } \\
\text { População: Gestantes entre } 26 \text { e } 28 \text { semanas de } \\
\text { gestação } \\
\text { Amostra: } 722 \text { gestantes } \\
\text { Coleta de dados: ICIQ-SF, questionário com } \\
\text { informações socioeconômicas, demográficas, } \\
\text { clínicas e obstétricas } \\
\text { Análise de dados: descritiva e inferencial }\end{array}$ & $\begin{array}{l}\text { A prevalência de IU com } 28 \text { semanas } \\
\text { de gestação variou de } 26 \% \text { a } 45 \% \text {, } \\
\text { considerando as origens africana, } \\
\text { oriente médio, asiática, europeia e } \\
\text { norte americana. Houve diferença } \\
\text { entre as africanas e europeias/norte } \\
\text { americanas ( } \mathrm{p}=0,011) \text { e entre } \\
\text { africanas e sul asiáticas ( } \mathrm{p}=0,035 \text { ). } \\
\text { Mulheres de origem africana tiveram } \\
58 \% \text { menos chance de IU. Mulheres } \\
\text { do leste asiático e africanas referiram } \\
\text { alto impacto da IU na gestação } \\
\text { (ICIQ-SF } 8,6 \pm 4,2 \text { e } 8,5 \pm 5,5, \\
\text { respectivamente). Houve associação } \\
\text { positiva da prevalência de IU com } \\
\text { idade materna e paridade. }\end{array}$ \\
\hline
\end{tabular}

(continua) 
Quadro 1

\begin{tabular}{|c|c|c|c|}
\hline $\begin{array}{c}\text { Autor } \\
\text { Ano } \\
\text { País }\end{array}$ & Objetivos & $\begin{array}{c}\text { Método } \\
\text { Desenho/População/Amostra/Coleta de } \\
\text { dados/Intervenção/Análise dos dados }\end{array}$ & Principais resultados \\
\hline $\begin{array}{l}\text { Stafne et al. } \\
2012 \\
\text { Noruega }\end{array}$ & $\begin{array}{l}\text { Avaliar se as gestantes com } \\
\text { seguimento de exercícios gerais, } \\
\text { incluindo exercícios perineais, } \\
\text { eram menos propensas a relatar IU } \\
\text { e IA no final da gestação, em } \\
\text { comparação com gestantes que } \\
\text { receberam o cuidado pré-natal } \\
\text { padrão. }\end{array}$ & $\begin{array}{l}\text { Desenho: ensaio clínico randomizado e } \\
\text { controlado } \\
\text { População: } 12.000 \text { gestantes } \\
\text { Amostra: } 855 \text { gestantes ( } 397 \text { no grupo } \\
\text { intervenção e } 365 \text { no grupo controle) } \\
\text { Coleta de dados: questionário com questões } \\
\text { relacionadas à IU e IA, respondido antes (18-22 } \\
\text { semanas de gestação) e após a intervenção (32- } \\
36 \text { semanas de gestação) } \\
\text { Intervenção: sessões semanais de } 60 \text { minutos de } \\
\text { exercícios, acompanhadas por fisioterapeuta, } \\
\text { com grupos de } 8 \text { a } 15 \text { gestantes, por } 12 \text { semanas; } \\
\text { as sessões incluíram instruções sobre anatomia e } \\
\text { contração do AP e as gestantes foram a realizar } \\
\text { os exercícios em casa, três vezes por semana ou } \\
\text { mais; as gestantes do grupo controle receberam o } \\
\text { acompanhamento pré-natal padrão; todas } \\
\text { gestantes receberam orientação sobre FMAP por } \\
\text { escrito } \\
\text { Análise de dados: análise por intenção de tratar e } \\
\text { regressão logística }\end{array}$ & $\begin{array}{l}\text { Entre as gestantes do grupo } \\
\text { intervenção: melhor adesão aos } \\
\text { exercícios em casa; menor } \\
\text { prevalência de IU nas nulíparas; } \\
\text { menos mulheres relataram IU ( } 11 \% \\
\text { contra 19\%; p=0,004); menos } \\
\text { mulheres relataram incontinência } \\
\text { fecal (3\% contra 5\%), mas essa } \\
\text { diferença não foi estatisticamente } \\
\text { significante. Exercícios perineais } \\
\text { previnem e tratam IU e IA na } \\
\text { gravidez; as instruções devem ser } \\
\text { completas, com orientação sobre AP } \\
\text { nas aulas de ginástica para mulheres } \\
\text { grávidas. }\end{array}$ \\
\hline
\end{tabular}

(continua) 
Quadro 1

(cont.)

\begin{tabular}{|c|c|c|c|}
\hline $\begin{array}{l}\text { Autor } \\
\text { Ano } \\
\text { País }\end{array}$ & Objetivos & $\begin{array}{c}\text { Método } \\
\text { Desenho/População/Amostra/Coleta de } \\
\text { dados/Intervenção/Análise dos dados }\end{array}$ & Principais resultados \\
\hline $\begin{array}{l}\text { Elenskaia et al. } \\
2011 \\
\text { Reino Unido }\end{array}$ & $\begin{array}{l}\text { Avaliar a função dos músculos do } \\
\text { AP no primeiro e segundo } \\
\text { trimestres da gestação e após o } \\
\text { parto. }\end{array}$ & $\begin{array}{l}\text { Desenho: coorte prospectiva } \\
\text { População: gestantes de baixo risco com } \\
\text { gestação única } \\
\text { Amostra: } 403 \text { gestantes (182 nulíparas e } 221 \\
\text { multíparas) } \\
\text { Coleta de dados: informações demográficas, } \\
\text { clínica, obstétricas e sobre realização de } \\
\text { exercícios perineais, perineometria (balão } \\
\text { vaginal) e palpação digital, avaliadas no segundo } \\
\text { e terceiro trimestres da gestação } \\
\text { Análise de dados: descritiva e inferencial }\end{array}$ & $\begin{array}{l}\text { Na perineometria, a pressão de } \\
\text { repouso e de contração máxima } \\
\text { aumentaram significativamente } \\
\text { durante a gestação, tanto nas } \\
\text { primíparas como nas multíparas. O } \\
\text { aumento da pressão de contração } \\
\text { máxima foi maior entre as gestantes } \\
\text { que realizaram exercícios perineais } \\
\text { regularmente. }\end{array}$ \\
\hline $\begin{array}{l}\text { Gameiro et al. } \\
2011 \\
\text { Brasil }\end{array}$ & $\begin{array}{l}\text { Comparar a FMAP entre mulheres } \\
\text { nulíparas e multíparas. }\end{array}$ & $\begin{array}{l}\text { Desenho: estudo prospectivo } \\
\text { População: gestantes nulíparas e primíparas } \\
\text { continentes antes da gestação } \\
\text { Amostra: } 100 \text { mulheres ( } 50 \text { nulíparas e } 50 \\
\text { multíparas) } \\
\text { Coleta de dados: questionário clínico, } \\
\text { perineometria (Dynamed) e palpação digital no } \\
\text { segundo e terceiro trimestres de gestação, em } \\
\text { diferentes posições (deitada com as pernas } \\
\text { estendidas, fletidas e sentada) } \\
\text { Análise de dados: descritiva, inferencial e } \\
\text { multivariada }\end{array}$ & $\begin{array}{l}\text { Entre as primíparas, } 19 \% \text { relataram } \\
\text { IU no segundo trimestre de gestação } \\
\text { e } 27 \% \text {, no terceiro trimestre. Na } \\
\text { perineometria, não houve diferença } \\
\text { estatisticamente significante entre as } \\
\text { nulíparas e primíparas no segundo e } \\
\text { terceiro trimestres de gestação. }\end{array}$ \\
\hline
\end{tabular}




\begin{tabular}{|c|c|c|c|}
\hline $\begin{array}{c}\text { Autor } \\
\text { Ano } \\
\text { País } \\
\end{array}$ & Objetivos & $\begin{array}{c}\text { Método } \\
\text { Desenho/População/Amostra/Coleta de } \\
\text { dados/Intervenção/Análise dos dados }\end{array}$ & Principais resultados \\
\hline $\begin{array}{l}\text { Hay-Smith et } \\
\text { al. } \\
2011\end{array}$ & $\begin{array}{l}\text { Determinar o efeito do treinamento } \\
\text { dos músculos do AP na IU, } \\
\text { comparado aos cuidados usuais no } \\
\text { pré-natal e pós-parto. }\end{array}$ & $\begin{array}{l}\text { Desenho: revisão sistemática Cochrane } \\
\text { População: ensaios clínicos randomizados e } \\
\text { quasi-randomizados na gestação e no pós-parto, } \\
\text { em que todos os estudos utilizaram treinamento } \\
\text { da FMAP } \\
\text { Amostra: } 16 \text { estudos, envolvendo } 6.181 \text { mulheres } \\
\text { (3.040 no grupo intervenção e } 3.141 \text { no grupo } \\
\text { controle) } \\
\text { Análise de dados: descritiva e metanálise }\end{array}$ & $\begin{array}{l}\text { Há alguma evidência de que } \\
\text { exercícios perineais em mulheres } \\
\text { primíparas podem evitar IU no final } \\
\text { da gravidez e após o parto. Gestantes } \\
\text { sem IU que foram randomizadas para } \\
\text { o programa de exercícios perineais } \\
\text { no pré-natal foram menos propensas } \\
\text { a relatar IU no final da gestação que } \\
\text { aquelas randomizadas para cuidados } \\
\text { usuais (cerca de } 56 \% \text { menos; } \\
\text { RR=0,44; } 95 \% \text { IC } 0,30-0,65) \text {. É } \\
\text { possível que os efeitos do } \\
\text { treinamento sejam maiores na } \\
\text { população-alvo, mas não em } \\
\text { mulheres que tiveram } \\
\text { hipermobilidade do colo da bexiga } \\
\text { no início da gravidez, bebê grande ou } \\
\text { parto fórceps. São necessários mais } \\
\text { estudos para determinar a eficácia em } \\
\text { longo prazo. }\end{array}$ \\
\hline
\end{tabular}

(continua) 
Quadro 1

\begin{tabular}{|c|c|c|c|}
\hline $\begin{array}{c}\text { Autor } \\
\text { Ano } \\
\text { País }\end{array}$ & Objetivos & $\begin{array}{c}\text { Método } \\
\text { Desenho/População/Amostra/Coleta de } \\
\text { dados/Intervenção/Análise dos dados }\end{array}$ & Principais resultados \\
\hline $\begin{array}{l}\text { Ko et al. } \\
2011 \\
\text { Taiwan }\end{array}$ & $\begin{array}{l}\text { Avaliar o efeito do exercício da } \\
\text { musculatura do AP durante o pré- } \\
\text { natal na prevenção e no tratamento } \\
\text { da IU durante a gravidez e após o } \\
\text { parto. }\end{array}$ & $\begin{array}{l}\text { Desenho: ensaio clínico } \\
\text { População: gestantes nulíparas entre } 16 \text { e } 24 \\
\text { semanas de gestação única } \\
\text { Amostra: } 300 \text { gestantes ( } 150 \text { no grupo de } \\
\text { intervenção e } 150 \text { no grupo controle) } \\
\text { Coleta de dados: entrevista com os questionários } \\
\text { Incontinence Impact Questionaire (IIQ-7) e } \\
\text { Urogenital Distress Inventory (UDI-6) e mais } \\
\text { duas questões sobre perda de urina; todas as } \\
\text { mulheres foram entrevistadas com } 36 \text { semanas de } \\
\text { gestação e três dias pós-parto, pessoalmente por } \\
\text { enfermeiras, e seis semanas e seis meses após } \\
\text { parto, via telefone } \\
\text { Intervenção: orientação, exercícios realizados em } \\
\text { casa, duas vezes ao dia, e treinamento em grupo } \\
\text { com } 10 \text { gestantes, uma vez por semana, } \\
\text { acompanhado por fisioterapeuta, e } \\
\text { preenchimento de diário de exercícios; as } \\
\text { gestantes do grupo controle receberam cuidado } \\
\text { usual } \\
\text { Análise de dados: descritiva, inferencial e } \\
\text { multivariada }\end{array}$ & $\begin{array}{l}\text { No grupo de intervenção: pontuações } \\
\text { menores no IIQ-7 e UDI-6, ao final } \\
\text { da gravidez e no período pós-parto, e } \\
\text { menor incidência de IU, no final da } \\
\text { gravidez e no sexto mês pós-parto. } \\
\text { Mulheres com parto vaginal foram } \\
\text { mais predispostas a desenvolver IU } \\
\text { no pós-parto. No sexto mês pós- } \\
\text { parto, não houve diferença } \\
\text { estatisticamente significante no } \\
\text { grupo que realizou exercícios } \\
\text { perineais. Os exercícios da } \\
\text { musculatura do AP durante a } \\
\text { gravidez são efetivos na prevenção e } \\
\text { no tratamento da IU. }\end{array}$ \\
\hline
\end{tabular}




\begin{tabular}{|c|c|c|c|}
\hline $\begin{array}{l}\text { Autor } \\
\text { Ano } \\
\text { País }\end{array}$ & Objetivos & $\begin{array}{c}\text { Método } \\
\text { Desenho/População/Amostra/Coleta de } \\
\text { dados/Intervenção/Análise dos dados }\end{array}$ & Principais resultados \\
\hline $\begin{array}{l}\text { Sangsawang e } \\
\text { Serisathien } \\
2011 \\
\text { Tailândia }\end{array}$ & $\begin{array}{l}\text { Examinar os efeitos de um } \\
\text { programa de exercícios da } \\
\text { musculatura do AP na IU de } \\
\text { esforço severa, em mulheres } \\
\text { grávidas. }\end{array}$ & $\begin{array}{l}\text { Desenho: ensaio clínico quasi-experimental } \\
\text { População: gestantes com queixa de IU de } \\
\text { estresse durante a gestação (moderada ou severa) } \\
\text { Amostra: } 66 \text { gestantes ( } 31 \text { no grupo experimental } \\
\text { e } 35 \text { no grupo controle) } \\
\text { Coleta de dados: grupo experimental realizou } \\
\text { programa de treinamento para a musculatura do } \\
\text { AP e grupo controle recebeu os cuidados usuais } \\
\text { Intervenção: programa de treinamento do AP } \\
\text { quinzenal, entre } 20 \text { e } 30 \text { semanas de gestação, } \\
\text { durante seis semanas, em grupos de duas a cinco } \\
\text { gestantes, em sessões de } 45 \text { minutos; a realização } \\
\text { dos exercícios foi registrada em um diário; grupo } \\
\text { controle recebeu cuidado usual } \\
\text { Análise de dados: descritiva, inferencial e } \\
\text { multivariada }\end{array}$ & $\begin{array}{l}\text { A quantidade da perda de urina no grupo } \\
\text { experimental foi significantemente } \\
\text { menor que antes da intervenção. Um } \\
\text { terço das mulheres não apresentou perda } \\
\text { de urina. Houve diminuição da } \\
\text { frequência e volume de IUE. A média do } \\
\text { escore da percepção da severidade da } \\
\text { perda de urina por estresse teve } \\
\text { diferenças estatisticamente significantes, } \\
\text { em comparação com as mulheres do } \\
\text { grupo controle. A média da frequência } \\
\text { da IUE no grupo controle foi } \\
\text { significantemente aumentado em relação } \\
\text { a volume, frequência e percepção da } \\
\text { severidade da perda de urina. O } \\
\text { programa de treinamento do AP de seis } \\
\text { semanas é capaz de reduzir a severidade } \\
\text { dos sintomas de IUE na gestante. }\end{array}$ \\
\hline
\end{tabular}

(continua) 
Quadro 1

\begin{tabular}{|c|c|c|c|}
\hline $\begin{array}{l}\text { Autor } \\
\text { Ano } \\
\text { País }\end{array}$ & Objetivos & $\begin{array}{c}\text { Método } \\
\text { Desenho/População/Amostra/Coleta de } \\
\text { dados/Intervenção/Análise dos dados }\end{array}$ & Principais resultados \\
\hline \begin{tabular}{|l} 
Solans- \\
Domènech, \\
Sanchez e \\
Espuna-Pons \\
2010 \\
Espanha
\end{tabular} & $\begin{array}{l}\text { Estimar a frequência e severidade e } \\
\text { identificar os fatores de risco de IU } \\
\text { e IA durante a gestação e após o } \\
\text { parto. }\end{array}$ & $\begin{array}{l}\text { Desenho: coorte } \\
\text { População: gestantes nulíparas continentes } \\
\text { atendidas no serviço público de saúde } \\
\text { Amostra: } 1128 \text { gestantes nulíparas continentes } \\
\text { Coleta de dados: informações } \\
\text { sociodemográficas, clínicas e obstétricas, ISI e } \\
\text { ICIQ-SF para IA e Jorge e Wexner Faecal } \\
\text { Continence Grading Scale, aplicados no } \\
\text { primeiro, segundo e terceiro trimestres da } \\
\text { gestação e no pós-parto. } \\
\text { Análise de dados: descritiva e multivariada }\end{array}$ & 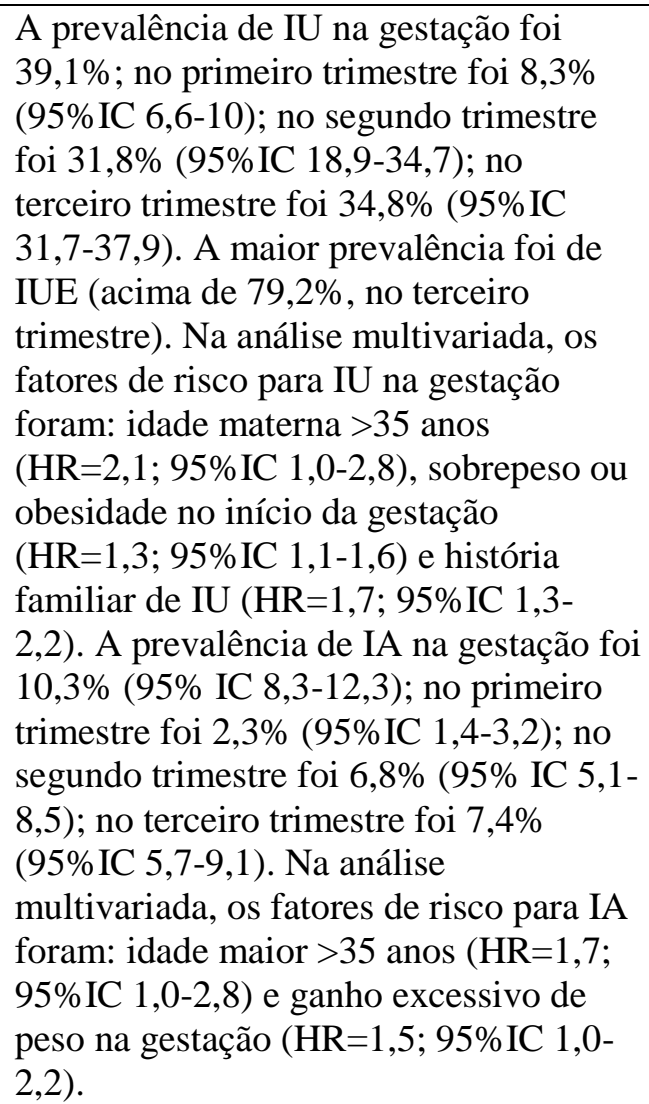 \\
\hline
\end{tabular}

(continua) 
Quadro 1

\begin{tabular}{|c|c|c|c|}
\hline $\begin{array}{l}\text { Autor } \\
\text { Ano } \\
\text { País }\end{array}$ & Objetivos & $\begin{array}{c}\text { Método } \\
\text { Desenho/População/Amostra/Coleta de } \\
\text { dados/Intervenção/Análise dos dados }\end{array}$ & Principais resultados \\
\hline $\begin{array}{l}\text { Dinc, Beji e } \\
\text { Yalcin } \\
2009 \\
\text { Turquia }\end{array}$ & $\begin{array}{l}\text { Determinar a eficácia de exercícios } \\
\text { para os músculos do AP sobre a IU } \\
\text { durante a gravidez e no período } \\
\text { pós-parto. }\end{array}$ & $\begin{array}{l}\text { Desenho: ensaio clínico } \\
\text { População: mulheres com IU na gestação } \\
\text { Amostra: } 80 \text { gestantes ( } 40 \text { no grupo de intervenção e } \\
40 \text { no grupo controle) } \\
\text { Coleta de dados: avaliação da FMAP com } \\
\text { perineômetro (Peritron), 1-h de padtests, palpação } \\
\text { digital e diário miccional } \\
\text { Intervenção: as mulheres foram orientadas quanto à } \\
\text { realização da contração dos músculos do AP antes da } \\
\text { avaliação; aquelas do grupo de estudo foram treinadas } \\
\text { para realizarem a contração corretamente e só depois } \\
\text { foram incluídas no protocolo de treinamento com } \\
\text { exercicios diários e graduais para serem realizados em } \\
\text { casa; uma semana depois, essas mulheres foram } \\
\text { avaliadas novamente e as que realizaram de forma } \\
\text { incorreta a contração foram submetidas novamente ao } \\
\text { treinamento e reavaliadas após uma semana; os } \\
\text { exercícios também eram verificados durante as } \\
\text { consultas de pré-natal; o grupo controle não recebeu } \\
\text { orientações para realização dos exercícios; a } \\
\text { avaliação da FMAP foi realizada entre } 36 \text { e } 38 \\
\text { semanas de gestação e entre seis e oito semanas após } \\
\text { o parto, em ambos os grupos } \\
\text { Análise de dados: descritiva, inferencial e } \\
\text { multivariada }\end{array}$ & $\begin{array}{l}\text { Prevalência de IU de } 48,8 \% \text { no } \\
\text { primeiro trimestre; } 25 \% \text { tinham IU } \\
\text { antes da gestação, } 32,5 \% \text { começaram } \\
\text { a ter IU no segundo trimestre e } \\
18,8 \% \text { desenvolveram no terceiro } \\
\text { trimestre. No final segundo trimestre, } \\
\text { a média da perineometria, em } \\
\text { cm }{ }_{2} \mathrm{O}, \text { foi: } 30,05( \pm 11,05) \text { no grupo } \\
\text { intervenção e } 28,08( \pm 12,95) \text { no } \\
\text { grupo controle. No terceiro trimestre, } \\
\text { variação após a intervenção, foi } \\
+10,43 \text { ( } \pm 5,20) \text { e }-1,88 \text { ( } \pm 4,44) \\
\text { cmH }{ }_{2} \mathrm{O}, \text { nos grupos intervenção e } \\
\text { controle, com diferença } \\
\text { estatisticamente significante. Houve } \\
\text { redução estatisticamente significante } \\
\text { dos episódios de IU no grupo } \\
\text { intervenção. Os resultados } \\
\text { mostraram que os exercícios para o } \\
\text { AP durante a gestação e no pós-parto } \\
\text { têm o mesmo efeito para prevenir e } \\
\text { tratar IU, por melhorar a FMAP. } \\
\text { Porém, não é possível afirmar que é a } \\
\text { única causa que reduz a } \\
\text { incontinência. }\end{array}$ \\
\hline
\end{tabular}

(continua) 
Quadro 1

(cont.)

\begin{tabular}{|c|c|c|c|}
\hline $\begin{array}{l}\text { Autor } \\
\text { Ano } \\
\text { País }\end{array}$ & Objetivos & $\begin{array}{c}\text { Método } \\
\text { Desenho/População/Amostra/Coleta de } \\
\text { dados/Intervenção/Análise dos dados }\end{array}$ & Principais resultados \\
\hline $\begin{array}{l}\text { Bø et al. } \\
2007 \\
\text { Noruega }\end{array}$ & $\begin{array}{l}\text { Avaliar o número de mulheres que } \\
\text { realizaram o treinamento da } \\
\text { musculatura do AP durante a } \\
\text { gravidez. }\end{array}$ & $\begin{array}{l}\text { Desenho: estudo observacional prospectivo } \\
\text { População: gestantes que utilizavam um centro } \\
\text { médico } \\
\text { Amostra: } 467 \text { mulheres } \\
\text { Coleta de dados: questionário sobre a prática de } \\
\text { atividades físicas regulares, incluindo o } \\
\text { fortalecimento do AP } \\
\text { Análise de dados: descritiva e inferencial }\end{array}$ & $\begin{array}{l}24 \% \text { das gestantes apresentaram } \\
\text { problemas com IU; apenas } 17 \% \\
\text { relataram a realização os exercícios } \\
\text { de fortalecimento do AP. }\end{array}$ \\
\hline $\begin{array}{l}\text { Oliveira et al. } \\
2007 \\
\text { Brasil }\end{array}$ & $\begin{array}{l}\text { Avaliar os efeitos do treinamento } \\
\text { da FMAP em gestantes nulíparas. }\end{array}$ & $\begin{array}{l}\text { Desenho: estudo comparativo, prospectivo, não } \\
\text { randomizado e controlado } \\
\text { População: gestantes nulíparas de baixo risco, } \\
\text { até } 20 \text { semanas de gestação } \\
\text { Amostra: } 46 \text { gestantes } \\
\text { Coleta de dados: entrevista, perineometria } \\
\text { (Perina) e palpação digital } \\
\text { Coleta de dados: todas as gestantes passaram por } \\
\text { duas avaliações na gestação: a primeira com } 20 \\
\text { semanas e a segunda com } 36 \text { semanas } \\
\text { Intervenção: as gestantes do grupo de exercícios } \\
\text { foram submetidas à CT do AP com duração de } \\
60 \text { minutos semanais, na clínica de pré-natal } \\
\text { Análise de dados: descritiva, inferencial e } \\
\text { multivariada }\end{array}$ & $\begin{array}{l}\text { Avaliação funcional do AP: ambos } \\
\text { os grupos com aumento significativo } \\
\text { da primeira para a segunda avaliação. } \\
\text { Perineometria sem biofeedback: na } \\
\text { segunda avaliação, somente o grupo } \\
\text { de exercícios teve aumento } \\
\text { significativo. Perineometria com } \\
\text { biofeedback: ambos os grupos com } \\
\text { aumento significativo; a diferença } \\
\text { percentual foi maior no grupo de } \\
\text { exercícios. }\end{array}$ \\
\hline
\end{tabular}

(continua) 


\begin{tabular}{|c|c|c|c|}
\hline $\begin{array}{c}\text { Autor } \\
\text { Ano } \\
\text { País } \\
\end{array}$ & Objetivos & $\begin{array}{c}\text { Método } \\
\text { Desenho/População/Amostra/Coleta de } \\
\text { dados/Intervenção/Análise dos dados }\end{array}$ & Principais resultados \\
\hline $\begin{array}{l}\text { Mørkved et al. } \\
2003 \\
\text { Noruega }\end{array}$ & $\begin{array}{l}\text { Avaliar se } 12 \text { semanas de } \\
\text { treinamento intensivo para a } \\
\text { musculatura do AP durante a } \\
\text { gravidez pode prevenir IU na } \\
\text { gestação e após o parto. }\end{array}$ & $\begin{array}{l}\text { Desenho: ensaio clínico randomizado } \\
\text { População: gestantes nulíparas } \\
\text { Amostra: } 301 \text { gestantes, distribuídas no grupo } \\
\text { experimental (n=148) e grupo controle (n=153) } \\
\text { Coleta de dados: entrevistas estruturadas, } \\
\text { avaliação da FMAP pela perineometria (balão } \\
\text { vaginal) e diário de exercícios } \\
\text { Intervenção: o grupo experimental recebeu } \\
\text { treinamento do AP com fisioterapeutas, com } \\
\text { duração de } 60 \text { minutos, por } 12 \text { semanas, entre } 20 \\
\text { e } 36 \text { semanas de gestação; os exercícios } \\
\text { consistiam de } 12 \text { contrações sustentadas por seis } \\
\text { a oito segundos, seguidas de quatro contrações } \\
\text { rápidas, realizadas nas posições sentada, } \\
\text { ajoelhada e em pé com as pernas afastadas; } \\
\text { gestantes desse grupo foram orientadas a } \\
\text { realizarem os exercicíos em casa, duas vezes por } \\
\text { dia; o grupo controle recebeu cuidado usual } \\
\text { Análise de dados: descritiva e inferencial }\end{array}$ & $\begin{array}{l}\text { A FMAP foi significativamente } \\
\text { maior no grupo experimental com } 36 \\
\text { semanas de gestação (p=0,008); as } \\
\text { gestantes desse grupo desenvolveram } \\
\text { menos IU ( } 32 \%) \text { que aquelas do } \\
\text { grupo controle }(48 \%) \text {. Porém, os } \\
\text { resultados só provaram benefícios } \\
\text { durante a gravidez e nos três meses } \\
\text { pós-parto. }\end{array}$ \\
\hline
\end{tabular}




\section{HIPÓTESES}

- A CT supervisionada do AP em gestantes incontinentes reduz a ocorrência de IU.

- A CT supervisionada do AP em gestantes incontinentes aumenta a FMAP. 


\section{OBJETIVOS}

- Avaliar o efeito da CT supervisionada do AP na IU e a interferência da IU na vida da gestante.

- Avaliar o efeito da CT supervisionada do AP na FMAP em gestantes incontinentes. 


\section{MÉTODO $^{1}$}

\subsection{Tipo de estudo}

Ensaio clínico paralelo, controlado e randomizado, aninhado a uma coorte de gestantes.

Na referida coorte, denominada "Cuidado perineal na gestação e após o parto: prevenção e morbidade relacionadas à força muscular perineal, função sexual e continência urinária", foram incluídas 500 gestantes que iniciaram o pré-natal no primeiro trimestre da gravidez, no período entre 21 de novembro de 2012 e 17 de setembro de 2013, consecutivamente.

\subsection{Local}

O estudo foi realizado no Centro Clínico de Obstetrícia e Pré-Natal (CCOPN), da SEISA Assistência Médica, empresa do Setor de Saúde Suplementar, localizado no município de Guarulhos, São Paulo.

A partir de 2014, com a incorporação da SEISA à empresa AMIL UnitedHealth Group, o CCOPN foi alocado no Centro Clínico da Mulher, com a denominação de NextClínica Mulher e Pré-Natal.

\footnotetext{
${ }^{1}$ Parte da descrição do Método foi extraída de: Riesco MLG. Cuidado perineal na gestação e após o parto: prevenção e morbidade relacionadas à força muscular perineal, função sexual e continência urinária [relatório de pesquisa]. São Paulo: Escola de Enfermagem, Universidade de São Paulo; 2015.
} 


\subsection{População}

A população constituiu-se das gestantes participantes da coorte.

Para inclusão na coorte, foram obedecidos os seguintes critérios: 18 anos ou mais; ensino fundamental completo; índice de massa corpórea (IMC) menor que 35; idade gestacional até 12 semanas e 6 dias, calculada pela data da última menstruação e confirmada pela ultrassonografia; gestação única, considerada de risco habitual; sem cirurgia urogenital prévia; sem doenças que podem interferir na FMAP (prolapso de órgão pélvico, doenças neurológicas, diabetes, lesão pélvica ou da coluna vertebral); não oferecer resistência à inserção da sonda do perineômetro na vagina; não realizar manobra de Valsalva à medição da FMAP; sem dificuldade no entendimento do idioma português ou na comunicação.

Os critérios de exclusão foram: complicações obstétricas ou clínicas durante a gestação; manobra de Valsalva à medição da FMAP. Para o ensaio clínico, foram seguidos os mesmos critérios de exclusão.

\subsection{Critérios de inclusão e amostra}

Todas as gestantes que atenderam ao seguinte critério de inclusão fizeram parte da amostra:

- Apresentar IU nas 4 semanas anteriores ao período compreendido entre as $20^{\mathrm{a}} \mathrm{e}$ $27^{\mathrm{a}}$ semanas de gestação, ou seja, entre 16 e 27 semanas.

\subsubsection{Cálculo do tamanho da amostra}

Inicialmente, realizou-se o cálculo do tamanho da amostra com base no estudo de Dinc, Beji e Yalcin (2009). No referido estudo, mulheres entre 36 e 38 semanas de gestação que realizaram CT do AP (grupo experimental) apresentaram média de FMAP 15,8 centímetros de água $\left(\mathrm{cmH}_{2} \mathrm{O}\right)$ maior, em relação àquelas que não o fizeram (grupo controle), avaliada pelo Peritron ${ }^{\mathrm{TM}}$.

Houve redução estatisticamente significante do número de episódios diários de IU e do volume de perda urinária entre as mulheres do grupo experimental, quando comparadas às do grupo controle. Os resultados indicaram que a possibilidade de IU no 
último trimestre da gestação é de $43 \%$ em mulheres que realizam CT do AP, e de $71 \%$ em mulheres que não o fazem.

Para o cálculo do tamanho amostral, avaliou-se a diferença de proporção de IU entre os grupos experimental e controle no final da gestação (43\% contra $71 \%$ ). Considerando-se o nível de significância de $5 \%$ e o poder do teste de $80 \%$, estimou-se 37 mulheres por grupo (Lwanga, Lemeshow, 1991).

Tratando-se de um estudo longitudinal, houve um acréscimo de 50\% de mulheres no grupo experimental e $20 \%$ no grupo controle, pela possibilidade de perda de seguimento das participantes. A amostra final foi estimada em 55 mulheres no grupo experimental e 45 no grupo controle, no total de 100 mulheres.

Embora a amostra inicial estimada fosse de 74 mulheres (37 no grupo experimental e 37 no grupo controle), este tamanho não foi obtido, pois as mulheres elegíveis para o ensaio clínico foram aquelas com IU no segundo trimestre da gestação que realizaram o seguimento da coorte previsto para esse período. Assim, o tamanho da amostra final foi de 96 gestantes, correspondendo ao total de gestantes com IU no período definido para inclusão das gestantes na coorte.

Porém, foram aleatorizadas 79 gestantes, pois 17 recusaram-se a participar do ensaio clínico. Dentre as gestantes aleatorizadas, apenas 53 foram avaliadas no final do estudo ( 31 do grupo experimental e 22 do grupo controle). Assim, com esse tamanho amostral, para detectar a mesma diferença prevista inicialmente, o poder do teste é de $41 \%$.

\subsubsection{Recrutamento e alocação}

As mulheres que apresentaram IU até a $27^{\mathrm{a}}$ semana de gestação na gestação atual, foram convidadas a participar do ensaio clínico e assinaram o Termo de Consentimento Livre e Esclarecido (TCLE) (Apêndice A). Foram alocadas de forma aleatorizada em um dos dois grupos - experimental e controle. No experimental, foram alocadas as gestantes para realizar CT do AP supervisionada e no grupo controle, aquelas que receberam orientação para realizar CT do AP sem supervisão, padronizada a todas as gestantes da coorte. 


\subsubsection{Aleatorização e cegamento}

A pesquisadora responsável pela aleatorização das gestantes nos grupos experimental e controle recebeu mensagem da equipe de pesquisa por e-mail ou telefone celular com nome e idade gestacional das gestantes que aceitaram participar do ensaio clínico. Não houve contato desta pesquisadora com nenhuma gestante antes da alocação nos grupos.

A sequência para alocação nos grupos experimental e controle foi realizada por meio de uma tabela de números aleatórios produzida eletronicamente. Foram empregados envelopes opacos sequencialmente numerados, com a especificação do grupo onde a gestante deveria ser alocada. A abertura do envelope foi realizada por pesquisadora que não participou do recrutamento e inclusão da gestante no estudo. Essa pesquisadora informou à gestante sobre a inclusão no grupo experimental por telefone, orientando sobre a data, horário e local da primeira sessão de CT supervisionada do AP. $\mathrm{Na}$ avaliação do desfecho, o cegamento está descrito no item 4.9 Avaliação dos desfechos.

\subsection{Exposição e desfechos}

A CT supervisionada do AP na segunda metade da gestação foi definida como exposição (intervenção). O desfecho primário foi a continência urinária, e os desfechos secundários foram a interferência da IU na vida da gestante e a FMAP. 


\subsection{Medidas e instrumentos de avaliação dos desfechos}

\subsubsection{Perineometria}

Um perineômetro eletrônico de pressão modelo Peritron ${ }^{\mathrm{TM}}$, da Laborie, Canadá, que registra as contrações musculares do AP por meio de sensor localizado em uma sonda vaginal de silicone de $8 \mathrm{~cm}$ de comprimento e $3 \mathrm{~cm}$ de diâmetro foi utilizado. $\mathrm{O}$ sensor está ligado a um microprocessador portátil que mensura a força da contração muscular do AP, numericamente, de 0,1 a $300 \mathrm{cmH}_{2} \mathrm{O}$. Esse aparelho não diferencia as contrações dos músculos do períneo e do abdome. O fabricante supõe que seja mais preciso do que os outros disponíveis no mercado, pois na leitura efetuada pelo Peritron $^{\mathrm{TM}}$, o erro não supera $1 \mathrm{cmH}_{2} \mathrm{O}$ (Figura 1).

Figura 1 - Peritron ${ }^{\mathrm{TM}}$ com sensor vaginal

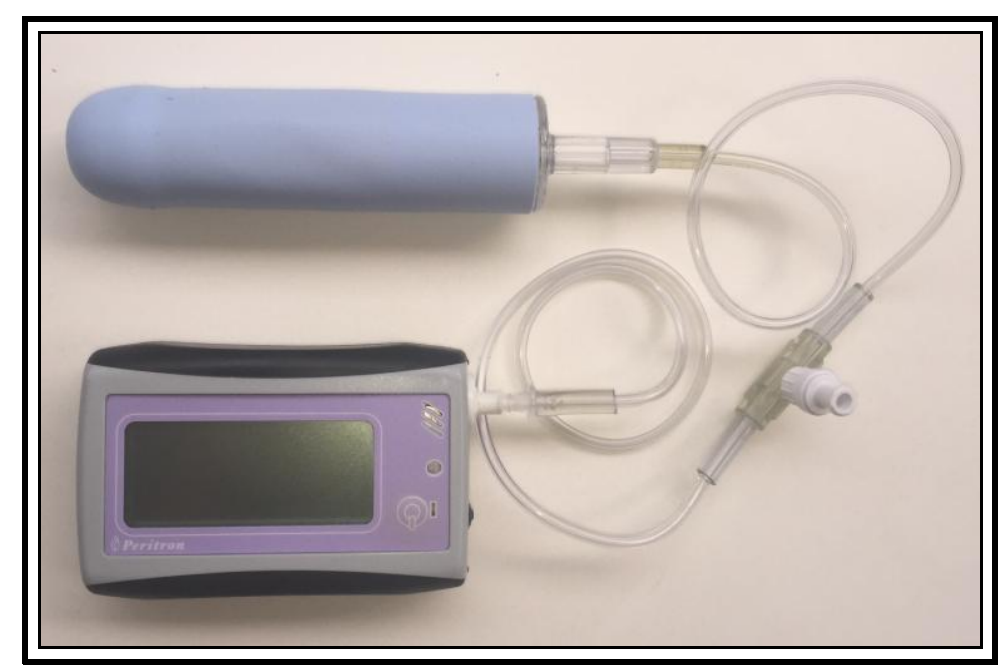

Fonte: A pesquisadora

\subsubsection{ICIQ-SF (Anexo 1)}

Consiste de quatro questões relativas à frequência e quantidade da perda urinária, interferência dessa perda na vida diária e situações em que a IU pode ocorrer. Para as respostas das três primeiras questões, são atribuídos valores, com escore final, variando de 0 a 21. A última questão (situações em que a IU pode ocorrer) possui oito alternativas de resposta qualitativa. 


\subsection{Coleta de dados e seguimento}

Inicialmente, foi realizada uma entrevista por enfermeiras ou obstetrizes da equipe de pesquisa com todas as mulheres incluídas na coorte, até 12 semanas e 6 dias de gestação (etapa 1 da coorte). Um formulário com dados clínicos e obstétricos e sintomas do trato urinário foi utilizado (Apêndice B). A entrevista foi feita no consultório de enfermagem. Foram verificados a estatura e o peso corporal, mensurada a FMAP e aplicado o ICIQ-SF. Todas as gestantes receberam orientação por escrito para realização da CT do AP em casa (Apêndice C).

Na ocasião, o retorno das gestantes entre 20 e 27 semanas de gestação (etapa 2 da coorte) foi marcado. Este período coincidiu com o retorno das gestantes para consulta com a enfermeira ou obstetriz, conforme protocolo do serviço. Nesta etapa, as mulheres com IU nas 4 semanas anteriores que aceitaram participar do ensaio clínico foram alocadas nos grupos experimental e controle, conforme descrito no item 4.4.3 Aleatorização e cegamento. A inclusão das gestantes no ensaio clínico foi encerrada quando todas as gestantes da coorte haviam realizado a etapa 2.

O retorno foi marcado entre 31 e 38 semanas de gestação (etapa 3 da coorte). Este período também coincidiu com o retorno das gestantes para consulta com a enfermeira ou obstetriz, conforme protocolo do serviço. Novamente, foi verificado o peso corporal, mensurada a FMAP e aplicado o ICIQ-SF. Foi perguntado sobre a frequência de realização dos exercícios perineais em casa. Além da orientação para manter a CT do AP, as mulheres foram orientadas a retornar para consulta após o parto (etapas 4 a 6 da coorte).

\subsubsection{Técnica de mensuração da FMAP ${ }^{2}$}

A mensuração da FMAP foi realizada no consultório de enfermagem, conforme os seguintes procedimentos:

1. Solicitar que a gestante esvazie a bexiga;

2. Colocar a gestante em posição ginecológica, com a região genital e os membros inferiores descobertos;

\footnotetext{
${ }^{2}$ Extraído de Riesco MLG. Cuidado perineal na gestação e após o parto: prevenção e morbidade relacionadas à força muscular perineal, função sexual e continência urinária [relatório de pesquisa]. São Paulo: Escola de Enfermagem, Universidade de São Paulo; 2015
} 
3. Ensinar a gestante a fazer contrações como se estivesse "segurando" a urina, usando somente os músculos do AP, evitando contrair os músculos abdominais, da coxa e das nádegas;

4. Puxar o êmbolo da seringa até $20 \mathrm{ml}$ e conectá-la ao aparelho;

5. Revestir a sonda elástica com um preservativo descartável não lubrificado;

6. Calçar luvas de procedimentos;

7. Lubrificar o preservativo com gel à base de água;

8. Instruir a gestante a relaxar os músculos do AP;

9. Ligar o perineômetro;

10. Introduzir 4 a $6 \mathrm{~cm}$ da sonda na vagina, de modo que, aproximadamente, $1,5 \mathrm{~cm}$ desta seja visualizada;

11. Retirar a luva da mão dominante para manusear o aparelho;

12. Insuflar o perineômetro até que a escala atinja $100 \mathrm{cmH}_{2} \mathrm{O}$

13. Zerar o aparelho, apertando o botão na parte anterior do aparelho, conforme recomendação do fabricante;

14. Girar a chave lateral do aparelho para verificar se foi zerado (se não estiver zerado, apertar o botão da parte anterior do aparelho novamente);

15. Solicitar que a gestante contraia e mantenha, por 5 segundos, a contração voluntária dos músculos perineais ao redor da sonda vaginal;

16. Observar a movimentação da sonda perineal na direção cranial, que indica que a contração foi realizada corretamente (caso não haja movimentação da sonda, orientar novamente a gestante, realizando o exame vaginal digital);

17. Registrar o valor acusado no aparelho;

18. Repetir os passos 13 a 17, por duas vezes, com intervalo de 30 segundos entre as medições;

\section{Observações:}

- O valor acusado (vide item 17 , acima) corresponde ao valor máximo da contração registrada na memória do aparelho. No entanto, memória do aparelho não registra valores inferiores a 5,0 $\mathrm{cmH}_{2} \mathrm{O}$. Nesses casos, considerar o valor máximo observado durante a perineometria, mesmo que este valor não seja registrado pela memória do aparelho.

- Confirmar a realização da manobra de Valsalva, realizando o exame vaginal digital. Nesse caso, a gestante deve ser excluída do estudo. 


\subsubsection{Aplicação do ICIQ-SF}

Dado que esse instrumento é autoaplicado, as gestantes receberam orientação sobre o preenchimento, imediatamente após a mensuração da FMAP. O questionário foi fornecido com uma prancheta e caneta, e seu preenchimento foi realizado na sala de espera do pré-natal.

\subsection{Intervenção}

A contração do AP foi orientada no primeiro trimestre da gestação, por uma das pesquisadoras da coorte, que forneceu um folheto com instruções para a prática dos exercícios no domicílio (Apêndice C). Estes deveriam ser realizados pela mulher nas posições ortostática, sentada e supina durante toda a gestação.

A CT foi feita com base na recomendação de Bø et al. (1990) e consistiu nos seguintes exercícios: três séries de 20 contrações rápidas, com intervalo de 1 segundo entre as contrações e 10 contrações sustentadas por 6 a 8 segundos, com intervalo de 12 a 16 segundos.

As gestantes aleatorizadas para o grupo experimental frequentaram até seis sessões de CT do AP supervisionadas pela fisioterapeuta da equipe de pesquisa, realizadas quinzenalmente, com uso de colchonetes em uma sala do CCOPN. Em todas as sessões, foi feito um diário com registro do desempenho das gestantes e das queixas relatadas.

Assim, a CT supervisionada do AP teve duração total de 12 semanas, com início entre as $20^{\mathrm{a}}$ e $27^{\mathrm{a}}$ semanas de gestação. Cada sessão supervisionada durou 45 minutos, com a participação de uma a três gestantes. No início de cada sessão, foram realizados exercícios de aquecimento global e, ao final, exercícios de alongamento dos músculos da região do quadril, musculatura da região adutora de coxa, músculos isquiotibiais e paravertebrais (Zanetti et al., 2007) (Apêndice D).

No grupo controle, as gestantes mantiveram apenas as orientações iniciais da CT do AP, conforme instruções do folheto (Apêndice C). 


\subsection{Avaliação dos desfechos}

A avaliação da incontinência urinária, da interferência da IU na vida da gestante e da FMAP, tanto no grupo experimental como no controle foi realizada, preferencialmente, por pesquisadoras que não participaram da alocação das gestantes nos grupos e da intervenção.

\subsection{Variáveis do estudo}

\subsubsection{Independente}

CT do AP - série de exercícios supervisionados, de acordo com o protocolo da pesquisa.

\subsubsection{Dependentes}

- IU na gestação atual - sim ou não;

- Interferência da IU na vida da gestante - frequência e quantidade da perda urinária e situações em que a IU pode ocorrer, avaliada por meio do ICIQ-SF, com escore entre 0 e 21 ;

- FMAP - contração da musculatura do AP, avaliada em $\mathrm{cmH}_{2} \mathrm{O}$ por meio da perineometria, considerado o maior valor registrado nas três medições da perineometria.

\subsubsection{Outras variáveis}

\subsubsection{Dados sociodemográficos}

- Idade - anos;

- Cor da pele - referida pela mulher;

- Escolaridade - ensino fundamental completo ou ensino médio incompleto; médio completo ou superior incompleto; superior completo;

- Ocupação - estudante, do lar e trabalho remunerado;

- Situação conjugal - tem ou não parceiro e vive ou não com o parceiro. 


\subsubsection{Dados obstétricos e clínicos e sintomas do trato urinário}

- Número de gestações anteriores;

- Número de abortos anteriores;

- Número e tipo de partos anteriores - vaginal e cesariana;

- Trauma perineal em parto anterior (laceração espontânea: presença espontânea de qualquer solução de continuidade tecidual; episiotomia);

- Maior peso do recém-nascido ( $\mathrm{RN})$ em parto anterior - gramas (g), imediatamente, após o nascimento;

- Estado nutricional - classificado de acordo com o IMC em baixo peso, adequado, sobrepeso e obesidade, considerando a idade gestacional (Atalah et al., 1997);

- IU prévia - referência à perda de urina em qualquer quantidade, frequência ou motivo, prévia à gestação atual, considerando: somente durante gravidez anterior; em gravidez anterior e que persiste; antes da gravidez atual e que persiste;

- Situações em que a perda de urina acontece na gestação atual - avaliada pelo ICIQ$\mathrm{SF}$;

- Frequência de realização dos exercícios perineais não supervisionados na gestação nunca ou esporadicamente (não realiza ou realiza menos que duas vezes por semana); regularmente (realiza, pelo menos, duas vezes por semana);

\subsection{Análise de dados}

Os dados foram digitados e armazenados em um banco no aplicativo Excel. O banco foi submetido à análise de consistência, em que para cada variável foi verificada a ocorrência de códigos não permitidos para o campo e conferidos com o instrumento correspondente (formulário de coleta de dados e ICIQ-SF). As inconsistências foram corrigidas, de acordo com as informações do instrumento. 


\subsubsection{Análise descritiva}

Para análise descritiva das variáveis qualitativas e quantitativas, foram calculadas as frequências absolutas e relativas e as medidas de tendência central e dispersão (média, desvio-padrão, mínimo e máximo), respectivamente.

\subsubsection{Análise inferencial}

$\mathrm{Na}$ análise bivariada, para avaliar a homogeneidade dos grupos experimental e controle em relação às variáveis de caracterização, foi utilizado o teste exato de Fisher.

$\mathrm{Na}$ análise bivariada da IU intra e intergrupos, foram utilizados os testes exato de Fisher e qui-quadrado, para a comparação de variáveis categóricas, e a metodologia de Modelos Lineares Generalizados para medidas repetidas, pelo modelo de Equações de Estimação Generalizadas (GEE). (Zeger, Liang, Albert, 1988) O teste-t para amostras independentes foi utilizado para comparação da IU e FMAP.

$\mathrm{Na}$ análise bivariada do ICIQ-SF e FMAP intra e intergrupos, foi utilizado o Modelo Linear de Efeitos Mistos (LMM).

$\mathrm{Na}$ análise multivariada para determinar o odds ratio (OR) da IU associado ao número de sessões de CT do AP, foi realizada a regressão logística longitudinal pelo processo backward stepwise.

Para as frequências, médias e odds ratio, foi calculado o intervalo de confiança de $95 \%$ (95\% IC).

Todos os testes foram feitos na forma bicaudal, admitindo-se a probabilidade de ocorrência de erro de primeira espécie de $5 \%$ (valor-p=0,05).

As análises foram feitas utilizando-se o pacote estatístico, SPSS para Windows (versão 22.0). 


\subsection{Aspectos éticos}

O estudo foi aprovado pelo Comitê de Ética em Pesquisa da Escola de Enfermagem da USP (CAAE 05096412.7.0000.5392) (Anexo 2), dado que à época de aprovação do estudo, a SEISA Assistência Médica não dispunha de Comitê de Ética em Pesquisa.

A realização da pesquisa foi autorizada pela gerência geral da SEISA mediante Termo de Autorização para a Realização da Pesquisa Científica (Apêndice E). As mulheres foram incluídas no estudo somente depois de receberem informações e após a leitura e assinatura do TCLE.

Vale destacar que as participantes da equipe de pesquisa não têm qualquer vínculo com os fabricantes ou distribuidores do equipamento utilizado neste estudo.

\subsection{Registro do protocolo}

Este ensaio foi submetido ao Registro Brasileiro de Ensaios Clínico (ReBEC), em 01/02/2013, com o título "Cuidado perineal na gestação e após o parto: prevenção e morbidade relacionadas à força muscular perineal, função sexual e continência urinária”. Identificado com o Universal Trial Number U111-1139-1749 e registro RBR8xj48n (http://ensaiosclinicos.gov.br/rg/RBR-8xj48n/ ) 


\section{RESULTADOS}

Os resultados referem-se aos dados obtidos no banco de dados da coorte de base, conforme descrito no Método e aos dados coletados no ensaio clínico.

No segundo trimestre da gestação (entre $21^{\mathrm{a}}$ e $26^{\mathrm{a}}$ semanas), as mulheres foram avaliadas (etapa 2 da coorte) e aquelas com IU foram convidadas a participar do ensaio clínico. Esta etapa foi conduzida de fevereiro de 2013 a janeiro de 2014.

A avaliação do desfecho (com ou sem IU) no terceiro trimestre da gestação (entre $31^{\mathrm{a}}$ e $38^{\mathrm{a}}$ semanas) foi iniciada em maio de 2013 e finalizada em maio de 2014.

O fluxograma das participantes (Figura 2) mostra que 226 gestantes foram avaliadas para elegibilidade, das quais, 96 apresentaram IU e foram consideradas elegíveis, por atenderem aos critérios de inclusão. Destas, 17 foram excluídas por recusa em participar e 79 foram alocadas aleatoriamente nos grupos experimental e controle. Dentre as 43 gestantes do grupo experimental, 42 foram alocadas para receber a intervenção e uma gestante foi excluída da alocação por complicação obstétrica. No grupo controle, foram alocadas 36 gestantes. Durante o seguimento, houve perda de 11 gestantes do grupo experimental e 14 do grupo controle, pois não realizaram a etapa 3 do estudo e, portanto, a FMAP e a ocorrência de IU não foram avaliadas. Assim, foram analisadas 31 gestantes no grupo experimental e 22 no grupo controle.

A seguir, os resultados são apresentados considerando os seguintes itens: $\mathbf{5 . 1}$ Caracterização da amostra (Tabela 1); 5.2 Análise da IU, ICIQ-SF e FMAP (Tabelas 2 a 18 e Figuras 3 a 6); 5.3 Considerações sobre a participação das gestantes nas sessões de CT supervisionada do AP (Quadro 2). 
Figura 2 - Fluxograma das participantes, Guarulhos, SP, 2013-2014

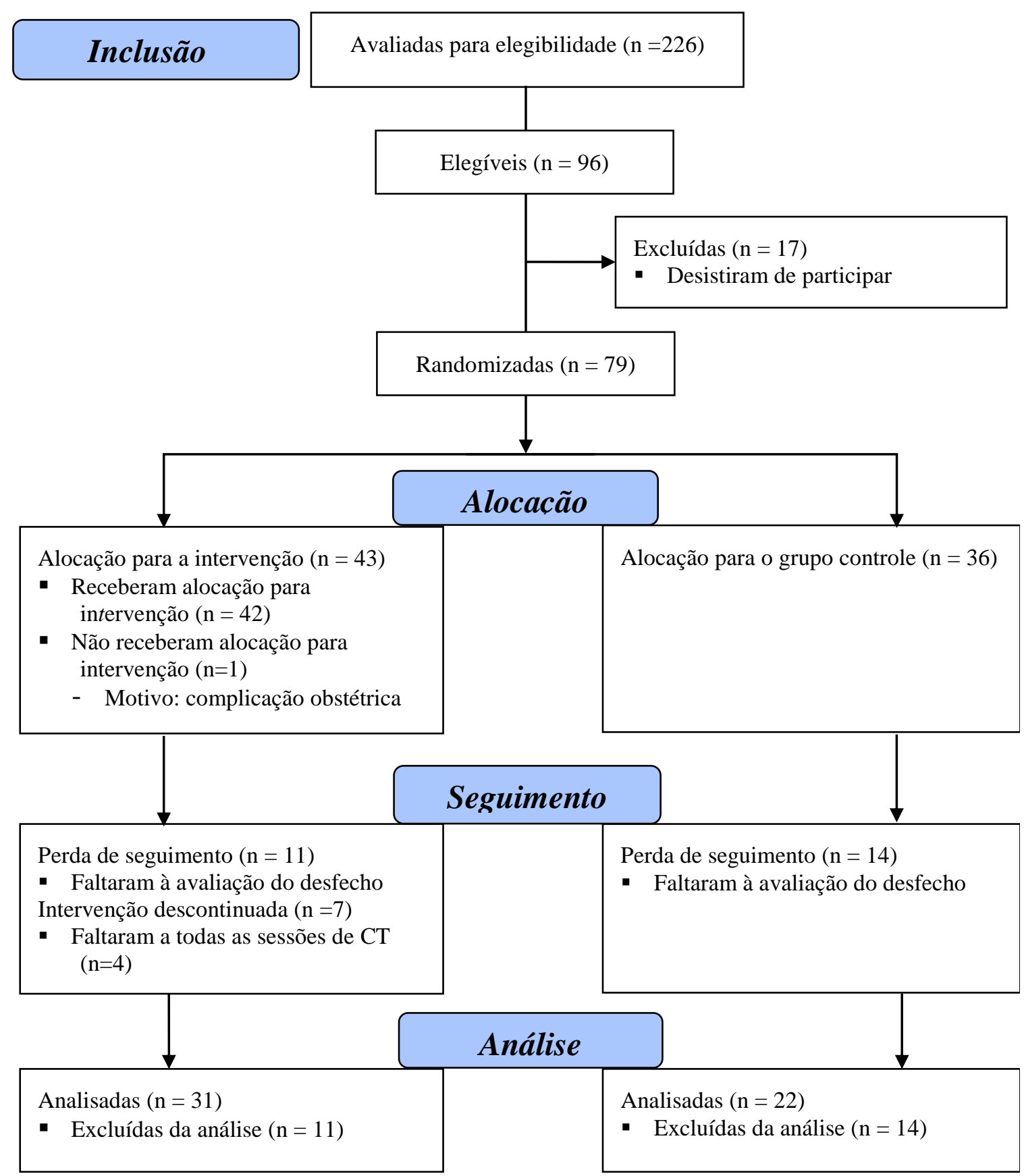

Fonte: A pesquisadora 


\subsection{Caracterização da amostra}

A idade gestacional média das mulheres quando da inclusão no estudo foi de 22,8 (d.p.=1,4) semanas, em ambos os grupos, e ao final do estudo foi de 34,1 (d.p.=1,5) e 34,7 (d.p.=1,1), nos grupos experimental e controle, respectivamente.

Com relação à idade das participantes, a variação foi de 18 a 46 anos, com média de 27,9 (d.p.=5,5) anos, sendo 27,8 (d.p.=6,5) anos no grupo experimental e 28,1 (d.p.=6,2) no grupo controle.

A seguir, os dados da Tabela 1 apresentam as demais características sociodemográficas e obstétricas das participantes no primeiro trimestre da gestação. Os resultados mostraram que os dois grupos eram homogêneos em relação a estas características, sem diferença estatisticamente significante.

Tabela 1 - Caracterização das gestantes dos grupos experimental e controle e valor-p, Guarulhos, SP, 2013-2014

\begin{tabular}{|c|c|c|c|c|c|c|c|}
\hline \multirow{3}{*}{ Característica } & \multicolumn{4}{|c|}{ Grupo } & \multirow{2}{*}{\multicolumn{2}{|c|}{ Total }} & \multirow{3}{*}{ Valor-p* } \\
\hline & \multicolumn{2}{|c|}{ Experimental } & \multicolumn{2}{|c|}{ Controle } & & & \\
\hline & $n=43$ & $\%$ & $n=36$ & $\%$ & $n=79$ & $\%$ & \\
\hline \multicolumn{8}{|l|}{ Faixa etária (anos) } \\
\hline$<20$ & 4 & 9,3 & 3 & 8,3 & 7 & 8,9 & \multirow{6}{*}{0,337} \\
\hline $20 \vdash 25$ & 12 & 27,8 & 7 & 19,5 & 19 & 24,1 & \\
\hline $25-30$ & 11 & 25,6 & 12 & 33,2 & 23 & 29,0 & \\
\hline $30-35$ & 10 & 23,3 & 7 & 19,5 & 17 & 21,5 & \\
\hline $35-40$ & 3 & 7,0 & 7 & 19,5 & 10 & 12,7 & \\
\hline$\geq 40$ & 3 & 7,0 & - & - & 3 & 3,8 & \\
\hline \multicolumn{8}{|l|}{ Cor da pele } \\
\hline Parda & 19 & 44,2 & 21 & 58,3 & 40 & 50,6 & \multirow{3}{*}{0,252} \\
\hline Branca & 19 & 44,2 & 14 & 38,9 & 33 & 41,8 & \\
\hline Negra & 5 & 11,6 & 1 & 2,8 & 6 & 7,6 & \\
\hline \multicolumn{8}{|l|}{ Escolaridade } \\
\hline Ensino fundamental & 3 & 7,0 & 3 & 8,3 & 6 & 7,6 & \multirow{3}{*}{0,790} \\
\hline Ensino médio & 34 & 79,1 & 26 & 72,3 & 60 & 75,9 & \\
\hline Ensino superior & 6 & 14,0 & 7 & 19,4 & 13 & 16,5 & \\
\hline \multicolumn{8}{|l|}{ Ocupação } \\
\hline Trabalho remunerado & 31 & 72,1 & 27 & 75,0 & 58 & 73,4 & \multirow{2}{*}{0,804} \\
\hline Do lar ou estudante & 12 & 27,9 & 9 & 25,0 & 21 & 26,6 & \\
\hline \multicolumn{8}{|l|}{ Situação conjugal } \\
\hline Vive com parceiro & 35 & 81,4 & 32 & 88,9 & 67 & 84,8 & \multirow{2}{*}{0,531} \\
\hline Não vive com parceiro & 8 & 18,6 & 4 & 11,1 & 12 & 15,2 & \\
\hline
\end{tabular}


Tabela 1

(cont.)

\begin{tabular}{|c|c|c|c|c|c|c|c|}
\hline \multirow{3}{*}{ Característica } & \multicolumn{4}{|c|}{ Grupo } & \multirow{2}{*}{\multicolumn{2}{|c|}{ Total }} & \multirow{3}{*}{ Valor-p* } \\
\hline & \multicolumn{2}{|c|}{ Experimental } & \multicolumn{2}{|c|}{ Experimental } & & & \\
\hline & $n=43$ & $\%$ & $n=36$ & $\%$ & $n=79$ & $\%$ & \\
\hline \multicolumn{8}{|c|}{ Gestação anterior } \\
\hline Nenhuma & 20 & 46,4 & 15 & 41,6 & 35 & 44,3 & \multirow{4}{*}{0,456} \\
\hline Uma & 15 & 34,9 & 15 & 41,6 & 30 & 38,0 & \\
\hline Duas & 6 & 14,0 & 2 & 5,6 & 8 & 10,1 & \\
\hline Três ou quatro & 2 & 4,7 & 4 & 11,2 & 6 & 7,6 & \\
\hline \multicolumn{8}{|l|}{ Aborto anterior } \\
\hline Nenhum & 36 & 83,7 & 29 & 80,6 & 65 & 82,3 & \multirow{2}{*}{0,773} \\
\hline Um ou dois & 7 & 16,3 & 7 & 19,4 & 14 & 17,7 & \\
\hline \multicolumn{8}{|c|}{ Parto vaginal anterior } \\
\hline Nenhum & 29 & 67,4 & 27 & 75,0 & 56 & 70,8 & \multirow{3}{*}{0,814} \\
\hline Um & 10 & 23,3 & 6 & 16,7 & 16 & 20,3 & \\
\hline Dois ou três & 4 & 9,3 & 3 & 8,3 & 7 & 8,9 & \\
\hline \multicolumn{8}{|c|}{ Cesariana anterior } \\
\hline Nenhuma & 37 & 86,0 & 26 & 72,2 & 63 & 79,7 & \multirow{2}{*}{0,164} \\
\hline Uma ou duas & 6 & 14,0 & 10 & 27,8 & 16 & 20,3 & \\
\hline \multicolumn{8}{|l|}{ IU prévia } \\
\hline Sim & 22 & 51,2 & 20 & 55,6 & 42 & 53,2 & \multirow{2}{*}{0,821} \\
\hline Não & 21 & 48,8 & 16 & 44,4 & 37 & 46,8 & \\
\hline
\end{tabular}

*Teste exato de Fisher

Fonte: A pesquisadora

Ainda em relação à caracterização das gestantes, vale destacar que todas as mulheres com parto vaginal anterior, em ambos os grupos, tinham antecedentes de episiotomia ou laceração espontânea.

No que se refere à IU prévia, as gestantes especificaram em que momento a IU ocorreu, com as seguintes respostas: "Antes da gravidez atual e que persiste até hoje" (18 gestantes do grupo experimental e 12 do grupo controle); "Em gravidez anterior e que persiste até hoje" (duas gestantes do grupo experimental e quatro do grupo controle); "Somente durante gravidez anterior" (duas gestantes do grupo experimental e quatro do grupo controle). Assim, pode-se considerar que 12 gestantes (quatro no grupo experimental e oito no grupo controle) apresentavam IU relacionada à gestação anterior e que 36 gestantes (20 no grupo experimental e 16 no grupo controle) iniciaram a gravidez atual com queixa de IU.

Quanto aos antecedentes em relação ao peso do recém-nascido em parto anterior, as mulheres com antecedentes de parto informaram o maior peso, com média de 3.189,8 (d.p.=299,4; mínimo=1.800; máximo=3.900) g e 3.103,8 (d.p.=386,4; 
mínimo=2.100; máximo=4.015) g, considerando os grupos experimental (19 gestantes) e controle (18 gestantes), respectivamente.

\subsection{Análise da IU, ICIQ-SF e FMAP}

Os dados das Tabelas 2 a 8 apresentam a análise da IU nos grupos experimental e controle depois da CT do AP.

Nos dados da Tabela 2, observa-se que a análise considerou todas as gestantes incluídas em ambos os grupos que foram avaliadas após a intervenção, independentemente do número de sessões de CT supervisionada do AP frequentado pelas mulheres do grupo experimental. Pode-se verificar que a ocorrência de IU no terceiro trimestre da gestação foi menos frequente em ambos os grupos, sem diferença estatisticamente significante. Essa redução foi de 58,1\% e 45,5\% nos grupos experimental e controle, respectivamente.

Tabela 2 - Distribuição das gestantes dos grupos experimental e controle segundo a IU e valor-p, Guarulhos, SP, 2013-2014

\begin{tabular}{lccccccc}
\hline \multirow{2}{*}{$\begin{array}{l}\text { IU depois } \\
\text { da CT }\end{array}$} & \multicolumn{6}{c}{ Experimental } & \multicolumn{3}{c}{ Controle } & \multirow{2}{*}{ Valor-p* } \\
\cline { 2 - 7 } & $\mathbf{N}$ & $\mathbf{\%}$ & $\mathbf{9 5 \%} \mathbf{~ I C}$ & $\mathbf{n}$ & $\mathbf{\%}$ & $\mathbf{9 5 \%} \mathbf{I C}$ & \\
\hline Sim & 13 & 41,9 & $34,4-69,6$ & 12 & 54,5 & $27,1-68,9$ & \multirow{2}{*}{0,413} \\
Não & 18 & 58,1 & $47,4-81,2$ & 10 & 45,5 & $15,7-55,7$ & \\
\hline Total & $\mathbf{3 1}$ & $\mathbf{1 0 0}$ & & $\mathbf{2 2}$ & $\mathbf{1 0 0}$ & \\
\hline
\end{tabular}

*Teste exato de Fisher

Fonte: A pesquisadora

Vale considerar que na análise conjunta das gestantes dos dois grupos $(\mathrm{n}=53)$, a redução da IU foi de 52,8\% ( $\mathrm{n}=28)$, mostrando diferença estatisticamente significante (valor-p<0,001; teste exato de Fisher); ou seja, houve redução da IU no terceiro trimestre da gestação, independentemente do grupo.

Em relação ao impacto do número de sessões de CT do AP na redução da IU, pode-se verificar que a queixa de IU no terceiro trimestre foi menos frequente entre as gestantes que participaram de, pelo menos, cinco sessões com diferença estatisticamente significante $(\mathrm{p}=0,028)$ (Tabela 3$)$. A análise de regressão logística indicou que cada sessão reduziu $41 \%$ a chance de IU (OR=0,59; 95\% IC 0,39-0,91; valor-p=0,015). 
Tabela 3 - Distribuição das gestantes dos grupos experimental segundo a UI e o número de sessões de CT do AP e valor-p, Guarulhos, SP, 2013-2014

\begin{tabular}{lccccccc}
\hline Número de & \multicolumn{6}{c}{ IU depois da CT } & \multirow{2}{*}{ Valor-p* } \\
\cline { 2 - 7 } sessões de & \multicolumn{5}{c}{ Sim } & \multicolumn{4}{c}{ Não } & \\
\cline { 2 - 7 } CT do AP & $\mathbf{N}$ & $\mathbf{\%}$ & $\mathbf{9 5 \%}$ IC & $\mathbf{n}$ & $\mathbf{\%}$ & $\mathbf{9 5 \%} \mathbf{~ I C}$ & \\
\hline Nenhuma & 6 & 46,1 & $9,2-83,1$ & 1 & 5,6 & $0,0-22,5$ & \\
Quatro & 2 & 15,4 & $0,0-56,2$ & 1 & 5,6 & $0,0-31,5$ & \multirow{2}{*}{$\mathbf{0 , 0 2 8}$} \\
Cinco & 2 & 15,4 & $0,0-39,0$ & 7 & 38,8 & $7,0-70,7$ & \\
Seis & 3 & 23,1 & $0,0-46,9$ & 9 & 50,0 & $21,7-78,3$ & \\
\hline Total & $\mathbf{1 3}$ & $\mathbf{1 0 0}$ & & $\mathbf{1 8}$ & $\mathbf{1 0 0}$ & \\
\hline
\end{tabular}

*Teste qui-quadrado

Fonte: A pesquisadora

Nos dados da Tabela 4, a análise da IU é apresentada, considerando exclusivamente as gestantes do grupo experimental que efetivamente participaram da CT supervisionada do AP e frequentaram de quatro a seis sessões e as gestantes do grupo controle. A redução de UI de 70,8\% e 45,5\% nos grupos experimental e controle, respectivamente, não mostrou diferença estatisticamente significante.

Tabela 4 - Distribuição das gestantes do grupo experimental que realizaram pelo menos quatro sessões de CT do AP e das gestantes do grupo controle segundo a IU e valor-p, Guarulhos, SP, 2013-2014

\begin{tabular}{lccccccc}
\hline \multirow{2}{*}{$\begin{array}{l}\text { IU depois } \\
\text { da CT }\end{array}$} & \multicolumn{9}{c}{ Experimental } & \multicolumn{3}{c}{ Controle } & \multirow{2}{*}{ Valor-p* } \\
\cline { 2 - 6 } & $\mathbf{N}$ & $\mathbf{\%}$ & $\mathbf{9 5 \%}$ IC & $\mathbf{n}$ & $\mathbf{\%}$ & $\mathbf{9 5 \%}$ IC & \\
\hline Sim & 7 & 29,2 & $8,7-49,6$ & 12 & 54,5 & $32,2-76,9$ & \multirow{2}{*}{0,134} \\
Não & 17 & 70,8 & $53,7-88,0$ & 10 & 45,5 & $26,7-64,2$ & \\
Total & $\mathbf{2 4}$ & $\mathbf{1 0 0}$ & & $\mathbf{2 2}$ & $\mathbf{1 0 0}$ & & \\
\hline
\end{tabular}

*Teste exato de Fisher

Fonte: A pesquisadora

Os dados da Tabelas 5 e 6 apresentam a distribuição das gestantes dos grupos experimental e controle, segundo o estado nutricional e a CT não supervisionada do AP, quando da inclusão no estudo.

No grupo experimental, foi maior a proporção de gestantes com sobrepeso; no grupo controle, prevaleceram as gestantes com peso adequado. No entanto, mais da metade das gestantes, em ambos os grupos, tinha sobrepeso ou obesidade, se consideradas em conjunto $(51,6 \%$ e $54,6 \%$ nos grupos experimental e controle, respectivamente).

Quanto à realização dos exercícios perineais sem supervisão, a orientação foi realizada na inclusão das participantes na coorte, no primeiro trimestre da gestação, 
conforme referido no Método. No segundo trimestre, 19,4\% das gestantes do grupo experimental citaram realizar exercícios regularmente (pelo menos, duas vezes por semana), em contraposição a 45,5\% das gestantes do grupo controle.

Tabela 5 - Distribuição das gestantes dos grupos experimental e controle segundo o estado nutricional antes da intervenção, Guarulhos, SP, 2013-2014

\begin{tabular}{lcccc}
\hline \multirow{2}{*}{ Estado nutricional } & \multicolumn{3}{c}{ Grupo } \\
\cline { 2 - 5 } & $\mathbf{n}$ & $\mathbf{\%}$ & $\mathbf{n}$ & $\mathbf{\%}$ \\
\cline { 2 - 5 } & 3 & 9,7 & 2 & 9,1 \\
\hline Baixo peso & 12 & 38,7 & 8 & 36,3 \\
Adequado & 13 & 41,9 & 6 & 27,3 \\
Sobrepeso & 3 & 9,7 & 6 & 27,3 \\
Obesidade & $\mathbf{3 1}$ & $\mathbf{1 0 0}$ & $\mathbf{2 2}$ & $\mathbf{1 0 0}$ \\
\hline Total & & &
\end{tabular}

Fonte: A pesquisadora

Tabela 6 - Distribuição das gestantes dos grupos experimental e controle segundo a CT não supervisionada do AP antes da intervenção, Guarulhos, SP, 2013-2014

\begin{tabular}{lcccc}
\hline & \multicolumn{4}{c}{ Grupo } \\
\cline { 2 - 5 } CT não supervisionada & \multicolumn{2}{c}{ Experimental } & \multicolumn{3}{c}{ Controle } \\
\cline { 2 - 5 } & $\mathbf{n}$ & $\mathbf{\%}$ & $\mathbf{n}$ & \% \\
\hline Regularmente & 6 & 19,4 & 10 & 45,5 \\
Nunca ou esporadicamente & 25 & 80,6 & 12 & 54,5 \\
\hline Total & $\mathbf{3 1}$ & $\mathbf{1 0 0}$ & $\mathbf{2 2}$ & $\mathbf{1 0 0}$ \\
\hline
\end{tabular}

Fonte: A pesquisadora

Conforme mostram os dados da Tabela 7, após a intervenção no grupo experimental, a maioria das mulheres que continuou com IU apresentavam baixo peso, sobrepeso ou obesidade; dentre aquelas com estado nutricional adequado, a quase totalidade mostrava-se continente. No grupo controle, essa distribuição foi similar em todas as categorias de estado nutricional. Apesar das variações observadas na frequência de IU, a análise inferencial (GEE) não mostrou diferença estatisticamente significante em relação aos grupos experimental e controle ou na interação entre estado nutricional e grupo.

Com relação à realização da CT não supervisionada do AP após a inclusão das participantes no ensaio clínico, em ambos os grupos a continência urinária esteve associada à realização de exercícios perineais regularmente (pelo menos, duas vezes por semana), com proporções de 72,2\% e 63,6\% de gestantes sem IU nos grupos experimental e controle, respectivamente. A análise inferencial mostrou diferença 
estatisticamente significante para o efeito dos exercícios (valor-p=0,014), independentemente do grupo ou da interação entre a CT não supervisionada do AP e os grupos (Tabela 8). 
Tabela 7 - Distribuição das gestantes dos grupos experimental e controle segundo a IU e o estado nutricional após a intervenção e valor-p*, Guarulhos, SP, 2013-2014

\begin{tabular}{|c|c|c|c|c|c|c|c|c|c|c|c|c|}
\hline \multirow{3}{*}{ Estado nutricional } & \multicolumn{12}{|c|}{ Grupo } \\
\hline & \multicolumn{6}{|c|}{ Experimental } & \multicolumn{6}{|c|}{ Controle } \\
\hline & $n=13$ & $\%$ & $95 \%$ IC & $n=18$ & $\%$ & \begin{tabular}{|l|} 
Total \\
$\mathbf{n}=\mathbf{3 1}$
\end{tabular} & $n=12$ & $\%$ & $95 \%$ IC & $n=10$ & $\%$ & $\begin{array}{l}\text { Total } \\
\mathrm{n}=\mathbf{2 2}\end{array}$ \\
\hline Adequado & 1 & 9,1 & $0,0-26,1$ & 10 & 90,9 & 11 & 4 & 57,1 & $20,5-93,8$ & 3 & 42,9 & 7 \\
\hline Sobrepeso & 5 & 55,6 & $23,1-88,0$ & 4 & 44,4 & 9 & 4 & 57,1 & $20,5-93,8$ & 3 & 42,9 & 7 \\
\hline Obesidade & 5 & 62,5 & $29,0-96,0$ & 3 & 37,5 & 8 & 3 & 50,0 & $10,0-90,0$ & 3 & 50,0 & 6 \\
\hline
\end{tabular}

*GEE: valor-p=0,389 para efeito do estado nutricional; valor-p=0,594 para efeito do grupo; valor-p=0,263 para efeito da interação do estado nutricional e grupo

Fonte: A pesquisadora

Tabela 8 - Distribuição das gestantes dos grupos experimental e controle segundo a IU e a CT não supervisionada do AP após a intervenção e valor-p*, Guarulhos, SP, 2013-2014

\begin{tabular}{|c|c|c|c|c|c|c|c|c|c|c|c|c|}
\hline \multirow{3}{*}{ CT não supervisionada } & \multicolumn{12}{|c|}{ Grupo } \\
\hline & \multicolumn{6}{|c|}{ Experimental } & \multicolumn{6}{|c|}{ Controle } \\
\hline & $\mathrm{n}=13$ & $\%$ & $95 \%$ IC & $\mathrm{n}=18$ & $\%$ & $\begin{array}{l}\text { Total } \\
\mathbf{n}=\mathbf{3 1}\end{array}$ & $\mathrm{n}=12$ & $\%$ & $95 \%$ IC & $n=10$ & $\%$ & $\mathrm{n}=\mathbf{2 2}$ \\
\hline Nunca ou esporadicamente & 8 & 61,5 & $35,1-88,0$ & 5 & 38,5 & 13 & 8 & 72,7 & $46,4-99,0$ & 3 & 27,3 & 11 \\
\hline
\end{tabular}

*GEE: valor-p=0,014 para efeito da CT não supervisionada; valor-p=0,452 para efeito do grupo; valor-p=0,924 para efeito da interação da CT não supervisionada e grupo

Fonte: A pesquisadora 
Os dados das Tabelas 9 a 12 e as Figuras 3 e 4 apresentam a análise do ICIQ-SF nos grupos experimental e controle.

Os resultados da Tabela 9 indicam diminuição na média do escore do ICIQ-SF no grupo experimental e aumento no grupo controle após a intervenção; essa variação está representada na Figura 3. Vale destacar que a diferença intragrupo de 1,0 e 1,7 pontos nos grupos experimental e controle, respectivamente, não mostrou diferença estatisticamente significante para grupo, trimestre e interação entre grupo e trimestre.

Tabela 9 - Média e desvio-padrão (d.p.) do escore do ICIQ-SF das gestantes dos grupos experimental e controle antes e depois da CT supervisionada do AP e valor-p, Guarulhos, SP, 2013-2014

\begin{tabular}{|c|c|c|c|c|c|c|c|}
\hline \multirow{3}{*}{$\begin{array}{l}\text { Escore do } \\
\text { ICIQ-SF }\end{array}$} & \multicolumn{4}{|c|}{ Grupo } & \multicolumn{3}{|c|}{ Valor-p* } \\
\hline & \multicolumn{2}{|c|}{ Experimental } & \multicolumn{2}{|r|}{ Controle } & \multirow{2}{*}{ Grupo } & \multirow{2}{*}{ Trimestre } & \multirow{2}{*}{$\begin{array}{c}\text { Grupo X } \\
\text { Trimestre }\end{array}$} \\
\hline & $\mathbf{N}$ & Média (d.p.) & $\mathbf{n}$ & Média (d.p.) & & & \\
\hline Antes da CT & 31 & $8,7(3,1)$ & 22 & $7,6(4,9)$ & \multirow{2}{*}{0,806} & \multirow{2}{*}{0,988} & \multirow{2}{*}{0,107} \\
\hline Depois da $\mathrm{CT} \dagger$ & 12 & $7,7(3,9)$ & 12 & $9,3(4,6)$ & & & \\
\hline
\end{tabular}

*LMM; †Uma gestante do grupo experimental com IU depois da CT não respondeu o ICIQ-SF

Fonte: A pesquisadora

Figura 3 - Média do escore do ICIQ-SF das gestantes dos grupos experimental e controle antes e depois da CT supervisionada do AP, Guarulhos, SP, 2013-2014

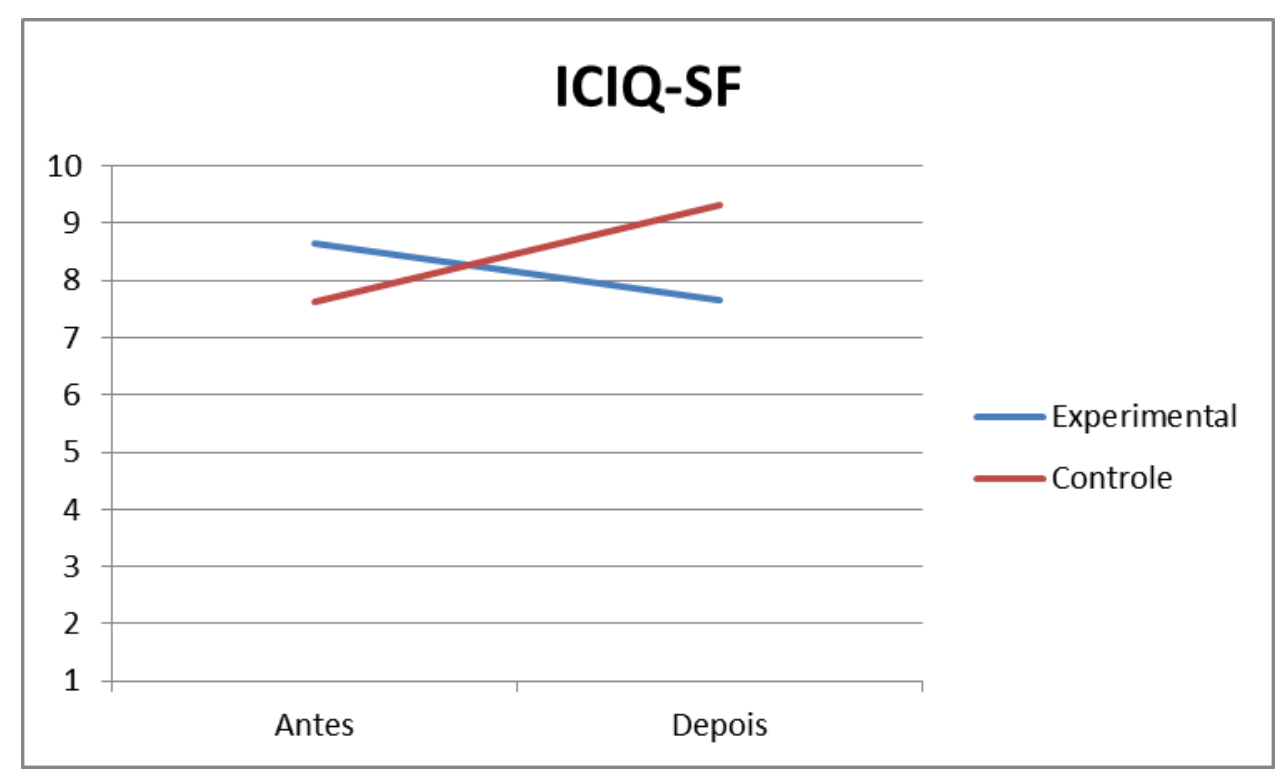

Fonte: A pesquisadora 
Em relação ao número de sessões de CT do AP que as gestantes frequentaram, pode-se verificar uma redução na média do escore do ICIQ-SF entre as gestantes que participaram de, pelo menos, quatro sessões. Entre as que não realizaram nenhuma sessão, o escore elevou-se no terceiro trimestre da gestação. No entanto, as variações observadas não mostraram diferença estatisticamente significante, considerando a totalidade das participantes do estudo (Tabela 10). Vale reiterar que no final de estudo, das 25 gestantes que tinham IU, apenas 24 responderam ao ICIQ-SF.

Tabela 10 - Média e desvio-padrão (d.p.) do escore do ICIQ-SF das gestantes dos grupos experimental e controle antes e depois da CT supervisionada do AP segundo o número de sessões e valor-p*, Guarulhos, SP, 2013-2014

\begin{tabular}{lcccc}
\hline Número sessões & \multicolumn{2}{c}{ Escore ICIQ-SF antes da CT } & \multicolumn{2}{c}{ Escore ICIQ-SF depois da CT } \\
\cline { 2 - 5 } de CT do AP & $\mathbf{n = 5 3}$ & Média (d.p.) & $\mathbf{n = 2 4}$ & Média (d.p.) \\
\hline Nenhuma $\dagger$ & 29 & $7,9(4,4)$ & 18 & $9,1(4,4)$ \\
Quarto $\dagger$ & 3 & $6,7(2,1)$ & 1 & 5,0 \\
Cinco & 9 & $8,2(2,2)$ & 2 & $6,5(2,1)$ \\
Seis & 12 & $9,4(4,2)$ & 3 & $7,7(4,7)$ \\
\hline
\end{tabular}

*LMM: valor-p=0,895; †Inclui as gestantes do grupo controle; $\$$ Uma gestante com IU depois da CT não respondeu ao ICIQ-SF

Fonte: A pesquisadora

Os dados da Tabela 11 mostram a média do escore do ICIQ-SF, considerando exclusivamente as gestantes do grupo experimental que frequentaram de quatro a seis sessões de CT supervisionada do AP. Neste caso, a análise mostrou que o efeito da interação entre grupo e trimestre foi estatisticamente significante $(\mathrm{p}=0,035)$, ou seja, a redução do escore no grupo experimental e a elevação no grupo controle podem ser atribuídas à intervenção realizada. A Figura 4 ilustra a variação nas referidas médias do escore do ICIQ-SF.

Tabela 11 - Média e desvio-padrão (d.p.) do escore do ICIQ-SF das gestantes do grupo experimental que realizaram pelo menos quatro sessões de CT e das gestantes do grupo controle antes e depois da CT supervisionada do AP e valor-p, Guarulhos, SP, 2013-2014

\begin{tabular}{|c|c|c|c|c|c|c|c|}
\hline \multirow{3}{*}{$\begin{array}{l}\text { Escore do } \\
\text { ICIQ-SF }\end{array}$} & \multicolumn{4}{|c|}{ Grupo } & \multicolumn{3}{|c|}{ Valor-p* } \\
\hline & \multicolumn{2}{|c|}{ Experimental } & \multicolumn{2}{|r|}{ Controle } & \multirow{2}{*}{ Grupo } & \multirow{2}{*}{ Trimestre } & \multirow{2}{*}{$\begin{array}{c}\text { Grupo X } \\
\text { Trimestre }\end{array}$} \\
\hline & $\mathbf{N}$ & Média (d.p.) & $\mathbf{n}$ & Média (d.p.) & & & \\
\hline Antes da CT & 24 & $8,6(3,4)$ & 22 & $7,6(4,9)$ & \multirow{2}{*}{0,520} & \multirow{2}{*}{0,425} & \multirow{2}{*}{$\mathbf{0 , 0 3 5}$} \\
\hline Depois da $\mathrm{CT}^{\dagger}$ & 6 & $6,8(3,3)$ & 12 & $9,3(4,6)$ & & & \\
\hline
\end{tabular}

*LMM; †Uma gestante do grupo experimental com IU depois da CT não respondeu ao ICIQ-SF

Fonte: A pesquisadora 
Figura 4 - Média do escore do ICIQ-SF das gestantes do grupo experimental que realizaram, pelo menos, quatro sessões de CT e das gestantes do grupo controle antes e depois da CT supervisionada do AP, Guarulhos, SP, 2013-2014

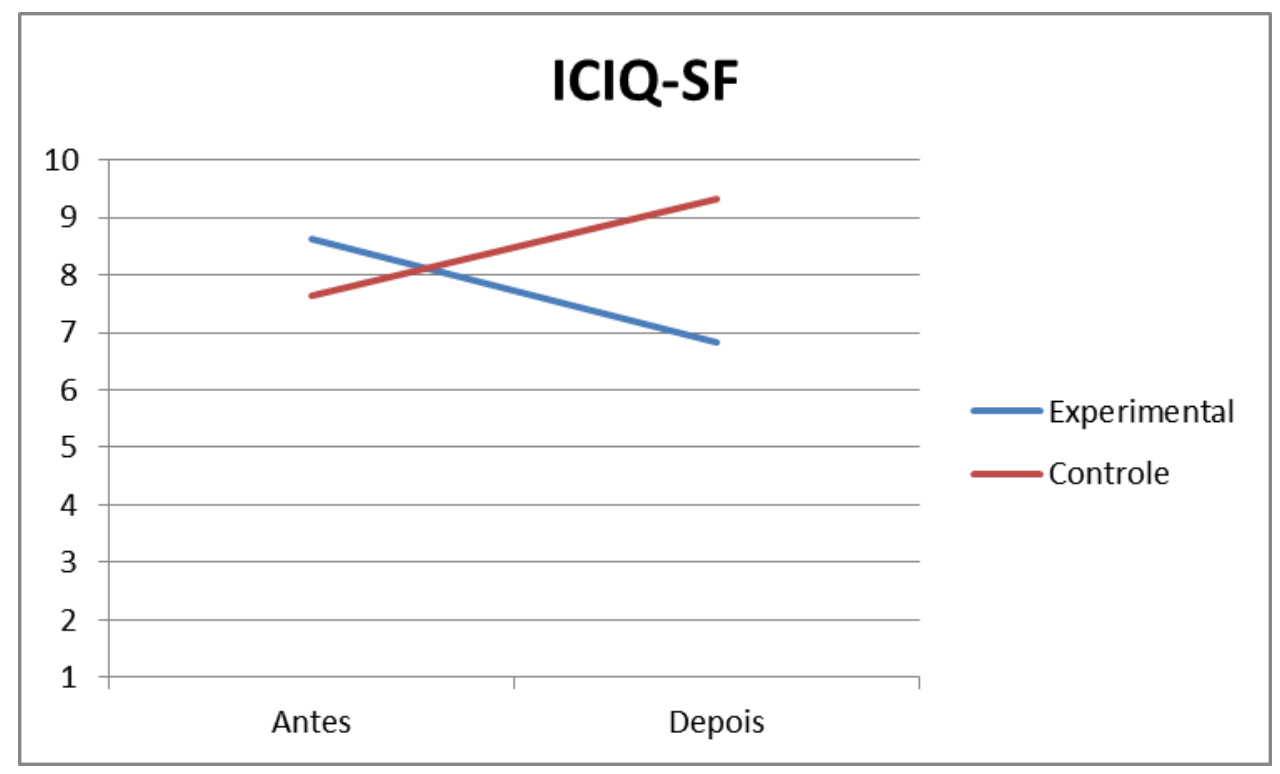

Fonte: A pesquisadora

Quanto às situações em que ocorre a perda urinária, as respostas das gestantes à questão 6 do ICIQ-SF estão apresentadas na Tabela 12. Pode-se verificar que em ambos os grupos, tanto no segundo como no terceiro trimestres da gestação predominaram as situações relacionadas ao esforço (tossir ou espirrar e fazer atividades físicas). Estas situações foram responsáveis por mais da metade das queixas de IU. 
Tabela 12 - Distribuição das situações em que ocorre IU nas etapas 2 e 3, segundo respostas das gestantes à questão 6 do ICIQ-SF (Quando você perde urina?), Guarulhos, SP, 2013-2014

\begin{tabular}{|c|c|c|c|c|c|c|c|c|}
\hline \multirow{3}{*}{$\begin{array}{l}\text { Situação em que } \\
\text { ocorre IU* }\end{array}$} & \multirow{2}{*}{\multicolumn{4}{|c|}{$\begin{array}{c}\text { Antes da CT } \\
\text { Grupo }\end{array}$}} & \multirow{2}{*}{\multicolumn{4}{|c|}{$\begin{array}{c}\text { Depois da CT } \\
\text { Grupo }\end{array}$}} \\
\hline & \multicolumn{2}{|c|}{ Experimental } & & Controle & \multicolumn{2}{|c|}{ Experimental } & & Controle \\
\hline & $\mathbf{n}$ & $\%$ & $\mathbf{n}$ & $\%$ & $\mathbf{n}$ & $\%$ & $\mathbf{n}$ & $\%$ \\
\hline "Perco quando tusso ou espirro" & 17 & 26,2 & 14 & 30,4 & 4 & 30,8 & 7 & 35,0 \\
\hline $\begin{array}{l}\text { "Perco quando estou fazendo } \\
\text { atividades físicas" }\end{array}$ & 28 & 43,0 & 21 & 45,7 & 4 & 30,8 & 4 & 20,0 \\
\hline $\begin{array}{l}\text { "Perco quando terminei de urinar e } \\
\text { estou me vestindo" }\end{array}$ & 5 & 7,7 & - & - & 2 & 15,4 & 1 & 5,0 \\
\hline $\begin{array}{l}\text { "Perco antes de chegar ao } \\
\text { banheiro" }\end{array}$ & 7 & 10,8 & 2 & 4,3 & - & - & 1 & 5,0 \\
\hline "Perco quando estou dormindo" & 5 & 7,7 & 5 & 10,9 & - & - & 2 & 10,0 \\
\hline "Perco sem razão óbvia" & 3 & 4,6 & 3 & 6,5 & 3 & 23,0 & 4 & 20,0 \\
\hline "Perco o tempo todo" & - & - & 1 & 2,2 & - & - & 1 & 5,0 \\
\hline Total & 65 & 100 & 46 & 100 & 13 & 100 & 20 & 100 \\
\hline
\end{tabular}

A seguir nos dados das Tabelas 13 a 18 e Figuras 5 e 6, é apresentada a análise da FMAP nos grupos experimental e controle.

Considerando a totalidade das gestantes de ambos os grupos, a média da FMAP depois da CT supervisionada do AP foi $1,7 \mathrm{cmH}_{2} \mathrm{O}$ maior no grupo experimental, e no grupo controle, a média sofreu redução de 2,0 $\mathrm{cmH}_{2} \mathrm{O}$, porém, sem diferença estatisticamente significante (Tabela 13 e Figura 5).

Tabela 13 - Média e desvio-padrão (d.p.) da FMAP das gestantes dos grupos experimental e controle antes e depois da CT supervisionada do AP e valor-p, Guarulhos, SP, 2013-2014

\begin{tabular}{|c|c|c|c|c|c|c|c|}
\hline \multirow{3}{*}{ FMAP } & \multicolumn{4}{|c|}{ Grupo } & \multicolumn{3}{|c|}{ Valor-p* } \\
\hline & \multicolumn{2}{|c|}{ Experimental } & \multicolumn{2}{|r|}{ Controle } & \multirow{2}{*}{ Grupo } & \multirow{2}{*}{ Trimestre } & \multirow{2}{*}{$\begin{array}{c}\text { Grupo X } \\
\text { Trimestre }\end{array}$} \\
\hline & $\mathbf{n}$ & Média (d.p.) & $\mathbf{n}$ & Média (d.p.) & & & \\
\hline Antes da CT & 31 & $26,3(16,8)$ & 22 & $25,7(14,8)$ & 0560 & 0850 & 0094 \\
\hline Depois da CT $\dagger$ & 30 & $28,0(17,8)$ & 22 & $23,7(12,8)$ & & & \\
\hline
\end{tabular}

*LMM; †Uma gestante do grupo experimental não realizou a perineometria depois da CT do AP

Fonte: A pesquisadora 
Figura 5 - Média da FMAP das gestantes dos grupos experimental e controle antes e depois da CT supervisionada do AP, Guarulhos, SP, 2013-2014

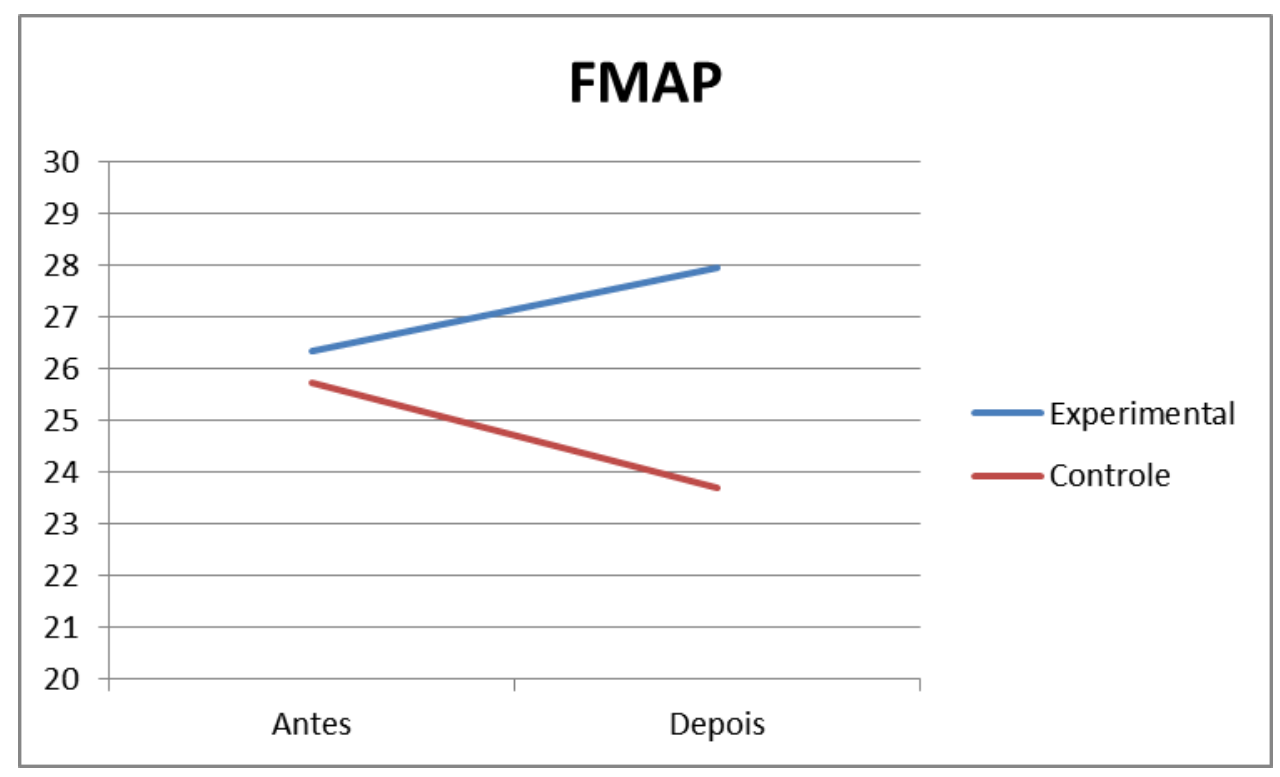

Fonte: A pesquisadora

Em relação ao número de sessões de $\mathrm{CT}$ do AP que as gestantes do grupo experimental frequentaram, na Tabela 14 pode-se verificar um aumento da FMAP entre as gestantes que participaram de, pelo menos, quatro sessões e uma diminuição entre as que não participaram de qualquer sessão, igualmente, sem diferença estatisticamente significante.

Tabela 14 - Média e desvio-padrão (d.p.) da FMAP das gestantes do grupo experimental antes e depois da CT supervisionada do AP, segundo o número de sessões e valor-p, Guarulhos, SP, 2013-2014

\begin{tabular}{|c|c|c|c|c|c|}
\hline \multirow{3}{*}{$\begin{array}{l}\text { Número de } \\
\text { sessões de CT } \\
\text { do AP }\end{array}$} & \multicolumn{4}{|c|}{ FMAP, } & \multirow{3}{*}{ Valor-p* } \\
\hline & \multicolumn{2}{|c|}{ Antes da CT } & \multicolumn{2}{|c|}{ Depois da CT } & \\
\hline & $\mathbf{n}$ & Média (d.p.) & $\mathbf{n}$ & Média (d.p.) & \\
\hline Nenhuma & 7 & $28,2(18,3)$ & 7 & $24,3(19,0)$ & \multirow{4}{*}{0,732} \\
\hline Quatro & 3 & $17,3(1,7)$ & 3 & $24,6(5,9)$ & \\
\hline Cinco & 9 & $26,4(15,4)$ & 9 & $29,5(16,9)$ & \\
\hline Seis & 12 & $27,5(19,6)$ & 11 & $30,0(21,1)$ & \\
\hline Total & 31 & 100 & 30 & 100 & \\
\hline
\end{tabular}

*LMM

Fonte: A pesquisadora

Os dados da Tabela 15 apresentam a média da FMAP antes e após a intervenção, excluindo-se as gestantes do grupo experimental que não participaram das sessões de 
CT supervisionada do AP. Assim, considerando apenas as 23 gestantes que frequentaram de quatro a seis sessões e que realizaram a perineometria ao final do estudo, pode-se observar um aumento de $3,3 \mathrm{cmH}_{2} \mathrm{O}$ na FMAP, com diferença estatisticamente significante $(\mathrm{p}=0,013)$, que pode ser atribuída à intervenção realizada. Esta variação das médias da FMAP está representada na Figura 6.

Tabela 15 - Média e desvio-padrão (d.p.) da FMAP das gestantes do grupo experimental que realizaram pelo menos quatro sessões de CT e das gestantes do grupo controle antes e depois da CT supervisionada do AP e valor-p, Guarulhos, SP, 2013-2014

\begin{tabular}{|c|c|c|c|c|c|c|c|}
\hline \multirow{3}{*}{ FMAP } & \multicolumn{4}{|c|}{ Grupo } & \multicolumn{3}{|c|}{ Valor-p* } \\
\hline & \multicolumn{2}{|c|}{ Experimental } & \multicolumn{2}{|r|}{ Controle } & \multirow{2}{*}{ Grupo } & \multirow{2}{*}{ Trimestre } & \multirow{2}{*}{$\begin{array}{c}\text { Grupo X } \\
\text { Trimestre } \\
\end{array}$} \\
\hline & $\mathbf{n}$ & Média (d.p.) & $\mathbf{n}$ & Média (d.p.) & & & \\
\hline Antes da CT & 24 & $25,8(16,6)$ & 22 & $25,7(14,8)$ & \multirow{2}{*}{0,541} & \multirow{2}{*}{0,535} & \multirow{2}{*}{$\mathbf{0 , 0 1 3}$} \\
\hline Depois da $\mathrm{CT}^{\dagger} \dagger$ & 23 & $29,1(17,6)$ & 22 & $23,7(12,8)$ & & & \\
\hline
\end{tabular}

*LMM; †Uma gestante do grupo experimental não realizou a perineometria depois da CT do AP

Fonte: A pesquisadora

Figura 6 - Média da FMAP das gestantes dos grupos experimental e controle antes e depois da CT supervisionada do AP, Guarulhos, SP, 2013-2014

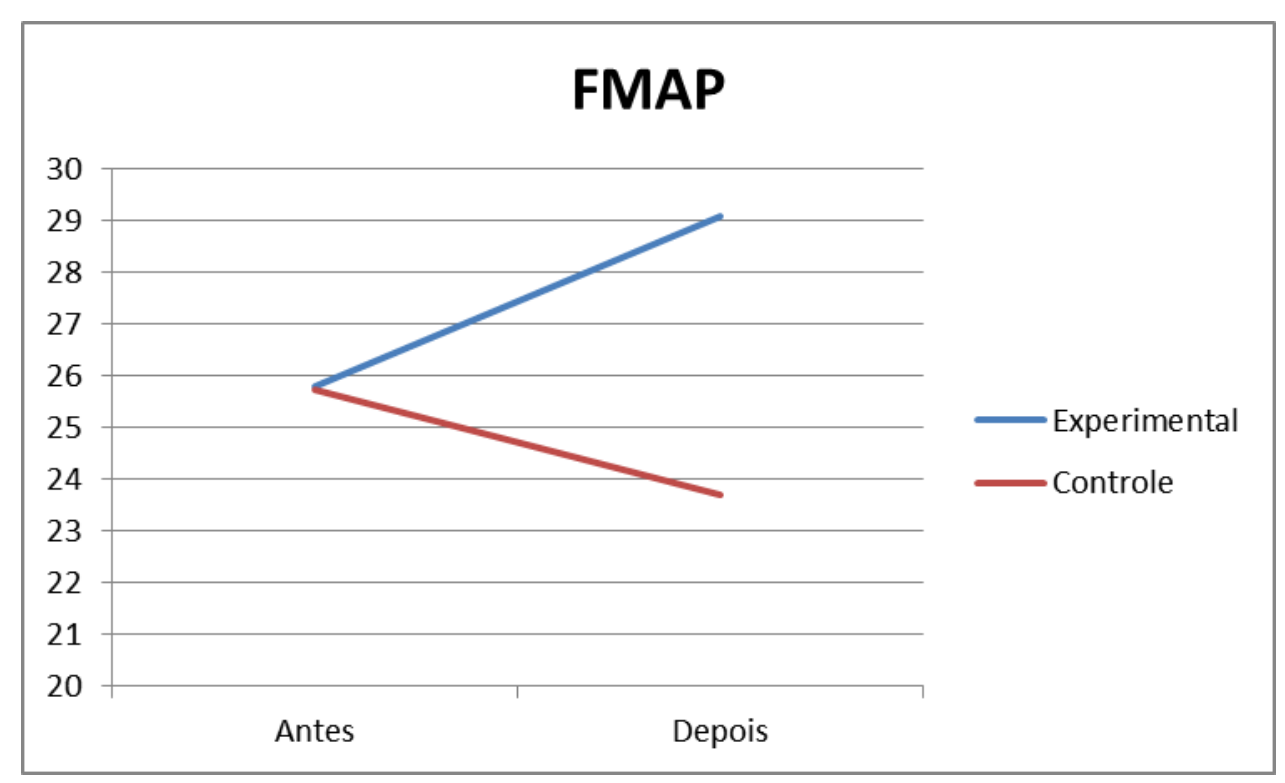

Fonte: A pesquisadora 
A relação entre a FMAP e as variáveis estado nutricional e CT não supervisionada do AP foram analisadas antes e depois da intervenção e o resultado é apresentado nas Tabelas 16 e 17.

Pode-se verificar que, em ambos os grupos, tanto no primeiro como no segundo trimestres da gestação quanto maior o índice de massa corpórea menor a média da FMAP (exceto no grupo controle, em que as gestantes com sobrepeso tiveram a média da FMAP menor que as gestantes com obesidade, no segundo trimestre), com diferença estatisticamente significante, independentemente do grupo de estudo e do trimestre $(\mathrm{p}=0,013)$ (Tabela 16).

Em relação à realização da CT não supervisionada do AP após a intervenção, embora a média da FMAP mostre redução entre as gestantes que referiam realizar exercícios perineais regularmente, em ambos os grupos, não houve associação estatisticamente significante para o efeito dessa variável (Tabela 17). 
Tabela 16 - Distribuição das gestantes dos grupos experimental e controle segundo a FMAP e o estado nutricional antes e depois da intervenção e valor-p*, Guarulhos, SP, 2013-2014

\begin{tabular}{|c|c|c|c|c|c|c|c|c|}
\hline \multirow{3}{*}{$\begin{array}{l}\text { Estado } \\
\text { nutricional }\end{array}$} & \multicolumn{8}{|c|}{ Grupo } \\
\hline & \multicolumn{4}{|c|}{ Experimental } & \multicolumn{4}{|c|}{ Controle } \\
\hline & Média (d.p.) & $95 \%$ IC & Média (d.p.) & $95 \%$ IC & Média (d.p.) & $95 \%$ IC & Média (d.p.) & $95 \%$ IC \\
\hline Adequado & $27,6(14,2)$ & $19,5-35,6$ & $31,7(19,3)$ & $20,3-43,1$ & $32,3(19,0)$ & $19,2-45,5$ & $27,6(11,0)$ & $19,5-35,7$ \\
\hline Sobrepeso & $25,2(17,8)$ & $15,5-34,8$ & $26,6(15,0)$ & $16,8-36,3$ & $17,0(5,2)$ & $12,3-29,4$ & $21,5(14,7)$ & $10,6-32,4$ \\
\hline Obesidade & $11,0(6,5)$ & $3,6-18,4$ & $17,2(14,0)$ & $6,8-27,6$ & $20,9(10,7)$ & $12,3-29,4$ & $19,3(9,6)$ & $11,6-27,1$ \\
\hline
\end{tabular}

*LMM: valor-p=0,013 para efeito do estado nutricional; valor- $p=0,516$ para efeito da interação do estado nutricional, grupo e trimestre

Fonte: A pesquisadora

Tabela 17 - Distribuição das gestantes dos grupos experimental e controle segundo a FMAP e a CT não supervisionada do AP antes e depois da intervenção e valor-p*, Guarulhos, SP, 2013-2014

\begin{tabular}{|c|c|c|c|c|c|c|c|c|}
\hline \multirow{3}{*}{$\begin{array}{l}\text { CT não } \\
\text { supervisionada }\end{array}$} & \multicolumn{8}{|c|}{ Grupo } \\
\hline & \multicolumn{4}{|c|}{ Experimental } & \multicolumn{4}{|c|}{ Controle } \\
\hline & Média (d.p.) & $95 \%$ IC & Média (d.p.) & $95 \%$ IC & Média (d.p.) & $95 \%$ IC & Média (d.p.) & $95 \%$ IC \\
\hline $\begin{array}{l}\text { Nunca ou } \\
\text { esporadicamente }\end{array}$ & $25,8(17,2)$ & $19,0-32,6$ & $28,1(21,5)$ & $16,5-39,8$ & $26,3(17,5)$ & $16,4-36,2$ & $26,4(13,2)$ & $18,6-34,2$ \\
\hline
\end{tabular}

*LMM: valor-p=0,707 para efeito da CT não supervisionada; valor-p=0,742 para efeito da interação da CT não supervisionada, grupo e trimestre Fonte: A pesquisadora 
Os dados da Tabela 18 mostram a média da FMAP das gestantes dos grupos experimental e controle com e sem IU no final do estudo. Pode-se verificar que, embora a média da FMAP seja 7,0 cmH2O maior entre as gestantes sem IU $(29,4$ contra 22,4), essa diferença não foi estatisticamente significante, com coincidência entre os intervalos de confiança.

Tabela 18 - Média, desvio-padrão (d.p.) e intervalo de confiança de 95\% (95\% IC) da FMAP das gestantes dos grupos experimental e controle segundo a IU depois da CT supervisionada do AP e valor-p, Guarulhos, SP, 2013-2014

\begin{tabular}{|c|c|c|c|c|}
\hline \multirow{2}{*}{$\begin{array}{l}\text { IU depois } \\
\text { da CT }\end{array}$} & \multirow[b]{2}{*}{$\mathbf{n}$} & \multicolumn{2}{|c|}{ FMAP } & \multirow{2}{*}{ Valor-p* } \\
\hline & & Média (d.p.) & $95 \%$ IC & \\
\hline Sim & 24 & $22,4(15,4)$ & $16,2-28,5$ & \multirow{2}{*}{0,113} \\
\hline Não & 28 & $29,4(15,8)$ & $23,5-35,2$ & \\
\hline
\end{tabular}

*Teste-t para amostras independentes

Fonte: A pesquisadora

\subsection{Considerações sobre a participação das gestantes nas sessões de CT supervisionada do AP}

Conforme referido no Método, em todas as sessões de CT supervisionada do AP, foi utilizado um diário para registro das dificuldades, facilidades e queixas relatadas, que estão agrupadas no Quadro 2. Pode-se verificar que houve dificuldades relacionadas à execução dos exercícios e uma variedade de queixas durante as sessões, com destaque para dores e desconfortos. Vale salientar que a supervisão e orientação da fisioterapeuta foram individualizadas, para propiciar a adequação da CT do AP.

Quadro 2 - Desempenho e queixas das gestantes durante as sessões de CT do AP, Guarulhos, SP, 2013-2014

Desempenho e queixas das gestantes durante as sessões de CT do AP

Dificuldade em realizar exercícios sem comando verbal

Dificuldade em realizar exercícios em pé, por não perceber a contração perineal

Dificuldade em sustentar a contração perineal

Uso da musculatura acessória durante a contração perineal (músculos abdominais, glúteos e adutores de quadril)

Apneia durante a contração perineal

Falta de ar durante os exercícios

Desconforto pela movimentação do bebê durante os exercícios

Sono durante os exercícios

Dor de cabeça, no pescoço, no baixo ventre e nas costas durante os exercícios

Facilidade em sustentar a contração perineal além do tempo definido no programa

Fonte: A pesquisadora 


\section{DISCUSSÃO}

A discussão dos resultados deste estudo é apresentada considerando: 6.1 Efeito da CT supervisionada do AP na IU; 6.2 Efeito da CT supervisionada do AP na FMAP em gestantes incontinentes; 6.3 Limitações da pesquisa; 6.4 Implicações para a pesquisa e a prática.

Preliminarmente, vale reiterar a homogeneidade das características sociodemográficas e obstétricas e antecedentes de incontinência urinária (IU) das gestantes, dada sua alocação aleatória nos dois grupos. Nesse sentido, pode-se considerar que os grupos são adequadamente comparáveis em relação aos desfechos estudados: IU e força dos músculos do assoalho pélvico (FMAP).

\subsection{Efeito da CT supervisionada do AP na IU}

De acordo com os resultados apresentados no capítulo anterior, 53 gestantes incontinentes no segundo trimestre foram incluídas na análise (31 do grupo experimental e 22 do grupo controle), das quais mais da metade $(52,8 \%)$ deixou de apresentar a queixa no terceiro trimestre. A remissão da IU não mostrou diferença estatisticamente significante entre os grupos $(58,1 \%$ e $45,5 \%$ nos grupos experimental e controle, respectivamente), mesmo quando a análise excluiu as gestantes do grupo experimental que não frequentaram as sessões de CT supervisionadas do AP.

Vale considerar que as gestantes de ambos os grupos foram orientadas, verbalmente e por escrito, a realizar CT do AP em casa. Esta variável comportou-se como interveniente, pois $72,2 \%$ das gestantes do grupo experimental e $63,6 \%$ do grupo controle que realizaram exercícios perineais regularmente (pelo menos, duas vezes por semana), tornaram-se continentes.

Com base em estudos com amostra relevante, a literatura suporta que a CT do AP realizada com acompanhamento adequado e boa adesão ao protocolo de treinamento AP pode prevenir e tratar a IU durante a gestação e após o parto. Assim, os achados desta pesquisa corroboram os resultados de diversos autores (Bozkurt, Yumru, Sahin, 2014; Mørkved, Bø, 2014; Pelaez et al., 2014; Assis, 2013; Stafne et al., 2012; Hay- 
Smith et al., 2011; Kø et al., 2011; Sangsawang, Serisathien, 2011; Dinc, Beji, Yalcin, 2009; Mørkved et al., 2003).

Assis (2013) constatou que a ocorrência de IU na $38^{\mathrm{a}}$ semana de gestação foi menor entre as mulheres que realizaram a CT do AP, com ou sem supervisão $(6,9 \%$ e $7,1 \%$, respectivamente), contra as gestantes que não realizaram CT do $\mathrm{AP}(96,6 \%)$.

A revisão sistemática conduzida por Hay-Smith et al. (2011) mostrou que o treinamento dos músculos do AP em primigestas reduz a prevalência de IU na gestação e deve ser recomendado durante o pré-natal. O resultado da metanálise de três estudos indicou o efeito protetor da CT do AP (RR=0,44; 95\% IC 0,30-0,65).

Também Dinc, Beji e Yalcin (2009) confirmaram a redução estatisticamente significante dos episódios de IU no grupo que realizou CT do AP durante a gestação. No último trimestre da gestação, a IU foi referida por $43 \%$ das mulheres que realizam CT do AP, contra $71 \%$ entre aquelas do grupo controle.

A eficácia dos exercícios perineais supervisionados é enfatizada em diversos estudos, em especial, pela maior adesão das gestantes à realização dos exercícios de forma correta e regular.

Mørkved e Bø (2014) concluíram que o treinamento do AP é eficaz quando supervisionado e recomendam um protocolo que estimula contrações máximas e duradouras, por um período de 8 semanas.

Para Pelaez et al. (2014), o programa de exercícios perineais na gestação é eficaz na prevenção primária de IU em nulíparas continentes. No estudo com 73 gestantes que participaram de sessões de CT supervisionada do AP durante 22 semanas, os autores encontraram que próximo ao termo da gestação, a proporção de gestantes que continuava continente era superior àquelas do grupo controle, no qual as gestantes apenas recebiam informações sobre $\mathrm{CT}$ do AP, com diferença estatisticamente significante.

Estes resultados corroboram os achados do ensaio clínico controlado randomizado conduzido por Stafne et al. (2012). Embora todas as gestantes do estudo tenham recebido instruções para realizar exercícios perineais em casa, o relato de IU foi menos frequente entre as gestantes que participaram de um programa de CT do AP durante 12 semanas, sob supervisão fisioterápica, quando comparadas com as do grupo controle. 
Em outro estudo, realizado por $\mathrm{K} \varnothing$ et al. (2011), as gestantes na $36^{\mathrm{a}}$ semana de gestação que participaram do treinamento da musculatura do AP durante 12 semanas, com acompanhamento fisioterápico e orientação para realização no domicílio apresentaram um número significantemente menor na ocorrência de IU, comparado as gestantes que receberam cuidados pré-natal, sem orientação para realização de exercícios perinais.

Mesmo com um protocolo de CT supervisionada do AP, com sessões quinzenais, de apenas 6 semanas de duração, Sangsawang e Serisathien (2011), concluíram que esse programa de treinamento foi capaz de diminuir a frequência e a quantidade da perda de urina.

Estes resultados são condizentes com o estudo de Mørkved et al. (2003), em que a ocorrência de IU foi significativamente menor no grupo que realizou o treinamento do AP durante 12 semanas, com supervisão de um fisioterapeuta.

Na revisão sistemática realizada por Bozkurt, Yumru e Sahin (2014), os autores concluíram que a CT do AP previamente realizada na gestação e no pós-parto pode prevenir a IU durante os trimestres finais da gestação e no período pós-parto. Os autores destacam que a gestação é o fator de risco independente mais importante para IU e que, em $65 \%$ das mulheres, o primeiro episódio de IU ocorreu durante a gestação ou no pósparto.

Constata-se nos estudos referidos, anteriormente, que os programas e protocolos de CT supervisionada do AP na gestação são muito variados, em relação à periodicidade, duração e tipo de exercícios. No entanto, de modo geral, são iniciados no segundo trimestre, com sessões semanais ou quinzenais, durante 12 semanas, em sua maioria.

Destaca-se que, nesta pesquisa, o programa de CT do AP consistiu de seis sessões quinzenais, iniciadas no segundo trimestre da gestação. A principal diferença observada em relação aos demais estudos foi que todas as gestantes incluídas, em ambos os grupos, apresentavam IU. Assim, diferentemente da literatura apontada, o efeito da CT do AP, supervisionada ou não, foi no tratamento da IU.

O efeito da CT supervisionada do AP foi verificado pelo impacto do número de sessões frequentadas pelas gestantes do grupo experimental redução da IU. Pela análise de regressão logística, cada sessão reduziu $41 \%$ a chance de IU (OR=0,59; 95\% IC 0,39$0,91)$. 
Deve-se salientar que o acompanhamento da CT do AP possibilita que as mulheres aprendam a executar a contração correta do AP, sem utilizar a musculatura acessória, com a ajuda do comando verbal e o estímulo do fisioterapeuta.

No presente estudo, em relação à prática da $\mathrm{CT}$ não supervisionada do $\mathrm{AP}$, foi observado que, no grupo experimental, $19,4 \%$ das gestantes e $45,5 \%$ no grupo controle realizavam a CT não supervisionada do AP, no momento da inclusão no ensaio clínico. No terceiro trimestre, após a intervenção, 58,1\% das gestantes passaram a realizar os exercícios perineais em casa, regularmente.

No estudo prospectivo com 467 gestantes, B $\emptyset$ et al. (2003) verificaram que apenas $17 \%$ das gestantes relataram realizar CT do AP. Em estudo transversal realizado com 300 gestantes nulíparas, embora 89\% das mulheres tivessem informação sobre exercícios perineais, apenas 35\% realizavam uma ou mais vezes por semana Hilde et al. (2012). Por sua vez, Assis (2013) mostrou que a maior proporção de mulheres que realizava CT do AP após 12 meses de pós-parto, havia recebido orientações e realizado CT do AP durante a gestação.

Outra variável considerada importante na ocorrência de IU é o estado nutricional (Sangsawang, 2014). Solans-Domènech, Sanchez e Espuna-Pons (2010) apontam que o sobrepeso e a obesidade no início da gestação foram significativamente associados com a ocorrência de IU, e Oliveira et al. (2013) verificaram que a obesidade aumenta a chance de IU na gestação $(\mathrm{OR}=4,22 ; \mathrm{p}<0,001)$.

Estudo de coorte com 224 gestantes, realizado por Franco et al. (2014), mostrou que o IMC foi maior nas gestantes com IU (27,82 contra 25,92; p=0,01) e Zhu et al. (2012) relatam maior chance de IUE com o aumento do IMC, durante o pré-natal (OR=1,037; 95\% IC 1,020-1,054).

No presente estudo, o IMC foi avaliado antes e depois da intervenção. No segundo trimestre, pouco mais da metade das gestantes de ambos os grupos apresentava sobrepeso ou obesidade. Ao final do estudo, no terceiro trimestre, essa proporção manteve-se, sem diferença estatisticamente significante nos grupos experimental e controle em relação à IU ou na interação entre estado nutricional e grupo. Assim, podese considerar que o estado nutricional não afetou a distribuição da continência urinária nos grupos estudados, sem ação interveniente ou efeito confundidor em relação ao desfecho. 
Na vida da gestante, a inferência da IU, avaliada pelo ICIQ-SF, mostrou médias do escore na faixa de 6 a 9, no terceiro trimestre da gestação. Quando a análise incluiu todas as gestantes, a redução do escore no grupo experimental e aumento no grupo controle não mostrou diferença estatisticamente significante. Mas, quando a análise incluiu apenas as gestantes do grupo experimental que efetivamente participaram da CT supervisionada do AP, houve diferença estatisticamente significante, considerando, tanto o efeito de grupo como de trimestre $(\mathrm{p}=0,035)$. Assim, a interferência na vida diária melhorou para mulheres do grupo experimental que realizaram, pelo menos, quatro sessões de CT do AP (redução de 8,6 para 6,8), em comparação àquelas do grupo controle, em que a média do escore aumentou entre o segundo e o terceiro trimestre de gestação (de 7,6 para 9,3).

Este resultado vai ao encontro dos achados de Marques et al. (2013), no qual gestantes e puérperas que participaram de dez sessões individuais de treinamento do AP, com acompanhamento fisioterapêutico, tiveram uma melhora significativa na pontuação do ICIQ-SF ( $\mathrm{p}=0,009)$.

Segundo a classificação proposta por Klovning et al. (2009), o escore do ICIQ$\mathrm{SF}$, que varia de 0 a 21, pode ser dividido em quatro categorias: 1-5 (leve), 6-12 (moderada), 13-18 (severa) e 19-21 (muito severa). Desse modo, o impacto na vida das gestantes do presente estudo pode ser considerado como moderado.

Oliveira et al. (2013) classificaram como severo o impacto da IU na vida das gestantes incontinentes nas últimas 4 semanas de gestação, incluídas em seu estudo transversal, cujo escore médio do ICIQ-SF foi 12,1 ( $\min =3$; máx=21). No entanto, o escore obtido no estudo realizado com uma população multiétnica obteve a pontuação média de $6,3 \pm 3,5$. Vale destacar que esta avaliação foi feita com gestantes no $2^{\circ}$ trimestre da gravidez (Bø et al. (2012).

Ainda como resposta ao ICIQ-SF, as gestantes da presente pesquisa confirmaram que as situações que caracterizam IUE são mais frequentes na gestação (Franco et al., 2014; Solans-Domènech, Sanchez e Espuna-Pons, 2010). As situações "Perco quando tusso ou espirro" e "Perco quando estou fazendo atividades físicas" foram citadas pela maioria das gestantes dos dois grupos, em ambos os trimestres da gestação. 


\subsection{Efeito da CT do AP na FMAP em gestantes incontinentes}

Diversos estudos apontam o efeito da CT do AP sobre a FMAP. O ensaio clínico randomizado controlado conduzido por Oliveira et al. (2007) concluiu que o treinamento dos músculos do AP, com e sem biofeedback, resultou em um aumento significativo na pressão e na força dessa região durante a gravidez. Mørkved et al. (2003) mostraram que, com 36 semanas de gestação, a FMAP foi significativamente maior entre as mulheres que realizaram exercícios perineais supervisionados por fisioterapeuta e no domicílio, em comparação com o grupo controle $(p=0,008)$, corraborado no presente estudo.

Da mesma forma, Dinc, Beji e Yalcin (2009) verificaram que, após realizarem treinamento para os músculos do AP durante a gravidez, gestantes incontinentes apresentaram aumento da FMAP e diminuição dos episódios de IU. No final do segundo trimestre, a média da perineometria em $\mathrm{cmH}_{2} \mathrm{O}$, foi $30,05( \pm 11,05)$ no grupo intervenção e 28,08 $( \pm 12,95)$ no grupo controle. No terceiro trimestre, a variação após a intervenção foi $+10,43( \pm 5,20)$ e $-1,88( \pm 4,44) \mathrm{cmH}_{2} \mathrm{O}$, nos grupos intervenção e controle, com diferença estatisticamente significante.

No presente estudo, também houve aumento da média da FMAP no grupo experimental e redução no grupo controle. A diferença entre os grupos $\left(+3,3 \mathrm{cmH}_{2} \mathrm{O}\right.$ no grupo experimental e $-2,0 \mathrm{cmH}_{2} \mathrm{O}$ no grupo controle) foi estatisticamente significante quando as gestantes do grupo experimental que não frequentaram nenhuma sessão de CT do AP foram excluídas da análise $(\mathrm{p}=0,013)$. No entanto, esse efeito não foi observado em relação à CT não supervisionada do AP.

Na comparação das médias da FMAP entre as gestantes com e sem IU, ainda que as gestantes continentes apresentassem média 7,0 cmH2O maior, a associação entre FMAP e IU não foi estatisticamente significante na amostra estudada. O estudo de Valeton e Amaral (2011) corrobora este resultado que não encontrou correlação entre a FMAP e a IU no terceiro trimestre de gestação.

Em contraposição, Hilde et al. (2012) verificaram que mulheres continentes tiveram força e resistência muscular do AP maior que aquelas com IU, com diferença estatisticamente significante. Para Baracho et al. (2012), a FMAP foi um forte preditor da IUE e valores superiores a 35,5 $\mathrm{cmH}_{2} \mathrm{O}$ atuaram na prevenção da ocorrência de IU de esforço durante o pós-parto, na maioria das mulheres. 
Assim como em relação à IU, o estado nutricional é uma variável que pode estar associada com a FMAP. Embora realizado com mulheres fora da gestação e média de idade de 67 anos, o estudo de Silva et al. (2011), conduzido com 44 mulheres incontinentes mostrou que o grau de FMAP foi menor entre as obesas; houve fraca correlação negativa entre IMC e FMAP avaliada pela avaliação funcional do assoalho pélvico (AFA). Por sua vez, Sartori, Souza e Carneiro (2011) não encontraram associação entre IMC e FMAP, considerando a fraca correlação observada e o reduzido tamanho da amostra, que incluiu 28 mulheres pré-obesas e obesas, com média de idade de 47 anos.

Diferentemente, os resultados desta pesquisa mostraram diferença estatisticamente significante na média da FMAP $(\mathrm{p}=0,013)$, que foi menor entre as gestantes com sobrepeso e obesas nos dois trimestres da gestação, considerando as gestantes de ambos os grupos, experimental e controle.

\subsection{Limitações da pesquisa}

Uma das limitações deste estudo deveu-se ao delineamento aninhado a uma coorte de gestantes fechada. Desse modo, quando foram encerrados o recrutamento e a inclusão das participantes da coorte, não foi possível incluir novas gestantes para o ensaio clínico.

Portanto, a amostra estimada de 74 mulheres não foi obtida, considerando o critério de inclusão, que limitou o ensaio clínico às gestantes com IU nas 4 semanas anteriores à realização da etapa 2 da coorte (de 20 a 27 semanas de gestação). Com isto, o poder do teste, calculado post hoc, foi de apenas $41 \%$.

Por outro lado, foi possível minimizar limitações, mediante o controle de viés de seleção, informação e confundimento, conforme descrito a seguir (Medronho et al., 2009):

- Os critérios de inclusão e exclusão das gestantes na coorte foram definidos previamente;

- O uso de instrumentos validados para a pesquisa constituiu-se do ICIQ-SF e do perineômetro digital, de alta precisão; 
- A alocação das gestantes nos grupos ocorreu sem o contato prévio da pesquisadora responsável pela aleatorização e pela intervenção;

- A abertura do envelope opaco, com a designação do grupo de estudo foi apenas no momento da alocação da gestante no grupo;

- A avaliação dos desfechos, tanto no grupo experimental como no controle foi realizada, preferencialmente, por pesquisadoras que não participaram da alocação das gestantes nos grupos e da intervenção;

- A intervenção foi aplicada por uma única pesquisadora;

- O treinamento de toda a equipe participante da coleta de dados foi com a padronização dos procedimentos utilizados;

- O tratamento estatístico foi com controle das variáveis de confundimento (número de sessões de CT supervisionada do AP, estado nutricional e CT não supervisionada do AP).

\subsection{Implicações para a pesquisa e a prática}

Os resultados desta pesquisa trazem contribuições metodológicas para o delineamento de futuras pesquisas sobre o treinamento dos músculos do AP na gestação e após o parto.

$\mathrm{Na}$ prática assistencial, pode oferecer subsídios para orientação das gestantes com IU na realização de exercícios perineais com e sem supervisão fisioterápica. As dificuldades observadas e as queixas apontadas pelas gestantes deste estudo, durante as sessões de CT do AP, como o uso da musculatura acessória, dores e desconforto são indicativos dos cuidados que devem ser considerados na orientação individual às mulheres. 


\section{CONCLUSÃo}

Os resultados desta pesquisa permitem concluir que a CT do AP realizada, regularmente (pelo menos, duas vezes por semana), durante a gestação reduz a IU. Quando realizada sob supervisão, cada sessão contribui para a redução da IU.

A CT supervisionada do AP contribui para reduzir o impacto da IU na vida diária da gestante, que pode ser considerado moderado.

No final da gestação, a FMAP aumenta com a realização da CT supervisionada do AP. No entanto, não é possível concluir que o aumento da FMAP, por si só, reduz a IU.

O estado nutricional influencia a FMAP, que é menor em mulheres com sobrepeso e obesidade nos segundo e terceiro trimestres da gestação. 


\section{REFERÊNCIAS}

Abrams P, Cardoso L, Fall M, Griffiths D, Rosier P, Ulmesten U, et al. The standardization of terminology of lower urinary tract function: report from the standardization sub-committee of the international continence society. Urology. 2003;61(1):37-49.

Assis LC. Evolução da função muscular do assoalho pélvico no pós-parto [tese]. Botucatu (SP): Faculdade de Medicina, Universidade Estadual Paulista Júlio de Mesquita Filho; 2013.

Atalah ES, Castillo LC, Castro SR, Aldea P. Propuesta de un nuevo estándar de evaluación nutricional en embarazadas. Rev Med Chil. 1997;125(12):1429-36.

Baracho SM, Silva LB, Baracho E, Silva Filho AL, Sampaio RF, Figueiredo EM. Pelvic floor muscle strength predicts stress urinary incontinence in primiparous women after vaginal delivery. Int Urogynecol J. 2012;23(7):899-906.

Bø K, Haakstad L, Voldner N. Do pregnant women exercise their pelvic floor muscles? Int Urogynecol J Pelvic Floor Dysfunct. 2007;18(7):733-6.

$\mathrm{B} \emptyset \mathrm{K}$, Hagen RH, Kvarstein B, Jørgensen J, Larsen S. Pelvic floor muscle exercise for the treatment of female stress urinary incontinence: III. Effects of two different degrees of pelvic floor muscle exercises. Neurourol Urodyn. 1990;9(5):489-502.

$\mathrm{B} \emptyset \mathrm{K}, \emptyset$ glund GP, Sletner L, Mørkrid K, Jenum AK. The prevalence of urinary incontinence in pregnancy among a multi-ethnic population resident in Norway. BJOG. 2012;119(11):1354-60.

Bozkurt M, Yumru AE, Sahin L. Pelvic floor dysfunction, and effects of pregnancy and mode of delivery on pelvic floor. Taiwan J Obstet Gynecol. 2014;53(4):452-58.

Bump R, Norton PA. Epidemiology and natural history of pelvic floor dysfunction. Obstet Gynecol Clin North Am. 1998;25(4):723-46.

Burgio KL, Zyczynski H, Locher JL, Richter HE, Redden DT, Wright KC. Urinary incontinence in the 12-month postpartum period. Obstet Gynecol. 2003;102:1291-8.

Devreese A, Staes F, De Weerdt W, Feys H, Van Assche A, Penninckx F, et al. Clinical evaluation of pelvic floor muscle function in continent and incontinent women.

Neurourol Urodyn. 2004;23(3):190-7.

Dinc A, Beji NK, Yalcin O. Effect of pelvic floor muscle exercises in the treatment of urinary incontinence during pregnancy and the postpartum period. Int Urogynecol J. 2009;20(10):1223-31.

Elenskaia K, Thakar R, Sultan AH, Scheer I, Beggs A. The effect of pregnancy and childbirth on pelvic floor muscle function. Int Urogynecol J. 2011;22(11):1421-7. 
Gameiro MO, Sousa VO, Gameiro LF, Muchailh RC, Padovani CR, Amaro JL. Comparison of pelvic floor muscle strength evaluations in nulliparous and primiparous women: a prospective study. Clinics. 2011;66(8):1389-93.

Grosse D, Sengler J. Reeducação Perineal. São Paulo: Manole; 2002.

Hay-Smith J, Mørkved S, Fairbrother KA, Herbison PG. Pelvic floor muscle training for prevention and treatment of urinary and faecal incontinence in antenatal and postnatal women. Cochrane Database of Syst Rev. 2011;(4):CD007471.

Hilde G, Stær-Jensen J, Ellström Engh M, Brækken IH, Bø K. Continence and pelvic floor status in nulliparous women at midterm pregnancy. Int Urogynecol J. 2012;23(9):1257-63.

Kelleher C. Quality of life and urinary incontinence. Baillieres Best Pract Res Clin Obstet Gynaecol. 2000;14(2):363-79.

Klovning A, Avery K, Sandvik H, Hunskaar S. Comparison of two questionnaires for assessing the severity of urinary incontinence: The ICIQ-UI SF versus the incontinence severity index. Neurourol Urodyn. 2009;28(5):411-5.

Ko PC, Liang CC, Chang SD, Lee JT, Chao AS e Cheng PJ. A randomized controlled trial of antenatal pelvic floor exercises to prevent and treat urinary incontinence. Int Urogynecol J. 2011;22:17-22.

Lwanga SK, Lemeshow S. Sample size determination in health studies: a practical manual. Geneva: World Health Organization; 1991.

Marques J, Botelho S, Pereira LC, Lanza AH, Amorim CF, Palma P et al. Pelvic floor muscle training program increases muscular contractility during first pregnancy and postpartum: electromyographic study. Neurourol Urodyn. 2013;32(7):998-1003.

Martínez Franco E, Parés D, Lorente Colomé N, Méndez Paredes JR, Amat Tardiu L. Urinary incontinence during pregnancy. Is there a difference between first and third trimester? Eur J Obstet Gynecol Reprod Biol. 2014;182:86-90.

Medronho RA, Bloch KV, Luiz RR, Werneck GL, editores. Epidemiologia. $2^{\mathrm{a}}$ ed. São Paulo: Atheneu; 2009.

Moccellin AS, Rett MT, Driusso P. Incontinência urinária na gestação: implicações na qualidade de vida. Rev bras saúde matern infant. 2014;14(2):147-54.

Mørkved S, Bø K. Effect of pelvic floor muscle training during pregnancy and after childbirth on prevention and treatment of urinary incontinence: a systematic review. $\mathrm{Br}$ J Sports Med. 2014;48(4):299-310.

Mørkved S, Bø K. Prevalence of urinary incontinence during pregnancy and postpartum. Int Urogyn J. 1999;10:394-8.

Mørkved S, Bø K, Schei B, Salvesen KA. Pelvic floor muscle training during pregnancy to prevent urinary incontinence: a single-blind randomized controlled trial. Obstet gynecol. 2003;101(2):313-9. 
Oliveira C, Lopes MAB, Pereira LCL, Zugaib M. Effects of pelvic floor muscle training during pregnancy. Clinics (Sao Paulo). 2007;62(4):439-46.

Oliveira C, Seleme M, Cansi PF, Consentino RF, Kumakura FY, Moreira GA, et al. Urinary incontinence in pregnant women and its relation with socio-demographic variables and quality of life. Rev Assoc Med Bras. 2013;59(5):460-6.

Pelaez M, Gonzalez-Cerron S, Montejo R, Barakat R. Pelvic floor muscle training included in a pregnancy exercise program is effective in primary prevention of urinary incontinence: a randomized controlled trial. Neurourol Urodyn. 2014;33(1):67-71.

Sacomori C, Böer L, Sperandio FF, Cardoso FL. Prevalência e variáveis associadas à incontinência urinária no terceiro trimestre gestacional. Rev bras saúde matern infant. 2013; 13(3):215-21.

Saleh N, Bener A, Khenyab N, Al-Mansori Z, Al-Muraikhi A. Prevalence, awareness and determinants of health care-seeking behaviour for urinary incontinence in Qatari women: a neglected problem? Maturitas. 2005;50(1):58-65.

Sangsawang B, Serisathien Y. Effect of pelvic floor muscle exercise programme on stress urinary incontinence among pregnant women. J Adv Nurs. 2011;68(9):19972007.

Sangsawang B. Risk factors for the development of stress urinary incontinence during pregnancy in primigravidae: a review of the literature. Eur J Obstet Gynecol Reprod Biol. 2014;178:27-34.

Sartori DVB, Souza JP, Carneiro PR. A influência da obesidade na musculatura do assoalho pélvico em mulheres continentes. Online Red de Revistas Científicas de América Latina [Internet]. 2011 [cited 2015 Jan 15];15(3):9-23. Available from: http://www.redalyc.org/articulo.oa?id=26021120003

Silva JC, Prado MC, Romão JFF, Cestári CE. Grau de força muscular do assoalho pélvico em mulheres incontinentes obesas e não obesas. Ciência \& Saúde.

2011;4(2):37-44.

Solans-Domènech M, Sanchez E, Espuña-Pons M. Urinary and anal incontinence during pregnancy and postpartum: incidence, severity, and risk factors. Obstet Gynecol. 2010;115(3):618-28.

Stafne SN, Salvesen KÅ, Romundstad PR, Torjusen IH, Mørkved S. Does regular exercise including pelvic floor muscle training prevent urinary and anal incontinence during pregnancy? A randomised controlled trial. BJOG. 2012;119(10):1270-80.

Tamanini JTN, Dambros M, D'Acona CAL, Palma PCR, Netto Jr. NR. Validação para o português do International Consultation on Incontinence Questionnaire - Short Form (ICIQ-SF). Rev Saúde Pública 2004;38:438-44.

Valeton CT, Amaral VF. Evaluation of urinary incontinence in pregnancy and postpartum in Curitiba. Int Urogynecol J. 2011;22(7):813-8. 
Wijma J, Potters ANW, Wolf BTHM, Tinga DJ, Aarnoudse JG. Anatomical and functional changes in the lower utinary tract during pregnancy. Br J Obstet Gynaecol. 2001;108:726-32.

Zanetti MRD, Castro RA, Rotta AL, Santos PD, Sartori M, Girão MJBC. Impact of supervised physiotherapeutic pelvic floor exercises for treating female stress urinary incontinence. São Paulo Med J. 2007;125(5):265-9.

Zeger SL, Liang KY, Albert PS. Models for longitudinal data: a generalized estimating equation approach. Biometrics. 1988;44(4):1049-60.

Zhu L, Li L, Lang JH, Xu T. Prevalence and risk factors for peri and postpartum urinary incontinence in primiparous women in China: a prospective longitudinal study. Int Urogynecol J. 2012;23:563-72. 


\section{APÊNDICE A}

\section{TERMO DE CONSENTIMENTO LIVRE E ESCLARECIDO}

Eu, Maria Luiza Gonzalez Riesco, enfermeira obstétrica, professora da Escola de Enfermagem da Universidade de São Paulo, venho convidá-la a participar de mais uma parte da pesquisa "Cuidado perineal na gestação e após o parto: prevenção e morbidade relacionadas à força muscular perineal, função sexual e continência urinária", da qual você já participa.

Como complemento, o motivo que nos leva a realizar este estudo é conhecer melhor o efeito dos exercícios perineais usados para fortalecer os músculos do assoalho pélvico, em mulheres que têm incontinência urinária durante a gestação. Assim, o objetivo desta parte da pesquisa é avaliar o efeito destes exercícios, realizados com ou sem supervisão, para ajudar a mulher com incontinência urinária a segurar a urina.

O estudo será realizado com dois grupos e a sua participação em um dos grupos será por sorteio. No grupo de exercícios supervisionados, serão realizados exercícios em seis sessões quinzenais, sob supervisão de fisioterapeuta da equipe desta pesquisa, na própria SEISA. A participação no grupo sem supervisão será com a realização dos exercícios em casa, do mesmo modo que foram ensinados desde o começo da sua participação na pesquisa acima referida. Os procedimentos de coleta de dados são aqueles realizados no estudo do qual você já participa, sem nenhum outro procedimento, ou seja, com o aparelho eletrônico que mede a contração da vagina, através de uma sonda, e com os mesmos questionários autorrespondidos. Os dados deste estudo serão guardados pela pesquisadora, a sua identidade será mantida em sigilo e os resultados da pesquisa serão divulgados em eventos e publicações científicas.

Você será esclarecida sobre a pesquisa em qualquer aspecto que desejar. Você é livre para recusar-se a participar, retirar seu consentimento ou interromper a participação a qualquer momento. A sua participação é voluntária e a recusa em participar não irá acarretar qualquer penalidade ou perda de benefícios. Uma cópia deste termo de consentimento será arquivada pela pesquisadora e outra será fornecida a você. A participação no estudo não terá custos para você e não será oferecida nenhuma compensação financeira. Você receberá bilhete de transporte para participar das seis sessões de exercícios que ocorrerão na SEISA.

$\mathrm{Eu}$,

fui informada dos objetivos da pesquisa acima de maneira clara e detalhada e esclareci minhas dúvidas. Sei que em qualquer momento poderei solicitar novas informações e modificar minha decisão, se assim o desejar. Em caso de dúvidas poderei chamar a pesquisadora Maria Luiza Gonzalez Riesco por telefone (11-9248-0041) ou e-mail (riesco@usp.br) ou o Comitê de Ética em Pesquisa da Escola de Enfermagem da Universidade de São Paulo, sito à Av. Dr. Enéas de Carvalho Aguiar, 419, São Paulo, SP. Telefone: 11-3061-7548; e-mail: edipesq@usp.br

Declaro que concordo em participar desse estudo. Recebi uma cópia deste Termo de Consentimento Livre e Esclarecido e me foi dada oportunidade de lê-lo e de esclarecer as minhas dúvidas.

Participante:

Assinatura

Pesquisadora: Maria Luiza Gonzalez Riesco

Assinatura

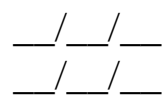




\section{APÊNDICE B}

\section{FORMULÁRIO}

Data de inclusão no estudo

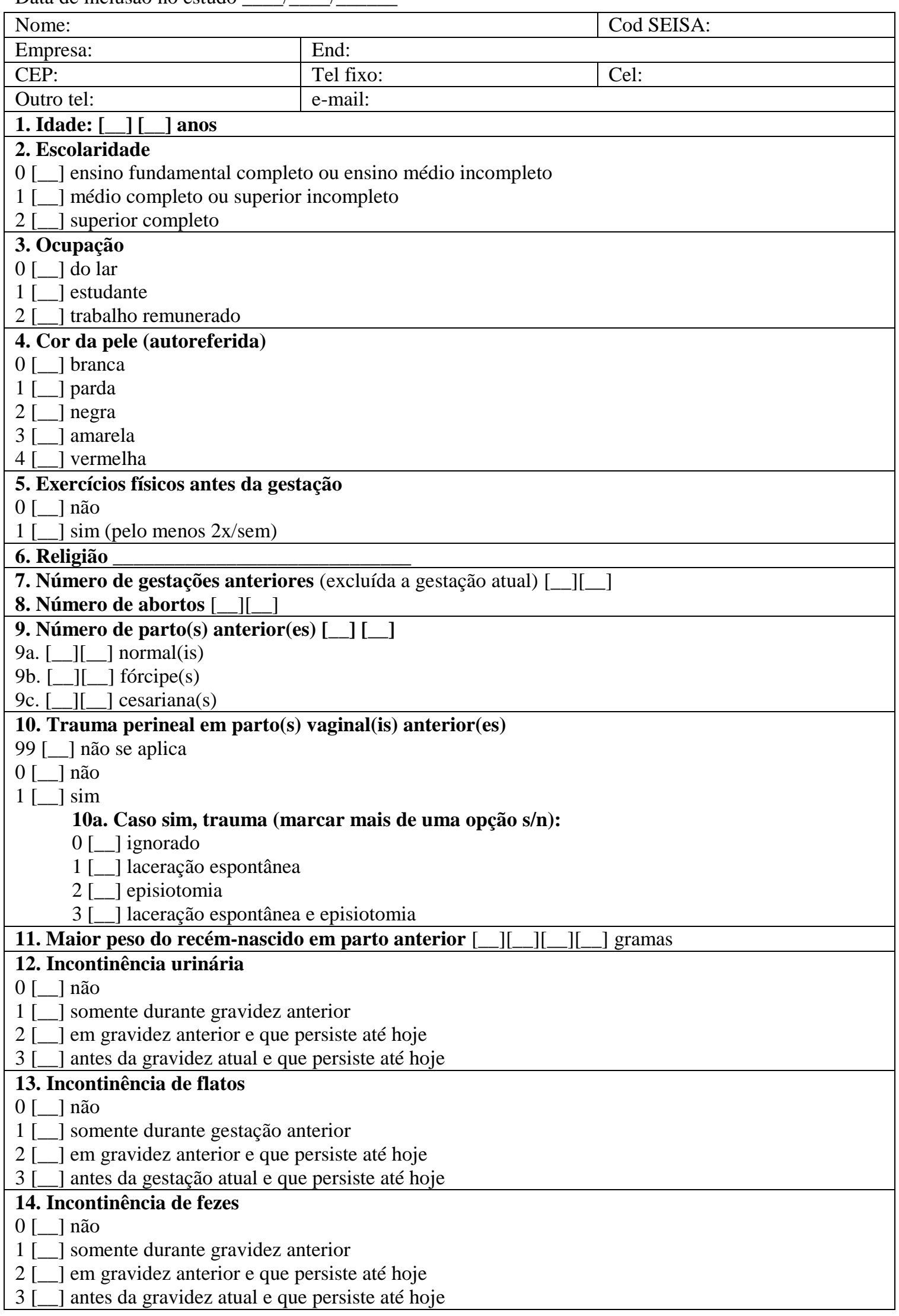




\section{ETAPAS CUMPRIDAS \\ 15. Etapa 1 \\ 1 [_] $\operatorname{sim}$ \\ 0 [__] não \\ 15a. Se não, motivo}

16. Etapa 2

1 [_] sim

0 [_] não

16a. Se não, motivo

17. Etapa 3

1 [_] $\operatorname{sim}$

0 [_] não

17a. Se não, motivo

\section{Etapa 4}

1 [_] sim

0 [_] não

18a. Se não, motivo

\section{Etapa 5}

1 [_] $\operatorname{sim}$

0 [_] não

19a. Se não, motivo

\section{Etapa 6}

1 [_] sim

0 [_] não

20a. Se não, motivo

\section{OBSERVAÇÕES}

\section{ETAPA 1}

DATA

22. Idade gestacional [ ] ] ] semanas [ ] dias

\section{2a. Método de cálculo}

0 [_] DUM

1 [_] USG

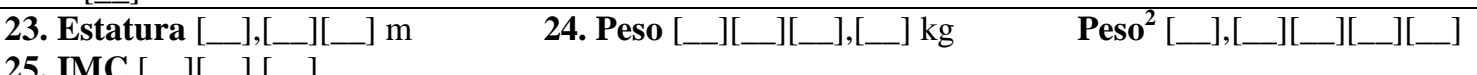

25. IMC [_][_], [_]

26. Estado nutricional

0 [__ ] baixo peso

1 [_] adequado

2 [_] sobrepeso

3 [_] obesidade

27. Situação conjugal

0 [_] não tem parceiro (NÃO aplicar IFSF)

1 [_] não vive com parceiro

2 [_] vive com parceiro

27a. Tempo de co-habitação

0 [_] menos de um ano

1 [_] um a cinco anos

2 [_] mais de cinco anos

27b. Idade do parceiro atual [ $[$ ] $[\ldots]$ anos 


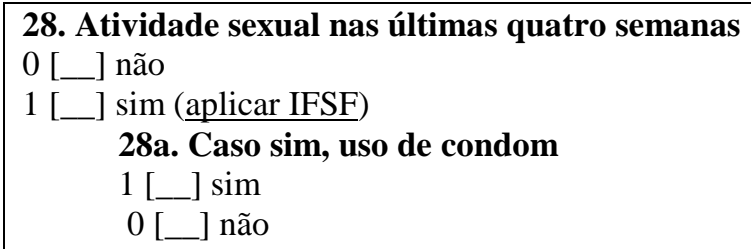

28b. Caso não, motivo

29. Incontinência urinária nas últimas quatro semanas

0 [__] não 1 [__ ] sim (

30. Incontinência de flatos atual

0 [__ não 1 [_] sim

31. Incontinência de fezes atual

0 [__ ] não 1 [_] $]$ sim

\section{Perineometria}

32. Primeira medida [__][_][__], [_]

33. Segunda medida [_] $][\ldots][\ldots],[\ldots]$

34. Terceira medida [_] $][\ldots][\ldots],\left[\_\right]$

35. Valor maior [_ $][\ldots][\ldots],[\ldots]$

CONTATOS TELEFÔNICOS (entre as etapas 1 e 2)

Data

36. Frequência de realização dos exercícios perineais

0 [_] não respondeu ao contato

1 [_] nunca (não realiza ou menos de $1 \mathrm{x} / \mathrm{sem}$ )

2 [_] esporadicamente (pelo menos $1 \mathrm{x} / \mathrm{sem}$ )

3 [_] regularmente (pelo menos 2x/semana)

Data

37. Frequência de realização dos exercícios perineais

0 [__ não respondeu ao contato

1 [__ nunca (não realiza ou menos de $1 \mathrm{x} / \mathrm{sem}$ )

2 [_] esporadicamente (pelo menos $1 \mathrm{x} / \mathrm{sem}$ )

3 [_] regularmente (pelo menos $2 \mathrm{x} /$ semana)

Data

38. Frequência de realização dos exercícios perineais

0 [__] não respondeu ao contato

1 [_] nunca (não realiza ou menos de $1 \mathrm{x} / \mathrm{sem}$ )

2 [_] esporadicamente (pelo menos $1 \mathrm{x} / \mathrm{sem}$ )

3 [_] regularmente (pelo menos $2 \mathrm{x} / \mathrm{semana}$ )

4 [_ ] não foi preciso realizar o contato 


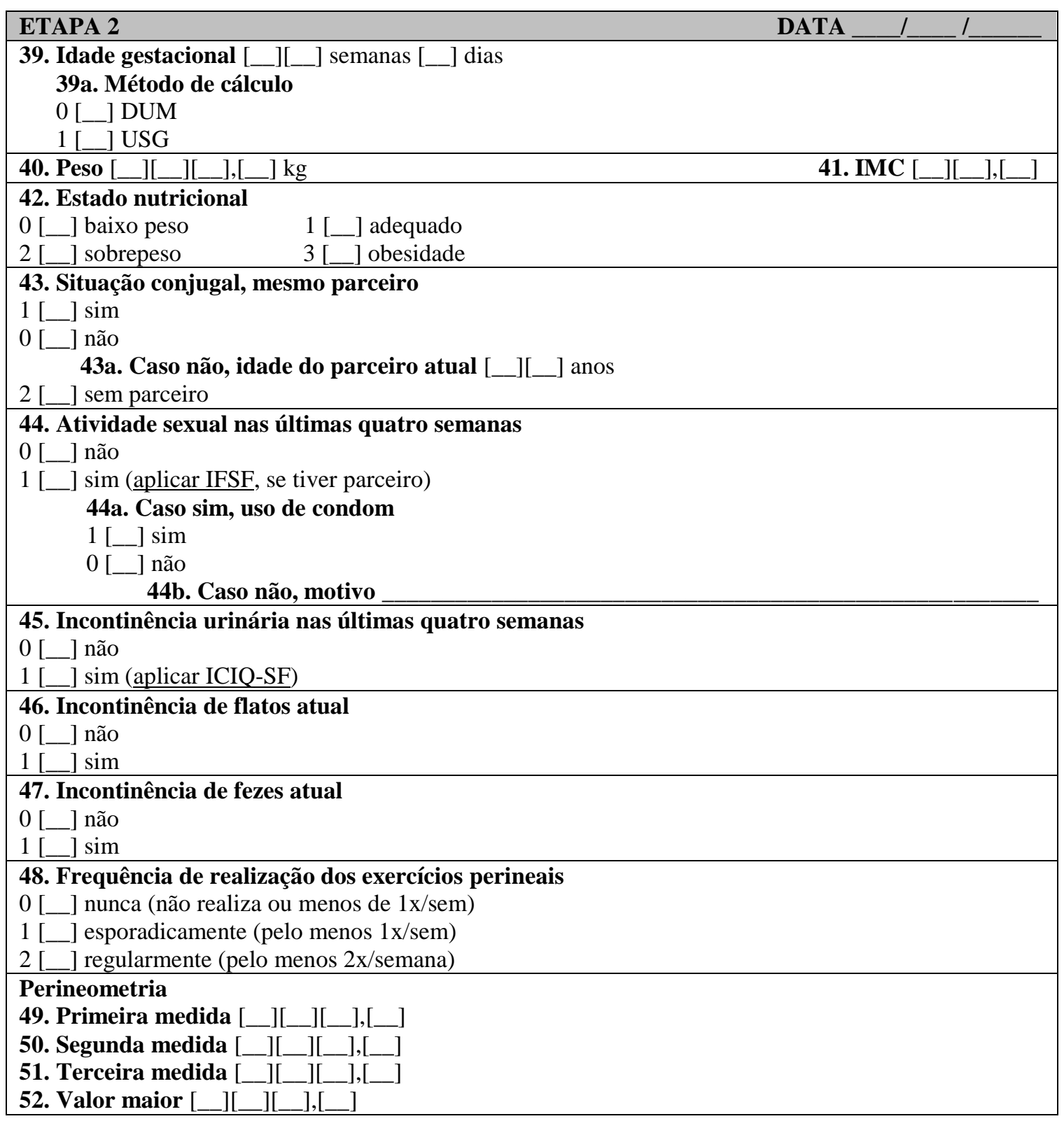




\begin{tabular}{|c|c|}
\hline ETAPA 3 & DATA \\
\hline $\begin{array}{l}\text { 53. Idade gestacional [__][_] semanas [__] dias } \\
\text { 53a. Método de cálculo } \\
0 \text { [__] DUM } \\
1 \text { [__] USG }\end{array}$ & \\
\hline 54. Peso [_] ]__][__],[_] $\mathrm{kg}$ & 55. IMC [__] [_], [_] \\
\hline $\begin{array}{ll}\text { 56. Estado nutricional } & \\
0 \text { [__] baixo peso } & 1 \text { [__] adequado } \\
2 \text { [__] sobrepeso } & 3 \text { [_] obesidade }\end{array}$ & \\
\hline $\begin{array}{l}\text { 57. Situação conjugal, mesmo parceiro } \\
1[\ldots] \text { sim } \\
0[\ldots] \text { não } \\
\quad \text { 57a. Caso não, idade do parceiro atual [_] }]\left[\_\right] \text {anos } \\
2[\ldots] \text { sem parceiro }\end{array}$ & \\
\hline $\begin{array}{l}\text { 58. Atividade sexual nas últimas quatro semanas } \\
0 \text { [__] não } \\
1 \text { [__ sim (aplicar IFSF, se tiver parceiro) } \\
\text { 58a. Caso sim, uso de condom } \\
1 \text { [_] sim } \\
0 \text { [_] não } \\
\quad \text { 58b. Caso não, motivo }\end{array}$ & \\
\hline $\begin{array}{l}\text { 59. Incontinência urinária nas últimas quatro semanas } \\
0 \text { [__] não } \\
1 \text { [__] sim (aplicar ICIQ-SF) }\end{array}$ & \\
\hline $\begin{array}{l}\text { 60. Incontinência de flatos atual } \\
0 \text { [_] não } \\
1 \text { [_] sim }\end{array}$ & \\
\hline $\begin{array}{l}\text { 61. Incontinência de fezes atual } \\
0 \text { [__] não } \\
1[\ldots] \text { sim }\end{array}$ & \\
\hline $\begin{array}{l}\text { 62. Frequência de realização dos exercícios perineais } \\
0 \text { [__] nunca (não realiza ou menos de } 1 \mathrm{x} / \mathrm{sem}) \\
1 \text { [_] esporadicamente (pelo menos } 1 \mathrm{x} / \mathrm{sem}) \\
2 \text { [_] regularmente (pelo menos } 2 \mathrm{x} / \mathrm{semana})\end{array}$ & \\
\hline 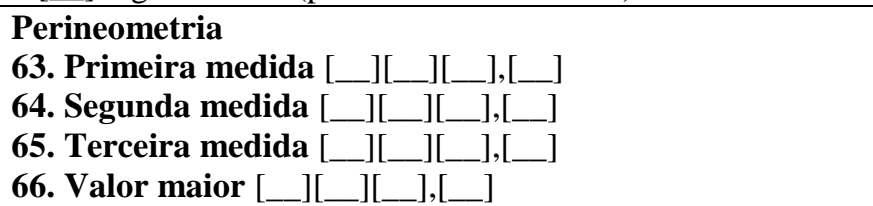 & \\
\hline
\end{tabular}




\section{APÊNDICE C}
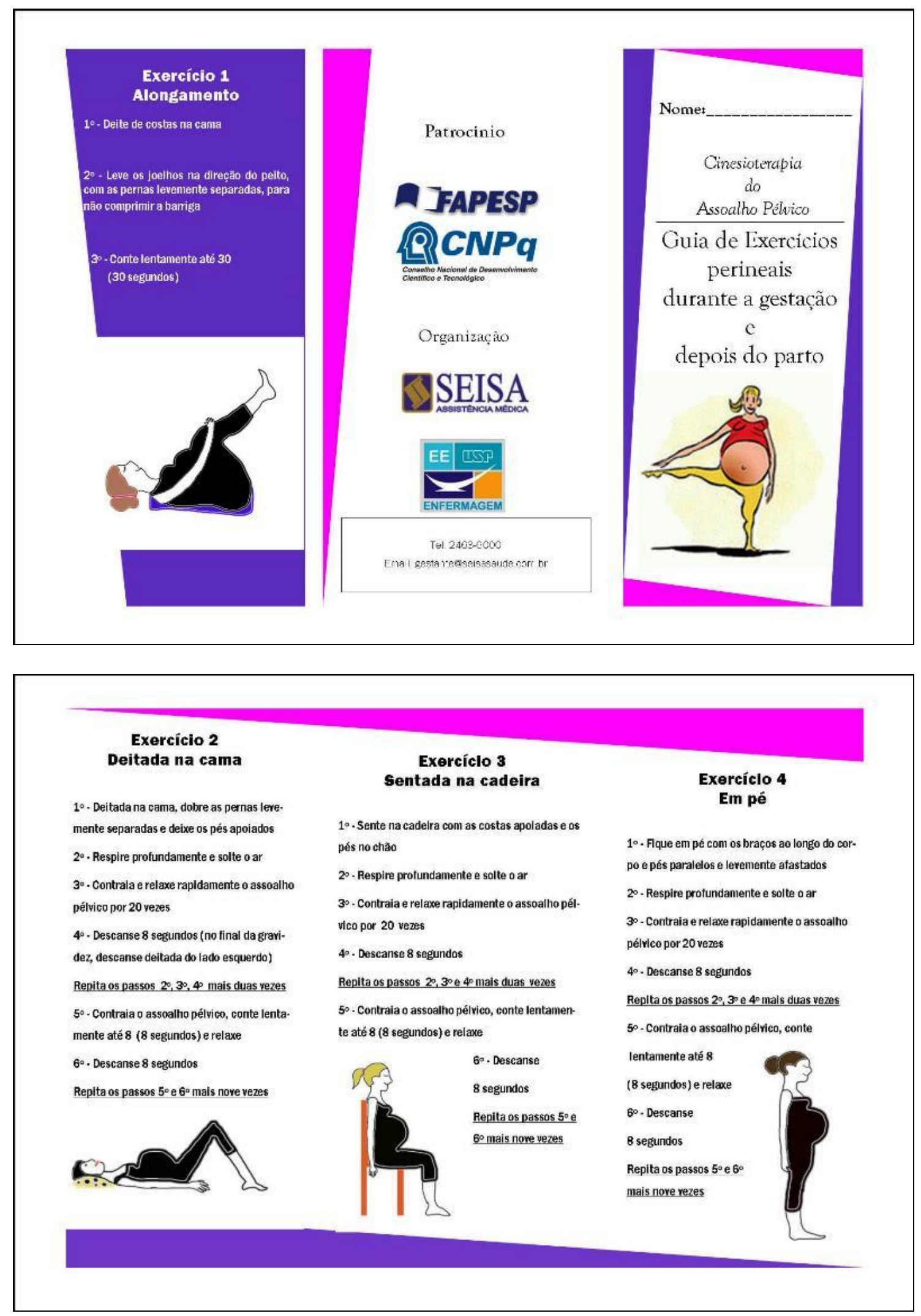


\section{APÊNDICE D}

\section{PROGRAMA DE CINESIOTERAPIA SUPERVISIONADA DO ASSOALHO PÉLVICO}

Local: Centro Clínico de Obstetrícia e Pré-Natal, da SEISA Assistência Médica

Ambiente $\boldsymbol{e}$ material: sala com privacidade, destinada exclusivamente à atividade prevista, com colchonete individual e disponibilidade de água e suco para as participantes

Período: seis sessões quinzenais, entre o segundo e terceiro trimestres da gestação, oferecidas em dois dias da semana, de manhã ou à tarde, para atender a disponibilidade das participantes

Duracão: 45 minutos

Participantes: gestantes com incontinência urinária aleatorizadas para o grupo experimental

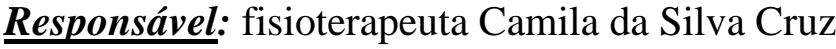

Programa (adaptado de adaptado de B $\phi$ et al., 1990):

Em cada sessão, as gestantes realizarão o programa de exercícios na posição deitada, sentada e em pé, conforme descrito a seguir.

EXERCÍCIO 1: Orientar exercícios de aquecimento global e alongamento de quadril, musculatura adutora de coxa, músculos isquiotibiais e paravertebrais, individualizados para cada gestante, durante 10 minutos.

EXERCÍCIO 2: Orientar 20 contrações rápidas, com intervalo de 1 segundo entre as contrações; repetir a sequência três vezes.

EXERCÍCIO 3: Orientar 10 contrações sustentadas por 6 a 8 segundos, com intervalos de 12 a 16 segundos entre as contrações; repetir a sequência dez vezes.

OBSERVAÇÃO: As mulheres do grupo experimental serão orientadas a realizar os exercícios indicados no folder, oferecido no primeiro trimestre da gestação a todas as gestantes incluídas na coorte. 


\section{APENDICE E}

\section{TERMO DE AUTORIZAÇÃO PARA A REALIZAÇÃO DA PESQUISA CIENTÍFICA}

São Paulo, 18 de julho de 2012.

\section{Ilma $S^{\text {ra }}$ Lidia A. S. S. Bueno de Miranda Gerente Geral da SEISA Assistência Médica}

Eu, Maria Luiza Gonzalez Riesco, enfermeira obstetra, docente da Escola de Enfermagem da Universidade de São Paulo, sou responsável pela pesquisa "Cuidado perineal na gestação e após o parto: Prevenção e Morbidade Relacionadas à Força Muscular Perineal, Função Sexual e Continência Urinária”, que tem como pesquisadoras assistentes a Enfermeira Obstetra Karina Fernandes Trevisan e a Obstetriz Nathalie Leister.

A pesquisa, cujo protocolo enviamos em anexo, será realizada com mulheres durante a gestação e por seis meses após o parto. Tem como objetivos: 1) analisar a força muscular perineal (FMP), a função sexual e a continência urinária de mulheres durante a gestação e nos seis primeiros meses após o parto; 2) avaliar o efeito da cinesioterapia (CT) supervisionada e não supervisionada do assoalho pélvico (AP) na continência urinária, na função sexual e na FMP em mulheres incontinentes durante a gestação e nos seis primeiros meses após o parto; 3) verificar a adesão das mulheres à CT do AP durante a gestação e nos seis primeiros meses após o parto.

Informamos que o projeto foi aprovado pelo Comitê de Ética em Pesquisa da Escola de Enfermagem da Universidade de São Paulo e que a participação das mulheres será inteiramente voluntária, após receberem informações e depois da leitura e assinatura do Termo de Consentimento Livre e Esclarecido.

Assim, solicitamos sua autorização para a realização da pesquisa no Centro Clínico de Obstetrícia e Pré-Natal (CCOPN), da SEISA Assistência Médica, e nos colocamos à disposição permanente para quaisquer esclarecimentos ou solicitações relativos à presente pesquisa.

Informamos que no protocolo acima referido constam os nomes dos membros da equipe de pesquisa, o cronograma e o orçamento de execução projeto, sob nossa resposabilidade.

Sem mais, agradecemos imensamente a colaboração.

Atenciosamente,

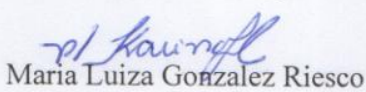

Professora Associada do Departamento de Enfermagem Materno-Infantil e Psiquiátrica da Escola de Enfermagem da Universidade de São Paulo

Responsável pela pesquisa

De acordo, 30107/ 12

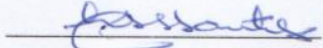

Lidia A. S. S. Buena de Mirandd

Diretora Executiva 


\title{
ANEXO 1
}

\section{INTERNATIONAL CONSULTATION ON INCONTINENCE QUESTIONNAIRE-SHORT FORM (ICIQ-SF) ICIQ -SF}

\begin{abstract}
Nome do Paciente:
Data de Hoje:

Muitas pessoas perdem urina alguma vez. Estamos tentando descobrir quantas pessoas perdem urina e o quanto isso as aborrece. Ficaríamos agradecidos se você pudesse nos responder às seguintes perguntas, pensando em como você tem passado, em média nas ÚLTIMAS QUATRO SEMANAS.
\end{abstract}

1. Data de Nascimento:

2. Sexo: Feminino $\square$ Masculino ( Dia / Mês / Ano )

3. Com que freqüêria voce perde urina? (assinale uma resposta)

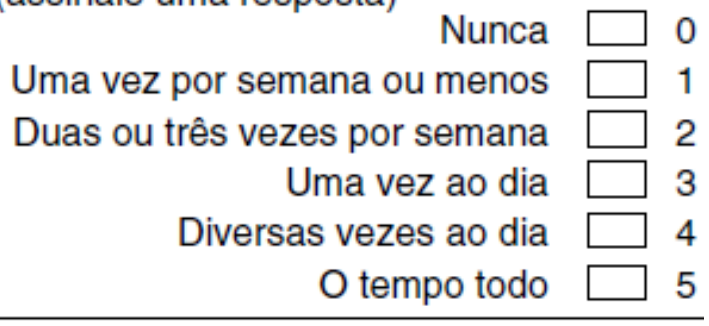

4. Gostaríamos de saber a quantidade de urina que você pensa que perde (assinale uma resposta)

Nenhuma $\square 0$ Uma pequena quantidade $\square 2$ Uma moderada quantidade $\square 4$

Uma grande quantidade $\square 6$

5. Em geral quanto que perder urina interfere em sua vida diária? Por favor, circule um número entre 0 (năo interfere) e 10 (interfere muito)

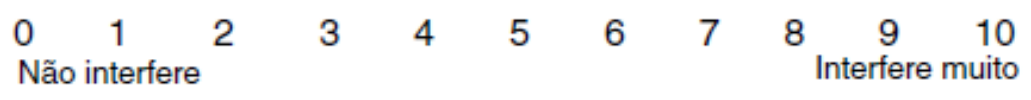

ICIQ Escore: soma dos resultados $3+4+5=$

6. Quando você perde urina?

(Por favor assinale todas as alternativas que se aplicam a você)

Nunca

Perco antes de chegar ao banheiro

Perco quando tusso ou espiro

Perco quando estou dormindo

Perco quando estou fazendo atividades físicas

Perco quando terminei de urinar e estou me vestindo

Perco sem razăo óbvia

Perco o tempo todo 


\title{
ANEXO 2
}

\section{PARECER DO COMITÊ DE ÉTICA EM PESQUISA}

\author{
Plataforma Brasil - Ministério da Saúde
}

Escola de Enfermagem da Universidade de São Paulo - EEUSP

PROJETO DE PESQUISA

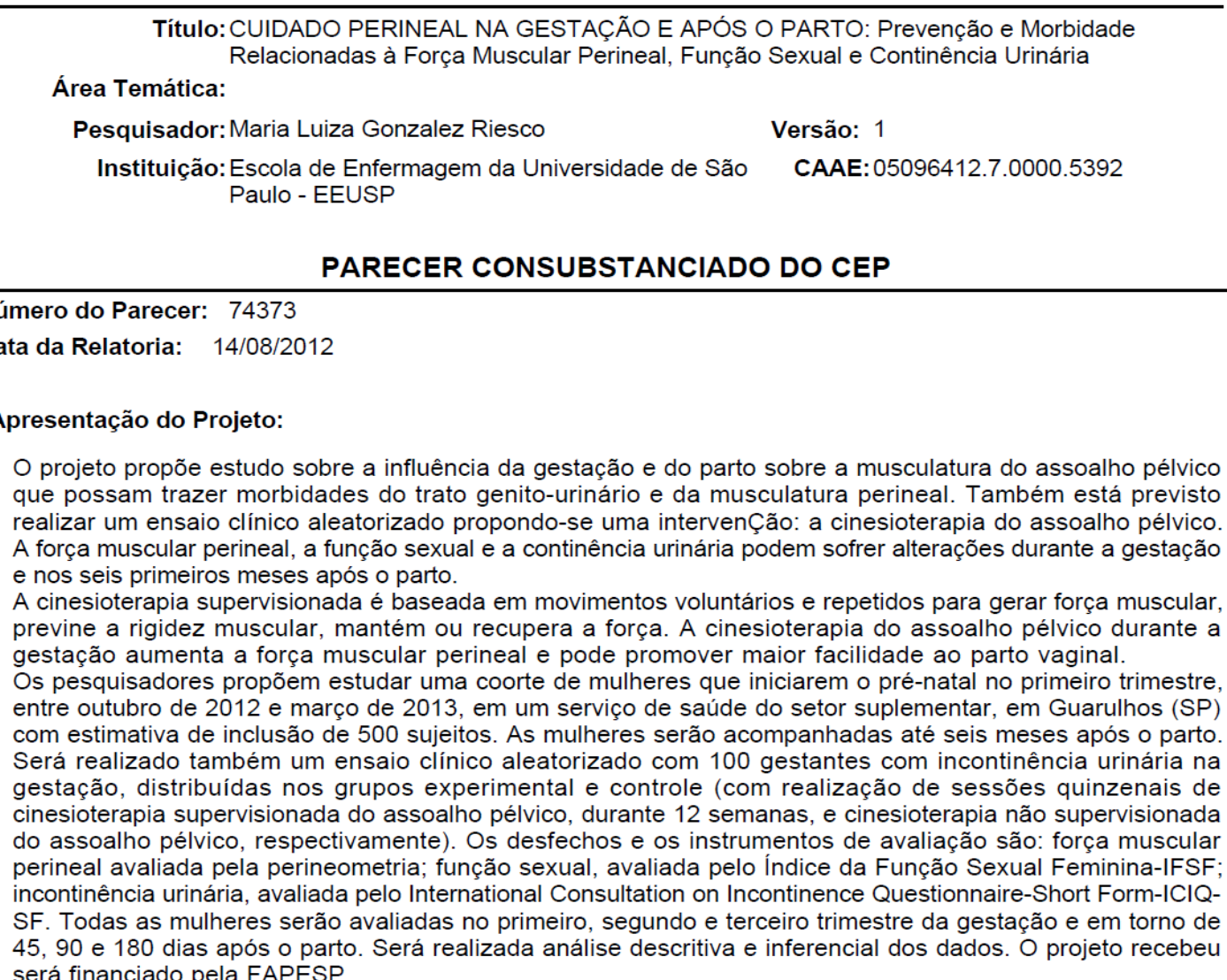
será financiado pela FAPESP.

\section{Objetivo da Pesquisa:}

Os objetivos são analisar a força muscular perineal de mulheres durante a gestação e nos seis primeiros meses após o parto; analisar a função sexual de mulheres durante a gestação e nos seis primeiros meses após o parto; analisar a continência urinária de mulheres durante a gestação e nos seis primeiros meses após o parto; avaliar o efeito da cinesioterapia (CT) supervisionada e não supervisionada do assoalho pélvico (AP) na continência urinária, na função sexual e na força muscular perineal em mulheres incontinentes durante a gestação e nos seis primeiros meses após o parto; verificar a adesão das mulheres à CT do AP durante a gestação e nos seis primeiros meses após o parto.

\section{Avaliação dos Riscos e Benefícios:}

A cinesioterapia do assoalho pélvica não traz riscos diretos à gestação, no entanto, algumas mulheres podem se sentir desconfortáveis com a realização dos exercícios.

Os benefícios referem-se à possibilidade de promover incremento na força muscular perineal das mulheres, e, no grupo observacional, poder detectar anormalidades e melhor conhecimento do assoalho pélvico. 
Plataforma Brasil - Ministério da Saúde

Escola de Enfermagem da Universidade de São Paulo - EEUSP

PROJETO DE PESQUISA

Título: CUIDADO PERINEAL NA GESTAÇÃO E APÓS O PARTO: Prevenção e Morbidade Relacionadas à Força Muscular Perineal, Função Sexual e Continência Urinária

Área Temática:

Pesquisador: Maria Luiza Gonzalez Riesco

Versão: 1

Instituição: Escola de Enfermagem da Universidade de São

Paulo - EEUSP

CAAE: 05096412.7 .0000 .5392

\section{PARECER CONSUBSTANCIADO DO CEP}

Número do Parecer: 74373

Data da Relatoria: 14/08/2012

\section{Apresentação do Projeto:}

O projeto propõe estudo sobre a influência da gestação e do parto sobre a musculatura do assoalho pélvico que possam trazer morbidades do trato genito-urinário e da musculatura perineal. Também está previsto realizar um ensaio clínico aleatorizado propondo-se uma intervenÇão: a cinesioterapia do assoalho pélvico. A força muscular perineal, a função sexual e a continência urinária podem sofrer alterações durante a gestação e nos seis primeiros meses após o parto.

A cinesioterapia supervisionada é baseada em movimentos voluntários e repetidos para gerar força muscular previne a rigidez muscular, mantém ou recupera a força. A cinesioterapia do assoalho pélvico durante a gestação aumenta a força muscular perineal e pode promover maior facilidade ao parto vaginal.

Os pesquisadores propõem estudar uma coorte de mulheres que iniciarem o pré-natal no primeiro trimestre, entre outubro de 2012 e março de 2013, em um serviço de saúde do setor suplementar, em Guarulhos (SP) com estimativa de inclusão de 500 sujeitos. As mulheres serão acompanhadas até seis meses após o parto. Será realizado também um ensaio clínico aleatorizado com 100 gestantes com incontinência urinária na gestação, distribuídas nos grupos experimental e controle (com realização de sessões quinzenais de cinesioterapia supervisionada do assoalho pélvico, durante 12 semanas, e cinesioterapia não supervisionada do assoalho pélvico, respectivamente). Os desfechos e os instrumentos de avaliação são: força muscular perineal avaliada pela perineometria; função sexual, avaliada pelo Índice da Função Sexual Feminina-IFSF; incontinência urinária, avaliada pelo International Consultation on Incontinence Questionnaire-Short Form-ICIQSF. Todas as mulheres serão avaliadas no primeiro, segundo e terceiro trimestre da gestação e em torno de 45, 90 e 180 dias após o parto. Será realizada análise descritiva e inferencial dos dados. $\bigcirc$ projeto recebeu será financiado pela FAPESP.

\section{Objetivo da Pesquisa:}

Os objetivos são analisar a força muscular perineal de mulheres durante a gestação e nos seis primeiros meses após o parto; analisar a função sexual de mulheres durante a gestação e nos seis primeiros meses após o parto; analisar a continência urinária de mulheres durante a gestação e nos seis primeiros meses após o parto; avaliar o efeito da cinesioterapia (CT) supervisionada e não supervisionada do assoalho pélvico (AP) na continência urinária, na função sexual e na força muscular perineal em mulheres incontinentes durante a gestação e nos seis primeiros meses após o parto; verificar a adesão das mulheres à CT do AP durante a gestação e nos seis primeiros meses após o parto.

\section{Avaliação dos Riscos e Benefícios:}

A cinesioterapia do assoalho pélvica não traz riscos diretos à gestação, no entanto, algumas mulheres podem se sentir desconfortáveis com a realização dos exercícios.

Os benefícios referem-se à possibilidade de promover incremento na força muscular perineal das mulheres, e, no grupo observacional, poder detectar anormalidades e melhor conhecimento do assoalho pélvico. 